Aus der Klinik für Anästhesiologie

(Prof. Dr. med. M. Quintel)

der Medizinischen Fakultät der Universität Göttingen

\title{
Der Einfluss des CD14 SNP rs2569190 auf den Krankheitsverlauf von an Sepsis erkrankten Patienten
}

\author{
INAUGURAL-DISSERTATION \\ zur Erlangung des Doktorgrades \\ der Medizinischen Fakultät der \\ Georg-August-Universität zu Göttingen
}

vorgelegt von

Benjamin Werner Liese

aus

Kassel

Göttingen 2018 
Dekan:

Referent:

Ko-Referent/in:
Prof. Dr. rer. nat. H. K. Kroemer

Priv.-Doz. Dr. med. A. Mansur

Prof. Dr. med. Ralf Dressel

Tag der mündlichen Prüfung: $\quad$ 14.08.2018 
Hiermit erkläre ich, die Dissertation mit dem Titel „Der Einfluss des CD14 SNP rs2569190 auf den Krankheitsverlauf von an Sepsis erkrankten Patienten" eigenständig angefertigt und keine anderen als die von mir angegebenen Quellen und Hilfsmittel verwendet zu haben.

Göttingen, den 01.03.2018 


\section{Inhaltsverzeichnis}

$1 \quad$ Einleitung.................................................................... 1

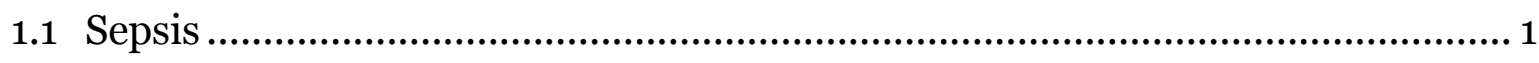

1.1.1 Definition und Diagnose ........................................................ 1

1.1.2 Epidemiologie......................................................................... 1

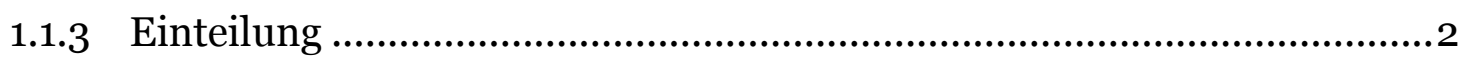

1.1.4 Primärer Infektionsort ..............................................................

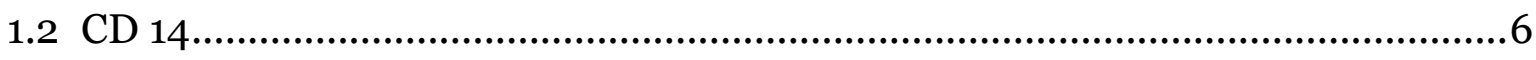

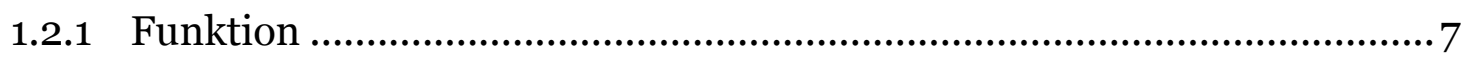

1.3 Genom und Genpolymorphismen......................................................... 16

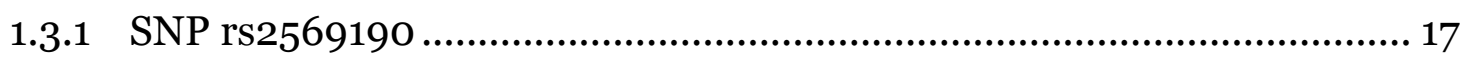

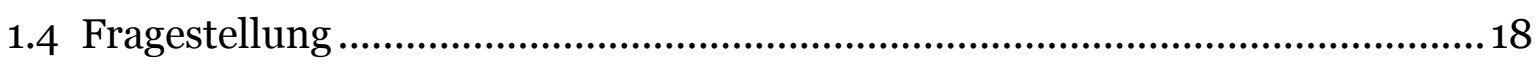

2 Material und Methoden............................................. 19

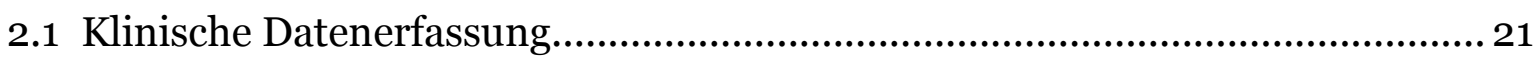

2.1.1 Patientendatenmanagement-System ........................................... 21

2.1.2 Erfassungsbogen .........................................................................22



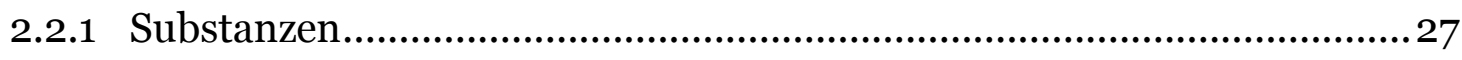

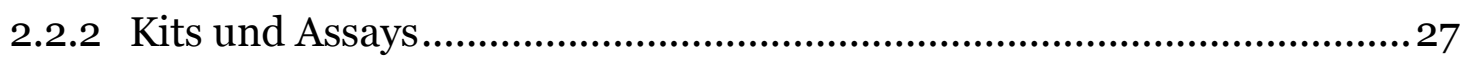

2.2.3 Gebrauchswaren ..........................................................................28



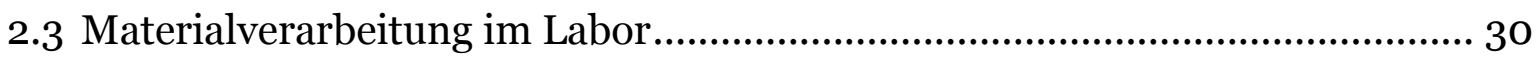

2.3.1 Isolierung von peripheren Blut-Leukozyten .................................... 30

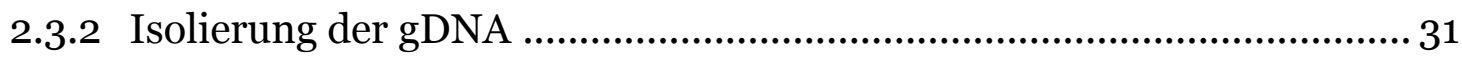

2.3.3 Bestimmung der DNA-Konzentration ...............................................32

2.3.4 Genotypisierung durch allelische Diskriminierung..............................32

2.3.5 DNA-Extraktion und Genotypisierung im Verlauf...............................33

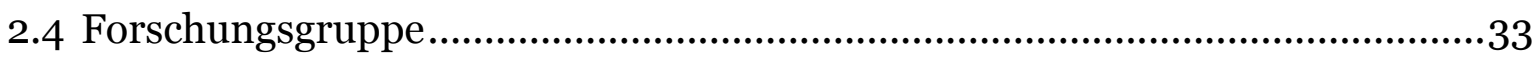

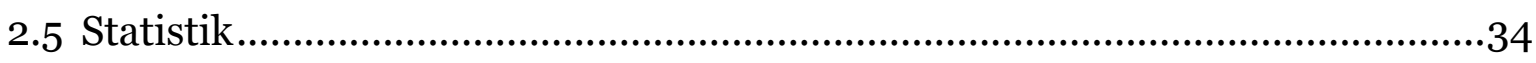


3 Ergebnisse............................................................36

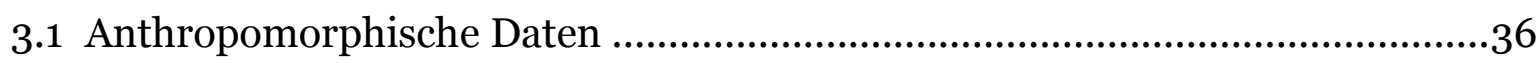

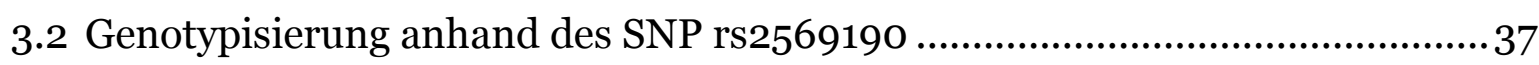

3.3 Klinische und intensivmedizinische Aufnahmedaten ...................................38

3.4 Klinische und intensivmedizinische Verlaufsdaten ................................... 41

3.4.1 Mikrobiologisch nachgewiesene Krankheitserreger...........................45

3.5 Analyse von Störfaktoren und Kovariablen .............................................46

3.6 Publikation ..........................................................................................46

4 Diskussion..............................................................47

5 Zusammenfassung $\ldots . . \ldots \ldots \ldots \ldots \ldots \ldots \ldots \ldots \ldots \ldots \ldots \ldots \ldots \ldots \ldots \ldots \ldots \ldots \ldots \ldots \ldots . \ldots 6$

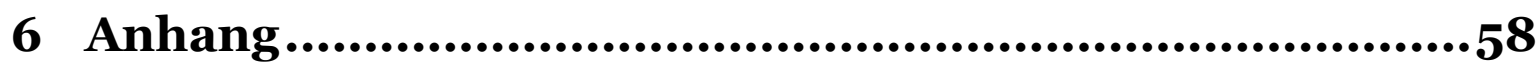

7 Literaturverzeichnis..................................................70 


\section{Abbildungsverzeichnis}

Abbildung 1.1: Signalweitergabe durch TLR4 ….............................................. 8

Abbildung 1.2: Struktureller Aufbau von LPS ..................................................... 9

Abbildung 1.3: Struktureller Aufbau und Liganden von TLRs ............................... 13

Abbildung 3.1: Kaplan-Meier Überlebenszeitanalyse nach 30 Tagen .................... 44

\section{Tabellenverzeichnis}

Tabelle 1.1: Diagnosekriterien für Sepsis, schwere Sepsis ...................................3

Tabelle 1.2: Infektionsorte bei schwerer Sepsis ...............................................5

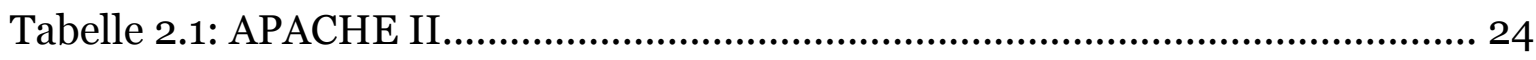

Tabelle 2.2: APACHE II-Mortalitätsrisiko .......................................................... 24

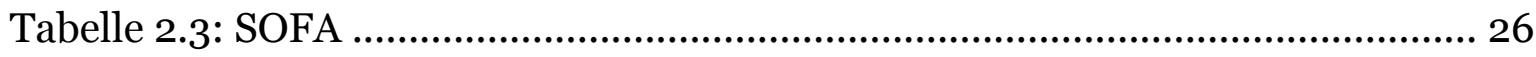

Tabelle 3.1: Alter, Geschlecht und BMI des Patientenkollektivs ........................... 36

Tabelle 3.2: Verteilung der Genotypen des SNP rs2569190 ..................................37

Tabelle 3.3: Klinische und intensivmedizinische Aufnahmedaten ....................... 38

Tabelle 3.4: Klinische und intensivmedizinische Verlaufsdaten ........................... 41

Tabelle 3.5: Verteilung der Krankheitserreger ..................................................45

Tabelle 3.6: Multivariate Cox-Regression zur Analyse von Störfaktoren und

Kovariablen......................................................................................... 46 


\section{Abkürzungsverzeichnis}

ACCP

ALT

APACHE II

AST

BMI

CD14

cHSP6o

COPD

$\mathrm{CpG}$

CRF

CRP

DIVI

DNA

DSG

dsRNA

EDTA

F Protein

HaploChIP

HGP

HR

HWE

ICCA

ICIP

IDDM

IFN- $\beta$

IL-1

IRF 3

$\mathrm{KDO}$

KHK

LBP

LPS
American College of Chest Physicians

Alanin-Aminotransferase

Acute Physiology and Chronic Health Evaluation II

Aspartat-Aminotransferase

body mass index

cluster of differentiation 14

chlamydial heat shock protein 60

chronic obstructive pulmonary disease

Cytosin-Phosphat-Guanin

clinical report form

C-reaktives Protein

Deutsche Interdisziplinäre Vereinigung für Intensiv- und Notfallmedizin

Desoxyribonukleinsäure

Deutsche Sepsis-Gesellschaft e.V.

double stranded RNA

Ethylendiamintetraessigsäure

fusion protein

haplo-type-specific chromatin immunoprecipitation

Human Genome Project

Hazard Ratio

Hardy-Weinberg-Equilibrium

IntelliSpace Critical Care and Anesthesia

IntelliVue Clinical Information Portfolio

insulin-dependent diabetes mellitus

Interferon- $\beta$

Interleukin-1

interferon regulatory factor 3

2-Keto-3-desoxy-octonat

koronare Herzkrankheit

LPS-Binding-Protein

Lipopolysaccharid 


\begin{tabular}{|c|c|}
\hline LRR & leucine rich repeat \\
\hline MAF & minor allele frequency \\
\hline $\mathrm{mCD} 14$ & membranständiges CD14 \\
\hline MD 2 & myeloid-differentiation-factor 2 \\
\hline MyD88 & myloid-differentiation-primary-response-gene 88 \\
\hline NASH & nicht-alkoholische Steatohepatitis \\
\hline $\mathrm{NF}-\kappa \mathrm{B}$ & nukleärer Transkriptionsfaktor- $\kappa \mathrm{B}$ \\
\hline NIDDM & non-insulin-dependent diabetes mellitus \\
\hline PAMP & pathogen-associated molecular pattern \\
\hline PBL & periphere Blut-Leukozyten \\
\hline PBS & phosphatgepufferte Salzlösung \\
\hline PD1 & programmed cell death 1 \\
\hline PDMS & Philips Patientendatenmanagement-System \\
\hline $\mathrm{PIP} 2$ & Phosphatidylinositol 4,5-bisphosphate \\
\hline PRR & pattern recognition receptor \\
\hline rLPS & rough lipopolysaccharid \\
\hline RSV & respiratory syncytial virus \\
\hline SCCM & Society of Critical Care Medicine \\
\hline sCD14 & soluble CD14 \\
\hline siRNA & short interfering $R N A$ \\
\hline SIRS & systemisches inflammatorisches Response-Syndrom \\
\hline sLPS & smooth lipopolysaccharid \\
\hline SNP & single nucleotide polymorphism \\
\hline SOFA & Sepsis-related Organ Failure Assessment \\
\hline SP-A & surfactant protein- $A$ \\
\hline SsRNA & single stranded $R N A$ \\
\hline TIR & toll/interleukin-1 receptor \\
\hline TIRAP & $\begin{array}{l}\text { toll/interleukin-1 receptor domain-containing } \\
\text { protein }\end{array}$ \\
\hline TLR4 & Toll-like-Rezeptor 4 \\
\hline $\mathrm{TNF}-\alpha$ & Tumornekrosefaktor- $\alpha$ \\
\hline TRAM & TRIF-related adaptor molecule \\
\hline TRIF & TIR-domain containing adaptor inducing IFN- $\beta$ \\
\hline UMG & Universitätsmedizin Göttingen \\
\hline ZNS & zentrales Nervensystem \\
\hline
\end{tabular}




\section{Einleitung}

\subsection{Sepsis}

\subsubsection{Definition und Diagnose}

Die Sepsis ist eine systemische Reaktion der menschlichen Immunabwehr auf eine Infektion des Körpers durch pathogene Keime (Werdan und Schuster 2005). Sie gilt als eine der häufigsten Diagnosen bei hospitalisierten Patienten auf Intensivstationen und ist trotz erweiterter Therapiemaßnahmen mit einer Mortalitätsrate von 30 bis 50 \% assoziiert (Fleischmann et al. 2016). Da die Sepsis ein komplexes Krankheitsbild mit vielen möglichen Infektionsorten und unterschiedlichen Reaktionen des Immunsystems auf die in den Körper eingedrungenen pathogenen Keime ist, wurde sie bisher nicht über einen einzelnen Parameter bestimmt, sondern die Gesamtheit der präsentierten körperlichen Symptome in Kombination mit den laborchemisch bestimmten Blutwerten führte zur Diagnose Sepsis. Daher wurden entsprechend der S-2kLeitlinie der Deutschen Sepsis-Gesellschaft e.V. (DSG) und der Deutschen Interdisziplinären Vereinigung für Intensiv- und Notfallmedizin (DIVI) die ACCP/SCCM Konsensus-Konferenz-Kriterien zur Diagnose einer Sepsis verwendet (Reinhart et al. 2010). Anfang 2016 wurden neuen Kriterien und Definitionen der Sepsis auf dem Jahreskongress der Society of Critical Care Medicine in Orlando vorgestellt und gleichzeitig im amerikanischen Ärzteblatt veröffentlicht. Im weiteren Verlauf werden daher nach einem Überblick über die Epidemiologie zunächst die S-2k-Leitlinie der DSG und der DIVI näher vorgestellt, da diese bei der Einteilung und Auswertung der Daten dieser Dissertationsarbeit noch Gültigkeit hatten und somit zur Anwendung kamen. Danach werden zur Vollständigkeit auch die Sepsis-3-Kriterien der Konsensus-Definitionen für Sepsis und septischen Schock vorgestellt.

\subsubsection{Epidemiologie}

Die Punktprävalenz der Sepsis für Patienten auf deutschen Intensivstationen betrug im Jahr 2007 etwa 12 \%. Für eine schwere Sepsis inklusive septischen Schock betrug die Punktprävalenz etwa 11 \% (Engel et al. 2007). Daten aus den USA zeigen, dass die Inzidenz im Zeitraum 2000 bis 2008 jährlich um 7 bis $8 \%$ zunahm (Hall et al. 2011). Auch in Deutschland nahm die Inzidenz im Zeitraum 2007 bis 2013 jährlich um etwa 5,7 \% zu (Fleischmann et al. 2016). Ähnliche 
Entwicklungen mit einer deutlichen Zunahme der jährlichen Inzidenz konnten beispielsweise auch in Spanien und Großbritannien gezeigt werden (Bouza et al. 2014; Harrison et al. 2006). Die durchschnittliche Liegedauer der Patienten mit einer Sepsis auf der Intensivstation betrug je nach Bettenzahl des Krankenhauses zwischen 12 und 19 Tagen, wobei die Liegedauer in Krankenhäusern mit mehr als 200 Betten länger war (Engel et al. 2007). Auch unter strenger Einhaltung der aktuellen Leitlinien liegt die Mortalität der schweren Sepsis bei etwa 30 bis $50 \%$ und des septischen Schocks bei etwa 50 bis 60 \% (Angus und van der Poll 2013; Fleischmann et al. 2016; Levy et al. 2010).

\subsubsection{Einteilung}

Die Sepsis lässt sich nach der S-2k-Leitlinie in insgesamt drei Unterformen unterteilen. Man unterscheidet Sepsis, schwere Sepsis und septischen Schock (Levy et al. 2003). Um die Diagnosekriterien einer Sepsis zu erfüllen, muss zunächst eine Infektion aufgrund eines mikrobiologischen Nachweises oder aber durch klinische Kriterien nachgewiesen werden. Zusätzlich müssen mindestens zwei Kriterien des systemischen inflammatorischen Response-Syndroms (SIRS) diagnostiziert werden (Levy et al. 2003). Von einer schweren Sepsis spricht man, wenn es neben den Kriterien für eine Sepsis zusätzlich zu mindestens einer akuten Organdysfunktion kommt. Als Organdysfunktion zählt hierbei eine Enzephalopathie, eine Thrombozytopenie, eine arterielle Hypoxämie, eine renale Dysfunktion oder eine metabolische Azidose (Levy et al. 2003). Der septische Schock ist, neben den Kriterien für eine Sepsis, durch eine nicht anders zu erklärende Hypotonie bzw. einen notwendigen Vasopressoreinsatz als Therapie einer Hypotonie definiert. Die Hypotonie besteht hierbei trotz adäquater Volumengabe und ist nicht durch andere Ursachen zu erklären. (Levy et al. 2003). 


\section{Infektion}

Diagnose einer Infektion über den mikrobiologischen Nachweis oder durch klinische Kriterien

II. mind. 2 Kriterien des systemic inflammatory response syndrome (SIRS)

- Fieber $\left(\geq 38{ }^{\circ} \mathrm{C}\right)$ oder Hypothermie $\left(\leq 36{ }^{\circ} \mathrm{C}\right)$

- Tachykardie (Herzfrequenz $\geq 90 / \mathrm{min}$ )

- Tachypnoe (Atemfrequenz $\geq 20 / \mathrm{min}$ ) oder Hyperventilation $(\mathrm{PaCO} 2 \leq 4,3 \mathrm{kPa} / \leq 33 \mathrm{mmHg})$

- Leukozytose $\left(\geq 12000 / \mathrm{mm}^{3}\right)$ oder Leukopenie $\left(\leq 4000 / \mathrm{mm}^{3}\right)$ oder $\geq 10 \%$ unreife Neutrophile im Differentialblutbild

\begin{tabular}{|c|c|}
\hline $\begin{array}{l}\text { Schwere } \\
\text { Sepsis }\end{array}$ & $\begin{array}{l}\text { Sepsis }+ \\
\text { III. mind. } 1 \text { Kriterium } \\
\text { Akute Organdysfunktion } \\
\text { - Akute Enzephalopathie } \\
\text { eingeschränkte Vigilanz, Desorientiertheit, Unruhe, } \\
\text { Delirium } \\
\text { Relative oder absolute Thrombozytopenie } \\
\text { Abfall der Thrombozyten um mehr als } 30 \% \text { innerhalb von } \\
24 \text { Stunden oder Thrombozytenzahl } \leq 10000 / \mathrm{mm}^{3} \text {; eine } \\
\text { Thrombozytopenie durch akute Blutung oder } \\
\text { immunologische Ursachen muss ausgeschlossen sein } \\
\text { Arterielle Hypoxämie } \\
\text { PaO2 } \leq 10 \text { kPa/ } \leq 75 \text { mmHg unter Raumluft oder ein } \\
\text { PaO2/FiO2-Verhältnis von } \leq 33 \mathrm{kPa} / \leq 250 \text { mmHg; } \\
\text { eine manifeste Herzerkrankung oder Lungenerkrankung } \\
\text { muss als Ursache ausgeschlossen sein } \\
\text { Renale Dysfunktion } \\
\text { eine Diurese von } \leq \text { o,5 ml/kg/h für wenigstens } 2 \text { Stunden } \\
\text { trotz ausreichender Volumensubstitution und/oder ein } \\
\text { Anstieg des Serumkreatinins auf über das zweifache des } \\
\text { üblichen Referenzbereiches } \\
\text { Metabolische Azidose } \\
\text { Base Excess } \leq-5 \text { mmol/l oder eine Laktatkonzentration von } \\
\text { 1,5x oberhalb des üblichen Referenzbereiches }\end{array}$ \\
\hline $\begin{array}{l}\text { Septischer } \\
\text { Schock }\end{array}$ & $\begin{array}{l}\text { Sepsis }+ \\
\text { für wenigstens eine Stunde } \\
\text { - ein systolischer arterieller Blutdruck } \leq 90 \mathrm{mmHg} \text { bzw. ein } \\
\text { mittlerer arterieller Blutdruck } \leq 65 \mathrm{mmHg} \\
\text { - oder notwendiger Vasopressoreinsatz, um den } \\
\text { systolischen arteriellen Blutdruck } \geq 90 \mathrm{mmHg} \text { oder den } \\
\text { arteriellen Mitteldruck } \geq 65 \mathrm{mmHg} \text { zu halten } \\
\text { Die Hypotonie besteht trotz adäquater Volumengabe und ist nicht } \\
\text { durch andere Ursachen zu erklären. }\end{array}$ \\
\hline
\end{tabular}

Tabelle 1.1: Diagnosekriterien für Sepsis, schwere Sepsis und septischen Schock

entsprechend den ACCP/SCCM-Konsensus-Konferenz Kriterien ("American College of Chest Physicians/Society of Critical Care Medicine Consensus Conference: definitions for sepsis and organ failure and guidelines for the use of innovative therapies in sepsis" 1992) 
Die Sepsis wird nach den im Februar 2016 neu veröffentlichten Sepsis-3-Kriterien nun als lebensbedrohliche Organdysfunktion aufgrund einer fehlregulierten Körperantwort auf eine Infektion definiert und nur noch in Sepsis und septischen Schock unterteilt. Bei der Einteilung wird nun auf die SIRS-Kriterien verzichtet. Stattdessen findet der SOFA Score (wird unter 2.1.2 ausführlich dargestellt) Anwendung (Singer et al. 2016). Eine Sepsis nach den Sepsis-3 Kriterien liegt vor, wenn sich der SOFA Score eines Patienten akut um zwei oder mehr Punkte erhöht. Ein septischer Schock liegt vor, wenn neben der Diagnose Sepsis trotz adäquater Flüssigkeitssubstitution der Einsatz von Vasopressoren notwendig ist, um einen mittleren arteriellen Blutdruck von $65 \mathrm{mmHg}$ oder höher $\mathrm{zu}$ erzielen und gleichzeitig das Laktat im Serum auf einen Wert von $2 \mathrm{mmol} / \mathrm{l}$ oder größer steigt. Neu eingeführt wurde außerdem der Begriff des qSOFA. Dieser Score besteht aus insgesamt drei Kriterien, die helfen sollen durch einfache klinische Untersuchung eine Sepsis bereits frühzeitig zu erkennen. Bestandteile dieses qSOFA sind ein systolischer Blutdruck von $100 \mathrm{mmHg}$ oder weniger, ein Anstieg der Atemfrequenz auf 22/min oder mehr und eine Bewusstseinsveränderung. Sind mindestens zwei der qSOFA Kriterien erfüllt, so gilt der qSOFA als positiv, und es sollte ein kompletter SOFA Score erhoben werden (Singer et al. 2016).

\subsubsection{Primärer Infektionsort}

Eine primäre Infektion der Atemwege, insbesondere die Pneumonie, ist mit 30 bis 40 \% insgesamt die häufigste Ursache für eine Sepsis und hat eine Mortalitätsrate von über 20 \% (Esper et al. 2006; Mayr et al. 2014). Allerdings ist hierbei anzumerken, dass die relative Häufigkeit der Pneumonie und auch die Mortalität im Zusammenhang mit einer Sepsis im Laufe der Zeit abgenommen haben (Friedman et al. 1998). Bei Männern und Patienten mit Alkoholabusus ist eine Pneumonie die häufigste Ursache für eine Sepsis, während bei Frauen häufig auch eine Infektion des Urogenitaltraktes nachzuweisen ist (Angus et al. 2001; Esper et al. 2006). Weitere primäre Ursachen für eine Sepsis sind abdominale Infektionen, Hautinfektionen, Infektion der Weichteile, Infektionen des zentralen Nervensystems oder die Endokarditis (Angus et al. 2001; Mayr et al. 2010) 


\begin{tabular}{|c|c|c|c|c|}
\hline \multirow{2}{*}{ Infektionsort } & \multicolumn{2}{|c|}{ Morbidität [\%] } & \multicolumn{2}{|c|}{ Mortalität [\%] } \\
\hline & männlich & weiblich & männlich & weiblich \\
\hline Atemwege & 42 & 36 & 22 & 22 \\
\hline Unspezifische Bakteriämie & 21 & 20 & 34 & 35 \\
\hline Urogenitaltrakt & 10 & 18 & 9 & 8 \\
\hline Abdomen & 9 & 8 & 10 & 11 \\
\hline Wund- /Weichteilinfektion & 9 & 8 & 9 & 12 \\
\hline Zentralnervöses System & 1 & 1 & 17 & 18 \\
\hline Endokarditis & 1 & 1 & 24 & 28 \\
\hline Andere & 7 & 9 & 8 & 7 \\
\hline
\end{tabular}

Tabelle 1.2: Infektionsorte bei schwerer Sepsis

Morbidität und Mortalität der primären Infektionsorte in Prozent bei Patienten mit schwerer Sepsis aufgeteilt nach Geschlecht und unter Angabe der assoziierten Mortalität. 


\subsection{14}

Cluster of differentiation 14 (CD14) ist ein Oberflächen-Protein, welches unter anderem von menschlichen Abwehrzellen gebildet wird und bei bakteriellen Infektionen an der Aktivierung des angeborenen Immunsystems beteiligt ist (Pugin et al. 1994). Neben einem membranständigen CD14 (mCD14) existiert auch eine lösliche Form des Rezeptors (sCD14) (Haziot et al. 1988). CD14 hat eine Molekülmasse von $55 \mathrm{kDa}$ und besteht unter anderem aus einem sich zehnfach wiederholenden Muster von Leucin-reichen Aminosäuren (Ferrero et al. 1990; Setoguchi et al. 1989) Die membranständige Form des Rezeptors wird durch Glykosylphosphatidylinositol (GPI) in der Membran der Zelle verankert, während der löslichen Form genau dieser GPI-Anker fehlt (Haziot et al. 1988). Es gibt zwei unterschiedliche Formen von sCD14, welche sich, wahrscheinlich bedingt durch ihre verschiedenen Entstehungsweisen, unterscheiden. Während die eine Form von sCD14 aus einem zunächst membranständigen Rezeptor entsteht, der von der Immunzelle durch Proteasen und Phospholipasen abgespalten wird und eine Molekülmasse von etwa $50 \mathrm{kDa}$ hat (Bazil et al. 1989; Haziot et al. 1988), wird die andere Form direkt von der Zelle sezerniert - ohne dass zuvor ein GPI-Anker an den Rezeptor angebaut wurde - und hat eine Molekülmasse von etwa $56 \mathrm{kDa}$ (Bufler et al. 1995; Labeta et al. 1993). CD14 (früher als gp55, My4 und My23 bezeichnet) wurde zunächst auf reifen Monozyten und Makrophagen nachgewiesen (Griffin et al. 1981). Die Anzahl der Rezeptoren pro Monozyt beträgt annäherungsweise 110 ooo (Antal-Szalmas et al. 1997). Mittlerweile ist bekannt, dass CD14 außerdem auch auf Neutrophilen, Basophilen, dendritischen Zellen und Lymphozyten zu finden ist (Jersmann 2005). Außerdem konnte CD14 auch auf Zellen, die nicht dem Immunsystem angehören, nachgewiesen werden. So findet man beispielweise auch auf Endothelzellen und Epithelzellen CD14 (Funda et al. 2001; Gong et al. 2002). Ebenso ist auf glatten Muskelzellen, Fibroblasten, Betazellen des Pankreas und Hepatozyten CD14 vorhanden (Choi und Lee 2004; Mertens et al. 2009; Sugawara et al. 1999; Vives-Pi et al. 2003). Die lösliche Form des Rezeptors kann hingegen im Serum und vielen anderen Körperflüssigkeiten wie beispielsweise in zerebro-spinaler Flüssigkeit, Urin, seminaler Flüssigkeit, Speichel, Tränen oder Brustmilch gefunden werden (Vidal und Donnet-Hughes 2008). Die physiologische Konzentration im Serum beträgt in etwa 2 bis $4 \mu \mathrm{g} / \mathrm{ml}$ 
(Ulevitch und Tobias 1995). Außerdem konnte gezeigt werden, dass sich die Konzentration von sCD14 durch das Vorhandensein von chronischen Infektionen, wie Borreliose oder Tuberkulose (Juffermans et al. 1998; Lin et al. 2000), aber auch durch Trauma und Sepsis auf Werte von etwa 3 bis $5 \mu \mathrm{g} / \mathrm{ml}$ erhöht (Burgmann et al. 1996; Kruger et al. 1991; Landmann et al. 1996).

\subsubsection{Funktion}

Nachdem Lipopolysaccharide (LPS) mit LPS-Binding-Proteinen (LBP) einen Komplex gebildet haben, ist CD14 in der Lage, diesen Komplex zu erkennen. Anschließend kann dieser dann entstandene Endotoxinmonomer-CD14-Komplex endotoxinmonomere auf myeloid-differentiation-factor 2 (MD2) übertragen. Es entsteht ein Endotoxinmonomer-MD-2-Komplex, welcher dann Toll-like-Rezeptor 4 (TLR4) aktiviert und eine Zellreaktion verursacht (Gioannini et al. 2005). Diese Zellreaktion führt entweder über eine myloid-differentiation-primary-responsegene 88 (MyD88)-abhängige Signalübertragung zur Aktivierung von nukleärem Transkriptionsfaktor- $\mathrm{kB} \quad(\mathrm{NF}-\mathrm{\kappa B})$ und damit zur Transkription von proinflammatorischen Zytokinen wie Tumornekrosefaktor- $\alpha$ (TNF- $\alpha$ ) oder aber über eine MyD88-unabhängige Signalübertragung über das TRIF-related adaptor molecule (TRAM) und den TIR-domain containing adaptor inducing IFN- $\beta$ (TRIF) zur Aktivierung von interferon regulatory factor 3 (IRF3) und damit zur Transkription von Interferon- $\beta$ (IFN- $\beta$ ) (Akira und Takeda 2004; Godowski 2005).

TNF- $\alpha$ verursacht dann, neben einer vermehrten Insulinresistenz, Appetitminderung und einer großen Zahl von anderen Reaktionen im menschlichen Organismus, vor allem proinflammatorische Mechanismen (Rahman und McFadden 2006). Aber auch INF- $\beta$ beeinflusst durch seine immunmodulatorischen Eigenschaften über die Produktion von Proteinen die Funktion des Immunsystems (Samarajiwa et al. 2009; Stark 2007). 


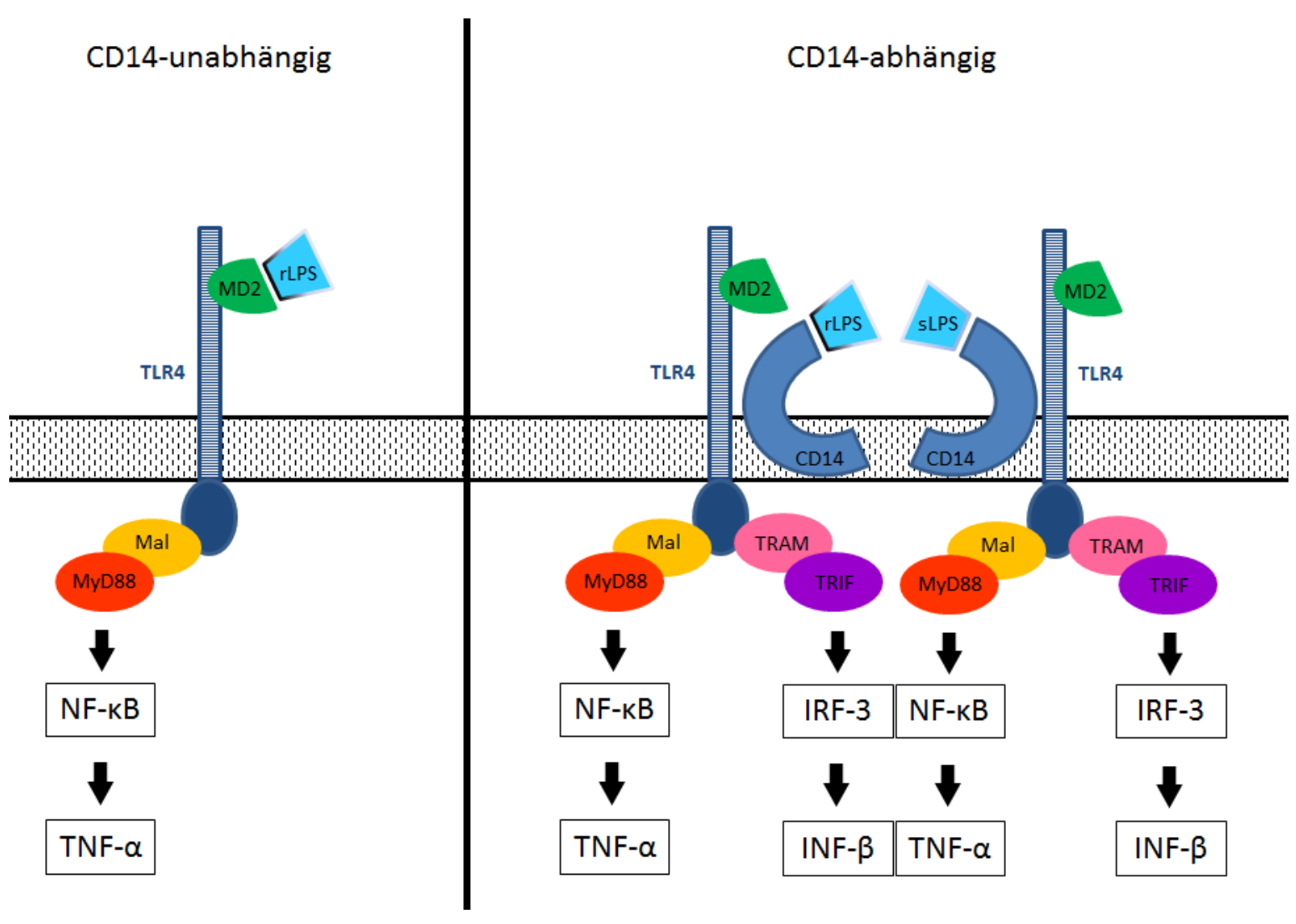

Abbildung 1.1: Signalweitergabe durch TLR4

In Abwesenheit von CD14 kann TLR4 in Kombination mit MD2 nach der Bindung von rauem LPS (rLPS) über den Adapter Mal (auch als Toll/interleukin-1 receptor domaincontaining adapter protein (TIRAP) bezeichnet) und MyD88 NF- $\kappa$ B aktivieren. Hierdurch wird die Transkription von proinflammatorischen Zytokinen wie TNF- a erhöht. In Anwesenheit von CD14 kann sowohl rLPS als auch glattes LPS (sLPS) gebunden werden. Hierdurch wird sowohl der zuvor beschriebene MyD88-abhängige Signalweg als auch der MyD88-unabhängige Signalweg über TRAM und TRIF aktiviert. Nach der Aktivierung von IRF-3 kommt es hierbei zur Transkription von IFN- $\beta$.

(modifiziert nach Godowski 2005, S.545)

\subsubsection{Lipopolysaccharide}

Lipopolysaccharide sind Moleküle, die sowohl aus Zucker- als auch aus Lipideinheiten bestehen und der Hauptbestandteil der äußeren Membran von gramnegativen Bakterien sind (Caroff und Karibian 2003; Nikaido 2003). Lipopolysaccharide lassen sich strukturell in einen Lipid-Abschnitt und einen Polysaccharid-Abschnitt einteilen. Dieser Polysaccharid-Abschnitt wiederum kann nochmal in zwei Untereinheit aufgespalten werden, sodass LPS aus insgesamt drei Untereinheiten bestehen: Lipid A, Core-Polysaccharid und O-Antigen (Caroff et al. 
2002). Lipid A bildet den hydrophoben Teil des Moleküls und besteht aus vier bis sieben Fettsäureketten. Diese Fettsäureketten sind über Ester-Bindungen an ein Disaccharid gebunden, das aus N-Acetylglucosaminphosphat besteht (Alexander und Rietschel 2001). Core-Polysaccharid lässt sich nochmals in einen inneren und einen äußeren Abschnitt einteilen. Der innere Abschnitt besteht hauptsächlich aus 2-Keto-3-desoxy-octonat (KDO), welches über Phosphatbrücken mit Ethanolamin verbunden sein kann. Außerdem stellt KDO die Verbindung zwischen CorePolysaccharid und Lipid-A her. Zusätzlich können im inneren Abschnitt noch Heptosen vorkommen. Der äußere Abschnitt des Core-Polysaccharids besteht aus neutralen Hexosen oder Aminohexosen wie D-Glukose, D-Galaktose, DGlukosamin, D-Galaktosamin oder N-Azetylderivaten (Wilkinson 1996). Das OAntigen besteht aus 3 bis 20 Hexoseeinheiten und bestimmt die Oberflächeneigenschaften des Bakteriums. Es unterscheidet sich je nach Bakterienspezies und ist daher sehr variabel. Wildtyp-Bakterien mit LPS und OAntigen bilden bei Anzucht auf einem Nährstoffboden glatte glänzende Kolonien. Mutierte Bakterien mit LPS ohne O-Antigen hingegen bilden unter Anzucht raue glanzlose Kolonien. Deshalb kann man zwischen Bakterien mit glattem LPS (sLPS) und rauem LPS (rLPS) unterscheiden (Caroff et al. 2002).

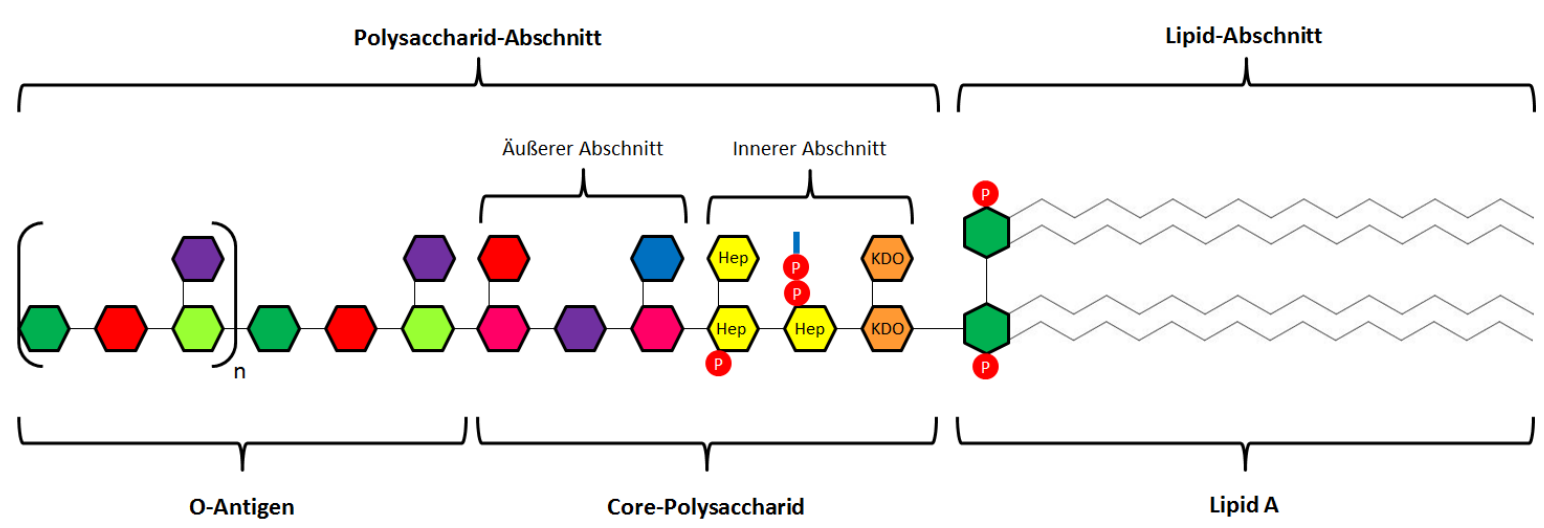

Abbildung 1.2: Struktureller Aufbau von LPS

LPS besteht aus einem hydrophoben Lipid-Abschnitt (Lipid A) und einem PolysaccharidAbschnitt. Dieser Polysaccharid-Abschnitt kann wiederrum in ein O-Antigen und ein Core-Polysaccharid unterschieden werden. Das Core-Polysaccharid besteht hierbei aus einem inneren und einem äußeren Abschnitt. 


\subsubsection{LPS-Binding-Protein}

LPS-Bindig-Protein ist ein Plasma-Protein, welches bei Bedarf hauptsächlich in der Leber produziert werden kann und zur Familie der Akute-Phase-Proteine zählt (Eckert et al. 2013; Fujihara et al. 2003). Im Vergleich zu anderen Akute-PhaseProteinen zeigt LBP einen relativ langsamen Anstieg seiner Konzentration und liegt erst zwei bis drei Tage nach Beginn der Akute-Phase-Reaktion in seiner maximalen Konzentration vor (Schumann 2011). In seiner reinen Form hat LBP eine Molekülmasse von $50 \mathrm{kDa}$ und wird in einer glykosylierten Form in den Blutkreislauf sezerniert. Der Hauptbildungsort des Proteins ist die Leber (Schumann et al. 1990). Es konnte jedoch gezeigt werden, dass LBP auch in Epithelzellen der Lunge und des Gastrointestinaltrakts sowie im Nebenhoden produziert werden kann (Klein et al. 1998; Malm et al. 2005; Vreugdenhil et al. 1999). LBP besitzt eine hohe Bindungsaffinität zu Lipid A, welches Bestandteil von LPS ist (Mathison et al. 1992). Es bildet aus LPS-Polymeren Monomere, welche dann von CD14 erkannt werden können (Hailman et al. 1994; Schumann et al. 1990). Weiterhin ist LBP aber auch in der Lage LPS auf Lipoproteine zu übertragen. Bei diesem Vorgang folgt keine unmittelbare inflammatorische Reaktion, sondern eine Neutralisierung von LPS (Lamping et al. 1996; Wurfel et al. 1994; Zweigner et al. 2001). Außerdem bindet LBP auch Lipopeptide, welche Bestandteile von grampositiven Bakterien oder auch Mykoplasmen sein können und überträgt diese auf CD14 (Schroder et al. 2004). Daher kann LBP als ein Muster-Erkennungsrezeptor (pattern recognition receptor, PRR) angesehen werden (Schumann 2011).

\subsubsection{Toll-like Rezeptor 4}

TLR4 ist einer von mindestens zehn im menschlichen Organismus vorkommenden Rezeptoren aus der Familie der Toll-like Rezeptoren (Seki und Brenner 2008). Der erste Rezeptor dieser Familie konnte eher zufällig durch Forschungen im Bereich der Entwicklungsbiologie von Drosophila melanogaster nachgewiesen werden (Hashimoto et al. 1988). Man fand heraus, dass Mutationen von TLRs zu einer geringeren Überlebenswahrscheinlichkeit infolge von Pilzinfektionen führen und vermutete daher eine immunmodulatorische Funktion von TLRs (Lemaitre et al. 1996). Anschließend konnten auch im menschlichen Immunsystem TLRs gefunden werden (Rock et al. 1998). Mittlerweile ist bekannt, dass TLRs die Funktion von membranständigen PRRs erfüllen, die in der Lage sind pathogen- 
associated molecular patterns (PAMPs) zu erkennen und daher dem angeborenen Immunsystem zuzuordnen sind (Medzhitov und Janeway 2000). Ihren Namen verdanken die TLRs dem Protein Toll, das bei Drosophila melanogaster entdeckt wurde und über dessen Entdeckung die damalige Forschungsgruppe so begeistert war, dass sie es Toll nannte (Weissmann 2010). TLRs bestehen aus Proteinen, die Toll ähneln, also Toll-like sind.

TLRs lassen sich strukturell in eine intrazelluläre und eine extrazelluläre Domäne unterscheiden. Die intrazelluläre Domäne wird hierbei als TIR-(Toll/interleukin-1 receptor)-Domäne bezeichnet und ist homolog zur intrazellulären Domäne des IL1 (Interleukin 1)-Rezeptors. Sie übernimmt bei allen Rezeptoren eine essentielle Rolle in der Signalübertragung (Akira und Takeda 2004). Die extrazelluläre Domäne hingegen unterscheidet sich nicht nur von der extrazellulären Domäne des IL-1 Rezeptors, sondern ist auch je nach TLR verschieden (Armant und Fenton 2002). Gemeinsam ist allen TLRs eine extrazelluläre leucinreiche Proteinsequenz (leucine rich repeats, LRR) von je 24-29 Aminosäuren Länge. Die unterschiedliche Beschaffenheit der extrazellulären Domäne erklärt daher auch die unterschiedlichen Liganden der einzelnen TLRs (Bell et al. 2003). Da TLRs an der primären Erkennung von pathogenen Keimen beteiligt sind, kommen sie vor allem auf der Oberfläche von Zellen der primären Immunantwort wie Neutrophilen, Makrophagen, dendritischen Zellen, dermalen Endothelzellen und Epithelzellen der Schleimhäute vor. TLR2 und TLR4 sind außerdem auch auf T- und BLymphozyten exprimiert (Imler und Hoffmann 2001). Die Rezeptoren TLR1, 2, 4, 5, 6 und 10 sind auf der äußeren Oberfläche der Zellmembran exprimiert, während TLR3, 7, 8, und 9 in der endosomalen Membran zum Lumen gerichtet zu finden sind (Bell et al. 2003; Matsumoto et al. 2003).

TLR1 und TLR6 bilden mit TLR2 ein Heterodimer und können dann Triacyl- bzw. Diacyl-Lipopeptide erkennen (Akira et al. 2006). $\mathrm{Zu}$ den erkennbaren Pathogenen gehören verschiedene Bakterien, Pilze und Protozoa (Akira und Takeda 2004; Szabo et al. 2006). TLR3 erkennt doppelsträngige RNA (double stranded RNA, dsRNA), die ein Erkennungsmerkmal viraler Infektionen ist, da sie während der Replikation der meisten Viren produziert wird (Alexopoulou et al. 2001). TLR 5 hingegen erkennt Flagellin, einen Hauptbestandteil bakterieller Geißeln, sowohl von grampositven als auch gramneagtiven Bakterien (Hayashi et al. 2001). TLR7 wird durch nicht-methylierte einzelsträngige RNA (single stranded RNA, ssRNA) und short interfering RNA (siRNA) aktiviert (Diebold et al. 2004; Hornung et al. 
2005). TLR8 kann ähnlich wie TLR7 auch durch ssRNA aktiviert werden (Heil et al. 2004). TLR9 wird durch häufige Wiederholungen von unmethylierten CytosinPhosphat-Guanin ( $\mathrm{CpG}$ )-Dinukleotiden, die typischerweise in dieser Form hauptsächlich in bakterieller DNA vorkommen, aktiviert (Hemmi et al. 2000). Für TLR1o konnte bisher noch kein Ligand nachgewiesen werden. Allerdings gibt es Hinweise darauf, dass es sich bei TLR10 um einen Rezeptor mit inhibitorischer und damit antiinflammatorsicher Wirkung handeln könnte (Oosting et al. 2014). TLR4 hingegen spielt, wie weiter oben bereits beschrieben, eine wichtige Rolle in der Erkennung von LPS. Dies konnte bereits sehr früh gezeigt werden und deutete darauf hin, dass die TLRs eine Rolle in der Erkennung von Pathogenen und der Aktivierung des Immunsystems spielen (Poltorak et al. 1998). Aber auch andere Liganden sind in der Lage, TLR4 zu aktivieren. So sorgt zum Beispiel das fusion (F) protein des respiratory syncytial virus (RSV) für eine Aktivierung der Signalkaskade über CD14 und TLR4 (Kurt-Jones et al. 2000). Aber auch chlamydial heat shock protein 6o (cHSP6o), ein Protein welches in hohem Maße von Chlamydien produziert wird, führt zur TLR4-Aktivierung (Bulut et al. 2002). Ein weiterer Ligand von TLR4 ist Fibrinogen, welches als Akute-Phase-Protein bei Infektionen vom Körper in hohem Maße produziert wird (Smiley et al. 2001). Außerdem konnte auch für Fibronektin, ein Glykoprotein, das bei Gewebsverletzungen freigesetzt werden kann, eine Aktivierung von TLR4 nachgewiesen werden (Okamura et al. 2001). Auch durch Anteile von Hyaluronsäure, einem Bestandteil der extrazellulären Matrix des menschlichen Organismus, kann TLR4 aktiviert werden (Termeer et al. 2002). Genauso kann TLR4 auch noch von dem in der Lunge produzierten surfactant protein-A (SP-A) aktiviert werden (Guillot et al. 2002). Anzumerken ist außerdem noch, dass insbesondere für die Erkennung von LPS durch TLR4 und die damit verbundene Signalweitergabe neben CD14 auch das Molekül MD 2 notwendig ist (Shimazu et al. 1999). Es konnte gezeigt werden, dass MD 2, das als extrazelluläres Molekül im menschlichen Organismus vorhanden ist, Einfluss auf die Signalweitergabe nach Kontakt mit LPS hat (Schromm et al. 2001). 


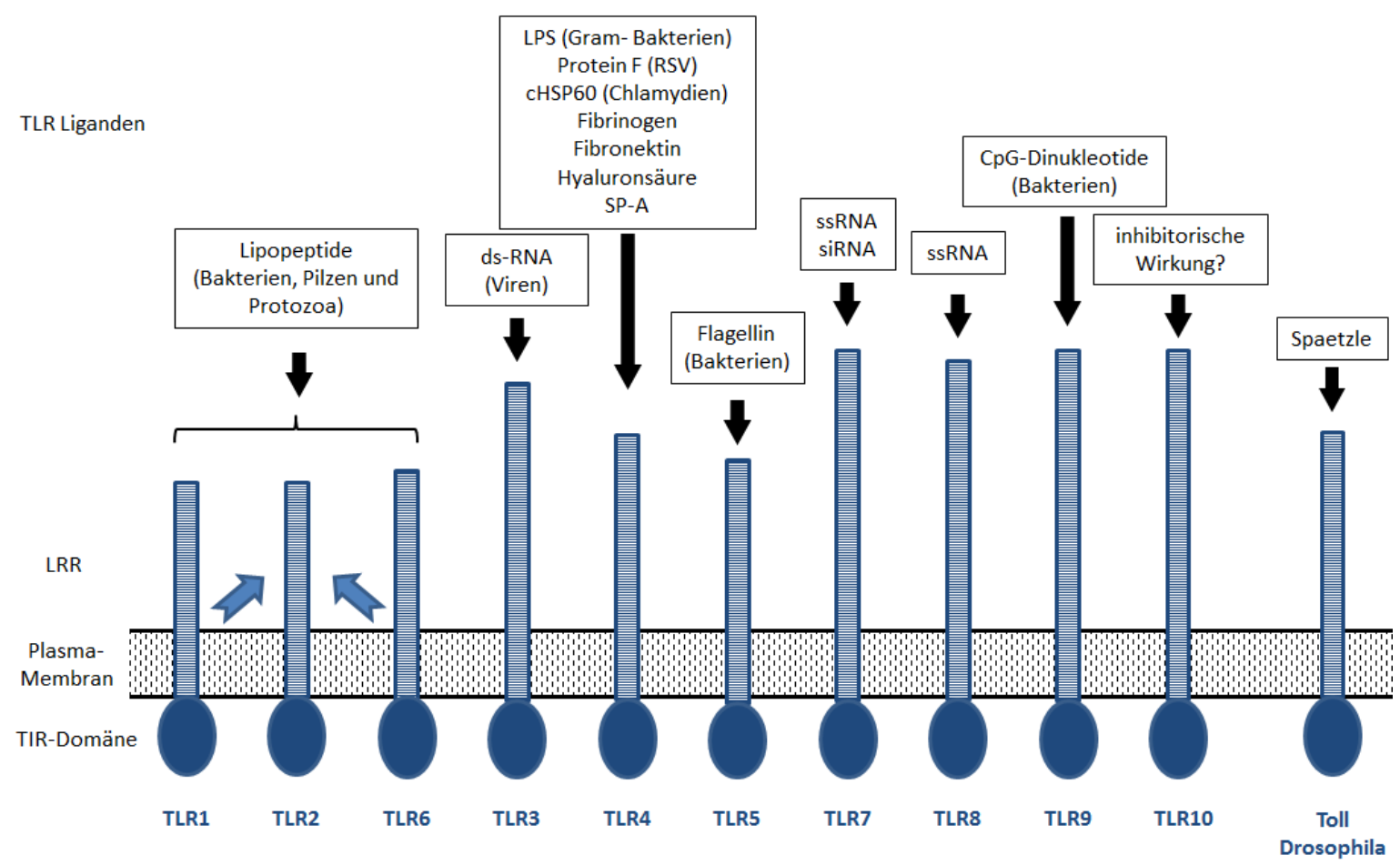

Abbildung 1.3: Struktureller Aufbau und Liganden von TLRs

$\mathrm{Zu}$ erkennen ist der strukturelle Aufbau der menschlichen Mitglieder der TLR-ProteinFamilie und das zuerst entdeckte Drosophila-Toll-Protein von Drosophila melanogaster. Allen gemeinsam ist eine amino-terminale extrazelluläre LRR-Domäne, die für die Ligandenbindung verantwortlich gemacht wird. Außerdem besitzen alle eine intrazelluläre TIR-Domäne, die für die Signalweitergabe notwendig ist. Angegeben sind die bisher entdeckten Liganden der verschiedenen TLRs. Die blauen Pfeile weisen darauf hin, dass TLR2 mit TLR1 und TLR6 ein Heterodimer bildet.

(modifiziert nach Armant und Fenton 2002, S.2)

\subsubsection{Intrazelluläre Adapter von TLR 4}

Insgesamt sind bisher fünf verschiedene intrazelluläre Adapter bekannt, die von den verschiedenen TLRs zur Signalweitergabe genutzt werden. TLR4 nimmt hierbei eine Sonderstellung ein, da er der einzige TLR ist, der insgesamt 4 intrazelluläre Adapter nutzt, während alle anderen TLRs höchstens zwei der Adapter nutzen (O'Neill und Bowie 2007). Die genaue Funktion der intrazellulären Adapter ist bisher noch nicht bis ins Detail verstanden, jedoch konnte bereits gezeigt werden, dass sowohl TIRAP als auch TRAM als Verbindungsadapter fungieren. TIRAP besitzt eine phosphatidylinositol 4,5bisphosphate (PIP2) Bindungs-Domäne, welche TIRAP mit der Zellmembran verbindet. Hierdurch ist TIRAP in der Lage, eine Verbindung von MyD88 mit aktiviertem TLR4 herzustellen und sorgt auf diese Art und Weise für eine 
Aktivierung der Signalweitergabe (Kagan und Medzhitov 2006). Es kommt zu einer Aktivierung von NF- $\kappa \mathrm{B}$ und damit zur Transkription von u.a. TNF- $\alpha$ (Akira und Takeda 2004). TRAM hingegen ist im Unterschied $\mathrm{zu}$ TIRAP über eine Myristoylierung in der Lage eine Verbindung mit der Zellmembran einzugehen (Rowe et al. 2006). Genau wie im zuvor beschriebenen MyD88-Signalweg sorgt auch TRAM für eine Verbindung zwischen in diesem Fall aktiviertem TLR4 und TRIF (Oshiumi et al. 2003). Erst nachdem der entstandene Komplex aus TLR4, TRAM und TRIF zu einem Endosom transportiert wurde, wird der IRF3Signalweg aktiviert, der schließlich zu einer Transkription von IFN- $\beta$ führt (Kagan et al. 2008).

\subsubsection{Proinflammatorische Zytokine}

Nach der Aktivierung der TLR4-Signalkaskade spielt zum einen die Aktivierung von NF- $\kappa \mathrm{B}$ und zum anderen der IRF3-Signalweg eine besondere Rolle. Infolge der NF- $k B$-Aktivierung kommt es durch eine Aktivierung von Genen $\mathrm{zu}$ einer Produktion von TNF- $\alpha$ und Interleukin-1 (IL-1) (Karin und Ben-Neriah 2000). Über den IRF3-Signalweg hingegen kommt es zu einer Ausschüttung von IFN- $\beta$ und $\mathrm{zu}$ einer späteren Aktivierung von NF- $\mathrm{BB}$ (Yamamoto et al. 2002). TNF- $\alpha$ wird hauptsächlich von Makrophagen produziert. Außerdem wird es aber auch von vielen anderen Zellen, wie Lymphozyten, Mastzellen, Endothelzellen, Fibroblasten und neuronalen Geweben, hergestellt. Zudem wird vermutet, dass TNF- $\alpha$ eine Schlüsselrolle in der Entstehung des septischen Schocks spielt (Mannel und Echtenacher 2000). TNF- $\alpha$ ist in der Lage, eine große Zahl komplexer Vorgänge zu beeinflussen, die allesamt vor allem Einfluss auf die Immunantwort, aber auch auf andere Vorgänge wie beispielsweise die Insulinresistenz und das Appetitverhalten nehmen (Wajant et al. 2003). $\mathrm{Zu}$ den die Immunantwort beeinflussenden Vorgängen zählt unter anderem eine Veränderung der Körperkerntemperatur, die Produktion von Akute-Phase-Proteinen in der Leber, die Ausschüttung von $\mathrm{CRH}$ im Hypothalamus und eine dadurch verursachte Stimulierung der Hypothalamus-Hypophysen-Nebennieren-Achse, die Anregung von Makrophagen zur Phagozytose, eine migrationsfördernde Wirkung auf neutrophile Granulozyten oder aber die Einleitung von Apoptose (Aggarwal 2003; Hehlgans und Pfeffer 2005). IL-1 wird hauptsächlich von Makrophagen, Monozyten, Fibroblasten und Endothelzellen produziert. Neben der Induktion von Fieber ermöglicht IL-1 durch den Einbau von Selektinen in Endothelzellen, dass 
im Blut zirkulierende Leukozyten in angrenzende Gewebe auswandern können (Dinarello 1996). Auch IFN- $\beta$ kommt unter anderem in Fibroblasten und Makrophagen vor (Deonarain et al. 2002). Es aktiviert als Zytokin ebenfalls verschiedene immunmodulatorische Vorgänge (Decker et al. 2005). 


\subsection{Genom und Genpolymorphismen}

Das menschliche Genom beinhaltet alle vererbbaren Informationen eines Individuums und verschlüsselt diese Informationen über die Basen Adenin, Guanin, Cytosin und Thymin. Zusammen mit einer Pentose und einem Phosphorsäurerest bilden diese Basen ein Nukleotid. Diese Nukleotide wiederum bilden in ihrer Gesamtheit einen Desoxyribonukleinsäure (DNA)-Doppelstrang. Dieser DNA-Doppelstrang kann durch Replikation verdoppelt und während der Zellverdopplung an eine neue Zelle weitergegeben werden. Außerdem können durch Transkription und Translation aus den gespeicherten Informationen spezifische Proteine hergestellt werden, die für die Regulation der verschiedenen Vorgänge im menschlichen Organismus zuständig sind (Buselmaier und Tariverdian 2007).

Seit dem Jahr 1990 beschäftigt sich das Human Genome Project (HGP) damit, das menschliche Genom komplett zu sequenzieren. Man geht mittlerweile davon aus, dass das menschliche Genom aus etwa 3 Milliarden Basen und 20.000 bis 25.000 Genen besteht (International-Human-Genome-Sequencing-Consortium 2004). Außerdem konnte gezeigt werden, dass nur etwa $1 \%$ des Genoms aus sogenannten Exons besteht, die letztendlich auch translatiert werden. 24 \% des Genoms sind Introns, die zwar transkribiert, aber nicht translatiert werden. $75 \%$ des Genoms sind weder Introns noch Exons (Venter et al. 2001). Durch die Sequenzierung des menschlichen Genoms konnte herausgefunden werden, dass sich zwei verschiedene menschliche Genome nur um etwa 0,1\% unterscheiden (Venter et al. 2001). Die häufigste Unterscheidung stellt hierbei ein sogenannter single nucleotide polymorphism (SNP) dar. Bei einem SNP handelt es sich um eine Variation einer einzelnen Nukleotidbase innerhalb eines DNA-Strangs. Per Definitionem ist ein SNP eine Position im Genom, an der zwei alternative Nukleotide mit einer Häufigkeit von $>1 \%$ in der Population vorkommen (Wang et al. 1998). Je nachdem an welcher Stelle im Genom ein solcher SNP vorkommt, kann er daher ganz unterschiedliche Konsequenzen haben. Befindet sich ein SNP im Bereich eines Exons, so unterscheidet man zunächst zwischen einem synonymen und einem nicht-synonymen SNP. Ein synonymer SNP, welcher auch als stummer SNP bezeichnet wird, bewirkt zwar eine Veränderung der Nukleotidsequenz, aber aufgrund der Degeneriertheit des genetischen Codes verändert sich die translatierte Aminosäuresequenz nicht. Anders verhält es sich bei einem nicht-synonymen SNP. In diesem Fall bewirkt nämlich die Veränderung 
der Nukleotidsequenz auch eine Veränderung der Aminosäuresequenz. Man weiß heute, dass jeder Mensch zwischen 9.000 und 11.000 solcher Varianten trägt (Gonzaga-Jauregui et al. 2012). Man geht davon aus, dass 40 bis 100 dieser nichtsynonymen SNPs aufgrund ihrer vermuteten Auswirkungen auf die Primärstruktur von Proteinen mit großer Wahrscheinlichkeit als krankheitsursächlich eingestuft werden. Tatsächlich sind aber nur wenige dieser Varianten wirklich für eine Erkrankung verantwortlich (Bræne et al. 2013). Aber auch wenn sich ein SNP im Bereich eines Introns befindet, kann er Einfluss auf die Regulation der Genexpression haben (Hural et al. 2000). Selbst außerhalb von Exons und Introns kann ein SNP zu einer Veränderung der Genexpression führen, wenn er sich beispielsweise im Bereich von regulierenden Elementen wie Promotorregion oder anderer Transkriptionsfaktoren befindet (Vercelli 2002). Dies bedeutet letztendlich, dass ein SNP immer Einfluss auf die Genexpression nehmen kann, ganz unabhängig davon, an welcher Stelle im Genom er sich auch befindet.

\subsubsection{SNP rs2569190}

Der SNP rs2569190 befindet sich im Bereich der Genregion von CD14 auf Chromosom 5 im Bereich der Promotorregion und besteht an Basenpaarstelle -159 (Position vom Transkriptionsstart aus betrachtet) oder -260 (Position vom Translationsstart aus betrachtet) entweder aus einem T-Allel oder aber einem CAllel (Baldini et al. 1999). Die minor allele frequency (MAF) beträgt etwa 0,5 (LeVan et al. 2001). Der SNP rs256919o befindet sich entweder im Bereich eines Introns oder aber im Bereich einer nicht transkribierten Region nahe der Genregion von CD14 (Sherry et al. 2001). Die unterschiedliche Lokalisation des SNP rs2569190 entsteht durch alternatives Spleißen. Nach der Transkription entsteht zunächst eine prä-mRNA, welche erst durch Spleißen zur eigentlichen mRNA wird. Bei diesem Spleiß-Vorgang werden alle nicht relevanten Abschnitte der prä-mRNA erntfernt, sodass die mRNA entsteht, die dann für die Translation benutzt werden kann (Klug et al. 2007). Durch die Beeinflussung von regulierenden Proteinen ergeben sich unterschiedliche Spleiß-Stellen und daher auch verschiedene Möglichkeiten der Lokalisation des SNP rs2569190 (Barash et al. 2010; Faustino und Cooper 2003). 


\subsection{Fragestellung}

Aufgrund der wichtigen Rolle von CD14 im Rahmen der angeborenen Immunabwehr scheint ein Zusammenhang zwischen der korrekten Funktion des Rezeptors und der im Patienten ablaufenden Immunreaktion im Rahmen einer Infektion naheliegend. Diverse Studien konnten bereits zeigen, dass der SNP rs2569190 zum einen durch seine Lage in der Promotorregion und zum anderen durch die gesicherten Ergebnisse bezüglich der Konzentrationsveränderungen von sCD14 im Serum anscheinend Einfluss auf die Funktion von CD14 nimmt. Weitere Studien hingegen zeigten bezüglich des Einflusses des SNP rs2569190 auf die Immunantwort teilweise sehr unterschiedliche Ergebnisse. Deshalb bestand die Notwendigkeit diesen Polymorphismus näher zu untersuchen. Vorausgegangene Untersuchungen deuteten bereits auf einen Einfluss des SNP rs2569190 auf das klinische Bild der Sepsis hin. Außerdem gilt die Sepsis als eine der häufigsten Todesursachen für Patienten auf Intensivstationen und ist eine schwerwiegende Komplikation einer Infektion des menschlichen Organismus. Deshalb erschien die Untersuchung von genetischen Varianten, die CD14 betreffen, insbesondere bei Patienten mit Sepsis, sinnvoll.

Als Ziel der Untersuchungen wurden daher folgende Fragestellungen formuliert:

1. Existiert eine Assoziation zwischen dem SNP rs2569190 und der Mortalität an Sepsis erkrankter Patienten auf Intensivstationen?

2. Gibt es einen Zusammenhang zwischen dem SNP rs2569190 und der Schwere einer Sepsis?

3. Gibt es auf den SNP rs2569190 zurückzuführende Unterschiede im Hinblick auf die Organfunktion während einer Sepsis? 


\section{Material und Methoden}

Vor Beginn der Datenerhebungen wurde das geplante Konzept der Forschungsarbeit und die dafür notwendigen Vorgehensweisen dem Klinischen Ethikkomitee der Universitätsmedizin Göttingen vorgelegt und durch dieses am 28.03.2012 genehmigt. Außerdem wurde auf die Einhaltung der Grundsätze für die medizinische Forschung am Menschen entsprechend der Deklaration von Helsinki revidiert durch die WMA-Generalversammlung im Oktober 2008 in Seoul geachtet.

Das Patientenkollektiv dieser Arbeit setzt sich aus 417 kaukasischen Patienten zusammen, die zwischen April 2012 und Juni 2014 stationär auf einer der drei Intensivstationen der Universitätsmedizin Göttingen (UMG) behandelt wurden.

Täglich sind die Intensivstationen 0117 und 0118 , die durch die Klinik für Anästhesiologie betreut wurden, sowie die Intensivstation 1014, die durch die Klinik für Allgemein-, Viszeral- und Kinderchirurgie betreut wurde, auf potentielle Teilnehmer der Studie kontrolliert worden. Die Auswahl der Patienten erfolgte hierbei immer in enger Absprache mit den aktuell behandelnden Ärzten. Vor der Aufnahme möglicher Patienten in unsere Studie mussten diese außerdem entsprechend der Empfehlung der S-2k-Leitlinien der DSG und der DIVI die ACCP/SCCM Konsensus-Konferenz-Kriterien zur Diagnose einer Sepsis folgende Einschlusskriterien erfüllen:

I. Nachweis einer Infektion

- Mikrobiologischer Nachweis oder klinische Kriterien

II. Systemisches inflammatorisches Response-Syndrom (mind. 2 Kriterien)

- Fieber $\left(\geq 38^{\circ} \mathrm{C}\right)$ oder Hypothermie $\left(\leq 36^{\circ} \mathrm{C}\right)$

- Tachykardie (Herzfrequenz $\geq 90 / \mathrm{min}$ )

- Tachypnoe (Atemfrequenz $\geq 20 / \mathrm{min}$ ) oder Hyperventilation $\left(\mathrm{PaCO}_{2} \leq 33 \mathrm{mmHg}\right)$

- Leukozytose $\left(\geq 12000 / \mathrm{mm}^{3}\right)$ oder Leukopenie $\left(\leq 4000 / \mathrm{mm}^{3}\right)$

- oder $10 \%$ unreife Neutrophile im Differentialblutbild 
Zum Ausschluss möglicher Probanden trotz Erfüllung der Einschlusskriterien führten folgende Ausschlusskriterien:

- Alter unter 18 Jahre

- Bekannte Schwangerschaft

- Behandlung mit Immunsuppressiva bzw. Chemotherapie

- Verdacht auf Myokardinfarkt innerhalb der letzten 6 Wochen

- Herzinsuffizienz mit NYHA-Klassifikation IV

- HIV-Infektion

- Bei nichterwartetem Überleben der nächsten 28 Tage aufgrund einer vorbestehenden unheilbaren Erkrankung inklusive:

- Unheilbare Krebserkrankung

- Lungenerkrankung im Endstadium

○ Sauerstoffbedarf in der Häuslichkeit

○ Nierenerkrankung im Endstadium

- Eine fehlende Bereitschaft des Patienten oder des gesetzlichen Vertreters zur Teilnahme an der Studie

Um mögliche Störfaktoren zu eliminieren, wurde bei der Auswahl dieser Ausschlusskriterien darauf geachtet, dass das endgültige Patientenkollektiv aus einer möglichst homogenen Gruppe besteht und dass das Immunsystem und der Gesundheitszustand der Probanden möglichst nicht durch andere als die zu untersuchenden Parameter beeinflusst werden.

Bevor ein Patient Teilnehmer in dieser Studie werden konnte, wurde nach einem ausführlichen Gespräch mit dem Patienten selbst oder aber seinem gesetzlichen Vertreter bzw. Betreuer über die Inhalte der Studie und die dadurch notwendigen Maßnahmen eine freiwillige und schriftliche Einwilligung eingeholt. Der Patient bzw. sein Betreuer wurde in einem ausführlichen Informationsschreiben über die mit der Studie verbundenen Maßnahmen aufgeklärt. Der Patient bzw. sein Betreuer, bekundete durch seine Unterschrift, dass er mit der Entnahme von ca. 3oml Blut, der daran angeschlossenen genetischen Auswertung, dem Zugang zu medizinischen Daten und der Erhebung dieser Daten, welche im Rahmen des stationären Aufenthaltes erfasst werden, einverstanden ist. Dem Patienten bzw. seinem Betreuer wurde außerdem versichert, dass die Daten nach der Blutentnahme nur in verschlüsselter Form aufgezeichnet werden. Ein Zugriff auf 
personenbezogene Daten blieb dabei erhalten, war aber nur den Studienleitern möglich. Andere Mitarbeiter oder Studienbeteiligte hatten keinen Zugriff. Außerdem wurde jeder Teilnehmer darüber informiert, dass seine Teilnahme freiwillig ist und die Einwilligung jederzeit ohne Angabe von Gründen widerrufen und die Vernichtung der Blutprobe eingefordert werden kann, ohne dass dem Patienten daraus irgendwelche Nachteile entstehen.

\subsection{Klinische Datenerfassung}

Die Erfassung der klinischen Daten erfolgte durch tägliche Visiten auf den Intensivstationen. Die erhobenen Daten wurden zunächst handschriftlich in einem selbst entworfenen Erfassungsbogen (clinical report form, CRF) festgehalten und dann später in eine elektronische Datenbank eingefügt. Hierbei wurden die klinisch relevanten Daten auf den Intensivstationen von einem elektronischen Patientendatenmanagement-System (IntelliSpace Critical Care and Anesthesia (ICCA); Philips Healthcare, Andover, Massachusetts, USA) erfasst. Alle weiteren Daten wurden entweder nach Rücksprache mit den auf den Intensivstationen betreuenden Ärzten oder aber nach Rücksprache mit dem Patienten selbst, seinem Hausarzt oder aber den nächsten Angehörigen erhoben.

\subsubsection{Patientendatenmanagement-System}

IntelliSpace Critical Care and Anesthesia (ICCA), ehemals unter dem Namen „IntelliVue Clinical Information Portfolio“ (ICIP) bekannt, ist das Philips Patientendatenmanagement-System (PDMS), das dem Klinikteam zur Vereinfachung der Patientenversorgung zur Verfügung steht. ICCA ist eine skalierbare, modulare und erweiterbare Plattform von Philips und Critical Care. Mit ICCA können Patientendaten dokumentiert, weitergeben und ausgewertet werden. So bietet dieses Programm sowohl klinische Entscheidungsunterstützung, als auch administrative Übersicht. Außerdem bietet es Möglichkeiten zur Erfassung und Verarbeitung klinischer Informationen. Weiterhin können digitale Bilder importiert werden und der unmittelbare Zugriff auf Informationen von früheren Krankenhausaufenthalten eines Patienten ist gewährleistet. (Philips 2018). So konnten mit Hilfe von ICCA neben allgemeinen Patientendaten, Vorerkrankungen und Vormedikation auch Laborwerte, Ergebnisse mikrobiologischer Untersuchungen, radiologische Bildgebung, klinische Untersuchungsergebnisse und die aktuelle Therapie erfasst werden. 


\subsubsection{Erfassungsbogen}

Die während der Visiten auf den Intensivstationen erhobenen Daten wurden zunächst handschriftlich in einem selbst entworfenen Erfassungsbogen (auch clinical report form (CRF) genannt) festgehalten. Mit Hilfe dieses Erfassungsbogens wurden zunächst die Ein- und Ausschlusskriterien kontrolliert und dokumentiert. Neben dem Datum der Einwilligungserklärung wurde auch erfasst, ob der Patient selbst oder aber ein gesetzlicher Vertreter in die Studie eingewilligt hat. Auch das Datum der Blutentnahme und ob es sich bei diesem Blut um venöses oder arterielles Blut handelt, wurde dokumentiert. Genauso wurden neben dem Grund für die Krankenhausaufnahme auch das Datum der Krankenhausaufnahme, der Aufnahme auf die Intensivstation, der Beginn der Sepsis, das Alter des Patienten, sowie Körpergröße und Gewicht notiert. Auch wurde der operative Status des Patienten erhoben und insofern dieser positiv war, in Patienten mit Zustand nach elektiver oder aber nach Notfall-Operation unterschieden. Im Anschluss daran wurden alle relevanten Vorerkrankungen eruiert und nach den Bereichen Herz-Kreislauf, Atmung, Neurologie, Magen-Darm, Niere, Stoffwechsel, Immunsystem und andere unterschieden. Außerdem wurde im Rahmen der Vormedikation insbesondere auf die Einnahme von Statinen, Beta-Blockern, ACE Hemmern, Coronartherapeutika, Antidiabetika, Diuretika, Bronchodilatatoren, Antihypertensiva, Antiarrhythmika und Antikoagulantien geachtet.

Im Anschluss daran erhob der Erfassungsbogen für jeden der ersten 30 Tage nach Sepsisbeginn, die der Patient auf einer der Intensivstationen verbachte, die im Folgenden beschriebenen Werte. So wurden zur allgemeinen Beurteilung des Patienten höchste und niedrigste Körpertemperatur $\left({ }^{\circ} \mathrm{C}\right)$, Leukozytenzahl $\left(10^{3} / \mathrm{mm}^{3}\right)$, Hämatokrit (\%) und Thrombozytenzahl $\left(10^{3} / \mathrm{mm}^{3}\right)$ erfasst. Außerdem wurden als Herz-Kreislaufparameter höchste und niedrigste Herzfrequenz (min-1), höchster und niedrigster mittlerer arterieller Blutdruck (mmHg), höchster und niedrigster systolischer Blutdruck (mmHg) sowie die höchste und niedrigste Dosis von Dobutamin ( $\mu \mathrm{g} / \mathrm{kg} / \mathrm{min})$, Adrenalin $(\mu \mathrm{g} / \mathrm{min})$ und Noradrenalin $(\mu \mathrm{g} / \mathrm{min})$ ermittelt. Weiterhin wurden zur Kontrolle der Atmungsparameter die höchste und niedrigste Atemfrequenz (min-1), der niedrigste $\mathrm{PaO}_{2}(\mathrm{mmHg})$ mit entsprechendem FiO2-Wert, der höchste und niedrigste arterielle $\mathrm{pH}$ und Base Excess, das höchste Laktat (mmol/l) sowie die Atmungsform (spontan oder künstlich) dokumentiert. Zur Kontrolle der Leberfunktion wurden Bilirubin (mg/dl), die Aspartat-Aminotransferase (AST) 
[IU/l], die Alanin-Aminotransferase (ALT) [IU/l], Quick [\%] und aPTT [sec] erfasst. Außerdem wurde dokumentiert, ob eine systemische Antikoagulation bzw. eine Thromboseprophylaxe durchgeführt wurde. Zur Beurteilung der Nierenfunktion wurden Kreatinin (mg/dl) und Urinausscheidung (ml) erhoben und eine eventuell durchgeführte Art von Dialyse dokumentiert. Auch der höchste und niedrigste Wert der Elektrolyte Natrium ( $\mathrm{mmol} / \mathrm{l}$ ) und Kalium (mmol/l), die Entzündungsparameter C-reaktives Protein (CRP) (mg/l) und Procalcitonin ( $\mu \mathrm{g} / \mathrm{l}$ ), sowie der höchste Wert der Glasgow Coma Scale zur Beurteilung des Bewusstseins wurden erfasst. Außerdem wurde dokumentiert, ob eine Röntgenaufnahme der Lunge durchgeführt wurde und ob auf dieser Infiltrate oder gar ein Lungenödem zu erkennen war. Schließlich wurde für Tag 1 der Acute Physiology and Chronic Health Evaluation II (APACHE II) Score und für Tag 1 bis 30 der Sepsis-related Organ Failure Assessment (SOFA) Score inklusive einer Unterteilung nach Organsystemen ermittelt. Der APACHE II Score, der zur Beurteilung der Schwere einer Erkrankung dient, wird durch verschiedene, in der Intensivmedizin relativ einfach zu erhebenden Daten, gebildet. Für die verschiedenen Werte werden Punkte vergeben, die am Ende zusammengezählt werden. Alle Werte werden innerhalb der ersten 24 Stunden nach Aufnahme erhoben, wobei der jeweils schlechteste Wert innerhalb dieser 24 Stunden in die Bewertung eingeht. Der APACHE II Score ist ein Risikoscore, der dazu dient das Mortalitätsrisiko eines Patienten einzuschätzen. Insgesamt setzt sich der APACHE II aus 3 verschiedenen Anteilen zusammen: dem Acute Physiology Score, den Age Points und dem Chronic Health Score (Knaus 2002; Knaus et al. 1985). Allerdings ist hierbei anzumerken, dass das erwartete Mortalitätsrisiko zwar mit der Höhe des APACHE II Scores stark korreliert, aber dennoch die Höhe des Scores keine absolut sichere Auskunft über das korrekte Mortalitätsrisiko geben kann. Deshalb sollte die Aussagekraft des Scores nicht überschätzt werden (Chiavone und Sens 2003). 


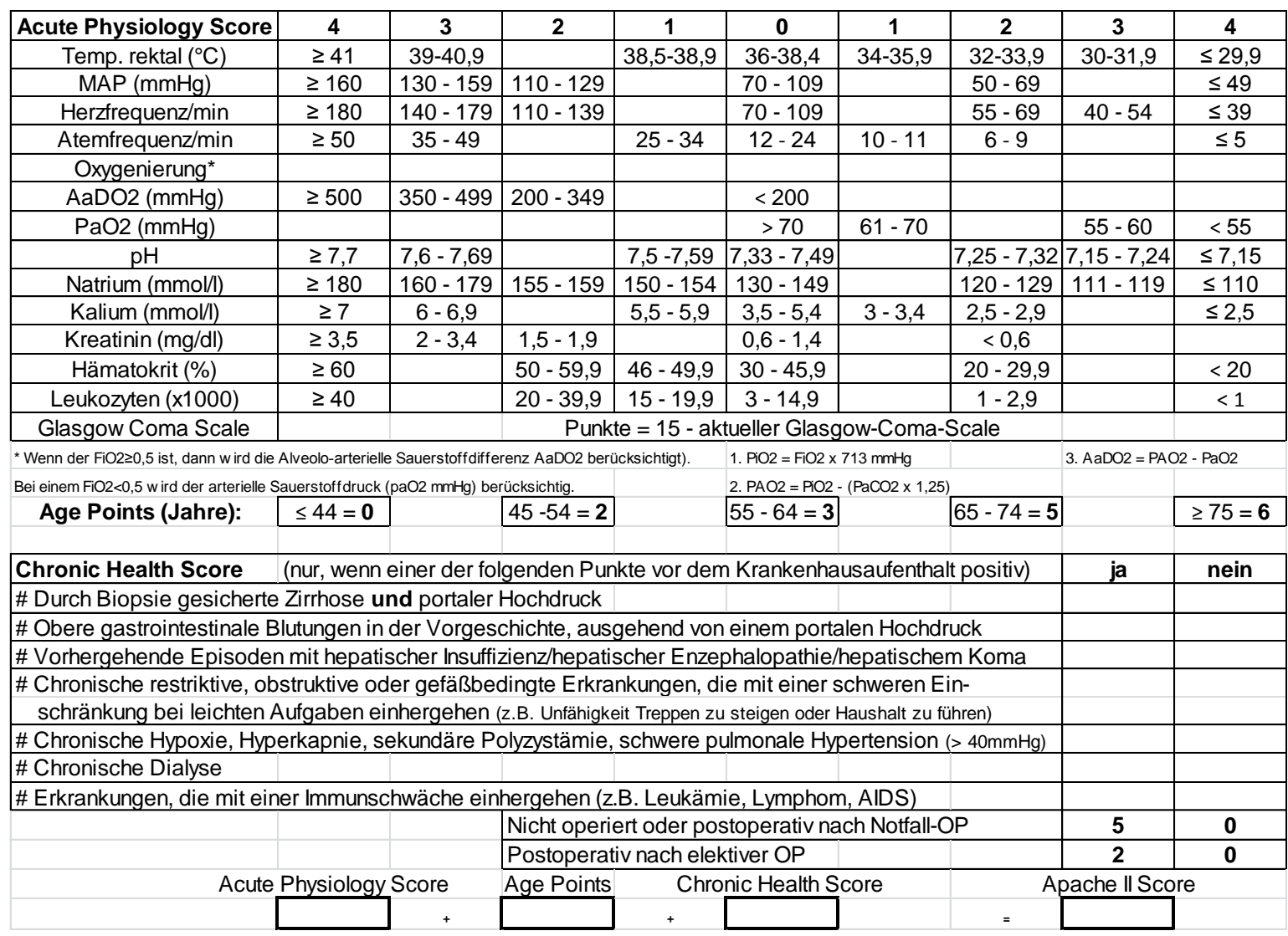

\section{Tabelle 2.1: APACHE II}

Der APACHE II Score setzt sich aus 3 verschiedenen Anteilen zusammen: dem Acute Physiology Score, den Age Points und dem Chronic Health Score. Der Gesamtwert soll Aufschluss über das zu erwartende Mortalitätsrisiko geben.

(modifiziert nach Knaus et. al 1985, S. 820)

\begin{tabular}{lcccccccc}
\hline Punktzahl & $0-4$ & $5-9$ & $10-14$ & $15-19$ & $20-24$ & $25-29$ & $30-34$ & $>34$ \\
\hline Mortalitätsrisiko & $\approx 4 \%$ & $\approx 8 \%$ & $\approx 15 \%$ & $\approx 25 \%$ & $\approx 40 \%$ & $\approx 55 \%$ & $\approx 75 \%$ & $\approx 85 \%$ \\
\hline
\end{tabular}

Tabelle 2.2: APACHE II-Mortalitätsrisiko

Das zu erwartende Mortalitätsrisiko anhand der Gesamtpunktzahl des APACHE II.

(modifiziert nach Knaus et. al 1985, S.823) 
Der Sequential Organ Failure Assessment (SOFA) Score ist ebenfalls ein Punktesystem, das versucht, den Gesamtgesundheitszustand von schwer erkrankten Patienten anhand von Punkten darzustellen. Im Unterschied zu APACHE II ist der SOFA Score allerdings nicht nur zur einmaligen Bestimmung des Gesundheitszustandes des Patienten 24 Stunden nach Aufnahme angedacht, sondern als Verlaufsparameter geeignet, der täglich neu erhoben werden kann (Vincent et al. 1996). Hierzu werden insgesamt sechs verschiedene Organsysteme beurteilt. Für jedes Organsystem werden hierbei zwischen o und 4 Punkte vergeben, wobei o mit einer normalen und 4 mit einer sehr schlechten Organfunktion assoziiert ist. So wird die Funktion der Lunge durch die Kontrolle des Oxygenierungsindex nach Horovitz bestimmt. Hierbei wird der Quotient aus arteriellem Sauerstoffpartialdruck ( $\mathrm{PaO} 2)$ und inspiratorischem Sauerstoffanteil (FiO2) gebildet (Horovitz et al. 1974). Die Funktion der Niere wird anhand der Kreatininkonzentration im Serum oder aber durch die Bestimmung der täglichen Urinausfuhr beurteilt. Die Leberfunktion wird durch die Bestimmung der Bilirubinkonzentration im Serum bewertet. Die Herz-/Kreislauffunktion wird durch die Bestimmung des mittleren arteriellen Blutdrucks oder aber aufgrund der Gabe von Katecholaminen eingestuft. Während die Funktion des Blutsystems durch die Höhe der Thrombozytenzahl bewertet wird, wird zur Beurteilung des zentralen Nervensystems (ZNS) die Glascow Coma Scale verwendet. Schließlich kann nach Beurteilung aller Organsysteme eine Gesamtpunktzahl gebildet werden. Die Höhe dieser Gesamtpunktzahl, aber auch der initial erhobene SOFA Score, der mittlere Gesamtwert sowie die tägliche Veränderung korrelieren nicht nur mit der tatsächlichen Organfunktion, sondern können auch als prognostischer Wert für die Gesamtmortalität verwendet werden (Ferreira et al. 2001; Moreno et al. 1999; Vincent et al. 1998). 


\begin{tabular}{|c|c|c|c|c|}
\hline Organsystem & $\mathbf{1}$ & 2 & 3 & 4 \\
\hline $\begin{array}{l}\text { Respiration } \\
\mathrm{PaO} 2 / \mathrm{FiO} 2\end{array}$ & $<400$ & $<300$ & $\begin{array}{c}<200 \\
\text { mit Beatmung }\end{array}$ & $\begin{array}{c}<100 \\
\text { mit Beatmung }\end{array}$ \\
\hline $\begin{array}{l}\text { Gerinnung } \\
\text { Thrombozyten } \\
{\left[10^{3} / \mathrm{mm}^{3}\right]}\end{array}$ & $<150$ & $<100$ & $<50$ & $<20$ \\
\hline $\begin{array}{l}\text { Leber } \\
\text { Bilirubin }[\mathrm{mg} / \mathrm{dl}]\end{array}$ & $1,2-1,9$ & $2,0-3,4$ & $3,5-4,9$ & $\geq 5,0$ \\
\hline $\begin{array}{l}\text { Herz-Kreislauf } \\
\text { Hypotension }[\mathrm{mmHg}]\end{array}$ & $\begin{array}{l}\text { MAP } \\
<70\end{array}$ & $\begin{array}{l}\text { Katecholamine } \\
\text { niedrig* }\end{array}$ & $\begin{array}{l}\text { Katecholamine } \\
\text { mittel* }\end{array}$ & $\begin{array}{l}\text { Katecholamine } \\
\text { hoch* }^{*}\end{array}$ \\
\hline $\begin{array}{l}\text { ZNS } \\
\text { Glasgow Coma Scale }\end{array}$ & $13-14$ & $10-12$ & $6-9$ & $<6$ \\
\hline $\begin{array}{l}\text { Niere } \\
\text { Kreatinin }[\mathrm{mg} / \mathrm{dl}] \text { oder } \\
\text { Ausfuhrmenge[ml/d] }\end{array}$ & $1,2-1,9$ & $2,0-5,9$ & $\begin{array}{l}6,0-11,9 \\
\quad<500\end{array}$ & $\begin{array}{l}>12 \\
<200\end{array}$ \\
\hline
\end{tabular}

Tabelle 2.3: SOFA

Sequential Organ Failure Assessment (SOFA) Score.

* Katecholamindosis:

niedrig: Dopamin $\leq 5 \mu \mathrm{g} / \mathrm{kg} / \mathrm{min}$ oder Dobutamin (jede Dosis) für mind. 1 Stunde;

mittel: Dopamin $>5 \mu \mathrm{g} / \mathrm{kg} / \mathrm{min}$ oder Adrenalin / Noradrenalin $\leq 0,1 \mu \mathrm{g} / \mathrm{kg} / \mathrm{min}$ hoch: Dopamin > $15 \mu \mathrm{g} / \mathrm{kg} / \mathrm{min}$ oder Adrenalin / Noradrenalin > 0,1 $\mu \mathrm{g} / \mathrm{kg} / \mathrm{min}$

(modifiziert nach Vincent et al. 1996, S. 708) 


\subsection{Material}

\subsubsection{Substanzen}

Ampuwa (DNase / RNase freies Wasser)

Buffer RLT Plus lysis buffer

Ethanol $100 \%$

Ficoll-PaqueTM PLUS

Formaldehyde-solution 36.5-38 \%

Glycin (10x)

2-Mercaptoethanol for synthesis

PBS (1x) Dulbecco's

PBS (10x)

Phenylmethylsulfonylfluorid (PMSF) 100mM

hexPrimer random $p(d N) 650$ A26o units

ProteaseInhibitorCocktail (PIC)

TaqMan® Genotyping MasterMix (2x)

TaqMan® Universal PCR MasterMix (2x);

Tryptan-Blau-Lösung (0,4 \%)

\subsubsection{Kits und Assays}

AllPrep DNA / RNA Mini Kit (50)

EZ1 DNA Blood $350 \mu$ Kit

QuantiTect@ Reverse Transcription Kit

(for use in real Time RT-PCR)

TaqMan® SNP Genotyping Assay-by-design (40x): Life Technology CD14 C__16043997_10 rs2569190
Fresenius Kabi

(Bad Homburg)

Qiagen GmbH (Hilden)

Merck (Darmstadt)

GE HealthCare

Bio-SciencesAB

(Uppsala/Schweden)

Sigma (Steinheim)

Active Motif

(La Hulpe/Belgien)

Merck (Darmstadt)

PAA Laboratoris GmbH

(Cölbe)

Active Motif

(La Hulpe/Belgien)

Active Motif

(La Hulpe/Belgien)

Roche (Mannheim)

Active Motif

(La Hulpe/Belgien)

Applied Biosystems

(Darmstadt)

Applied Biosystems

(Darmstadt)

Sigma (Steinheim)

Qiagen GmbH (Hilden)

Qiagen GmbH (Hilden)

Qiagen GmbH (Hilden) 


\subsubsection{Gebrauchswaren}

Küvetten (Eppendorf UVette) 8,5 mm

Eppendorf (Hamburg)

MicroAmpTM Fast Optical 96-Wells reaction plate

Applied Biosystems

(Darmstadt)

MicroAmpTM Optical Adhesive Film (RNase free)

Applied Biosystems

(Darmstadt)

Pipettenspitzen (steril, RNase / DNase frei)

Biozym (Oldendorf)

Combitips advanced $0,1 \mathrm{ml}$

Eppendorf (Hamburg)

QIAshredderTM (250)

Qiagen GmbH (Hilden)

Reaktionsgefäße (steril, RNase / DNase frei):

Micro tube $1,5 \mathrm{ml}$

Sarstedt (Nümbrecht)

BD Falcon Tubes $50 \mathrm{ml}$

Falcon (New Jersey/USA)

LeukosepTM-Röhrchen

Greiner bio-one

mit Trennscheibe $50 \mathrm{ml}$

(Frickenhausen)

S-Monovette $\AA 7.5 \mathrm{ml}$ (Lithium-Heparin)

Sarstedt (Nümbrecht)

S-Monovette $\AA 7.5 \mathrm{ml}$ (K3 EDTA)

Sarstedt (Nümbrecht)

\subsubsection{Geräte}

Biophotometer 8,5 mm

Eppendorf (Hamburg)

BioRobot EZ1

Qiagen GmbH (Hilden)

Cellstar serological Pipette $5 \mathrm{ml}$ (steril)

Greiner bio-one

(Frickenhausen)

Pipetten

Eppendorf (Hamburg)

pipetus $(-a k k u$

Hirschmann Laborgräte

(Eberstadt)

StepOne Plus Real-Time PCR System

mit Auswertungs-Software Version 2.1

Sterilbank LaminAir

Applied Biosystems

(Darmstadt)

Heraeus (Hanau)

Thermomixer comfort 1,5 ml

Eppendorf (Hamburg)

Thermomixer 5436

Schütt Labortechnik

(Göttingen)

Vortex

Heidolph (Kelheim)

Waage

Sartorius (Göttingen) 
Zentrifugen:

Centrifuge 5415 D

Thermo scientific Megafuge 1.o R

Rotanta $96 \mathrm{R}$

Rotixa /A

$3 \mathrm{~K} 30$ Centrifuge
Eppendorf (Hamburg)

Heraeus (Hanau)

Hettich (Kirchlengern)

Hettich (Kirchlengern)

Sigma (London/UK) 


\subsection{Materialverarbeitung im Labor}

\subsubsection{Isolierung von peripheren Blut-Leukozyten}

Zur Isolierung von peripheren Blut-Leukozyten (PBL) war zunächst eine Blutentnahme erforderlich, welche nach ausführlich durchgeführter Auswahl und Einwilligung der Patienten direkt auf den Intensivstationen erfolgte. Hierfür wurden den Patienten entweder $30 \mathrm{ml}$ venöses oder aber arterielles Blut in mehrere mit Lithium-Heparin oder aber mit Ethylendiamintetraessigsäure (EDTA) gefüllte Monovetten abgenommen. Insofern die Patienten noch nicht über einen zentralen Venenkatheter oder einen arteriellen Katheter verfügten, wurde eine Punktion vorzugsweise im Bereich der Ellenbeuge unter sterilen Bedingungen durchgeführt. Im Anschluss wurde das Blut direkt im Labor weiterverarbeitet.

Zur Isolierung der PBL aus der Blutprobe der Patienten wurden alle Arbeiten bei denen es zu einer Verunreinigung der Proben hätte kommen können, innerhalb einer Sterilbank durchgeführt. Zunächst wurde ein Leukosepröhrchen mit Filterscheibe mit $15 \mathrm{ml}$ Ficoll befüllt und für etwa 30 Sekunden bei $2300 \mathrm{rpm}$ unter Raumtemperatur zentrifugiert, damit die Lösung sich unterhalb der Filterscheibe sammeln konnte. Im Anschluss wurde das Blut der Monovettenröhrchen in ein leeres Falconröhrchen überführt, um das Blut im Anschluss mit Hilfe einer Pipette auf die Filterscheibe aufzubringen, jedoch ohne dabei die Gelperlen aus den Monovetten mitzunehmen. Anschließend wurde das Falconröhrchen mit Filterscheibe dann für 15 bis 20 Minuten bei 2300 rpm ohne Bremse zentrifugiert. Hierdurch entstehen aufgrund der unterschiedlichen Dichtewerte der Zellen verschiedene Schichten mit einheitlichen Zellen. Im Sediment unterhalb der Filterscheibe sammeln sich Erythrozyten und Granulozyten, während sich oberhalb eine Schicht aus mononukleären Zellen und Thrombozyten bildet, worüber sich schließlich das Plasma absetzt. Die Schicht oberhalb der Filterscheibe wurde daher in ein neues Falconröhrchen überführt. Anschließend wurden $\mathrm{zu}$ diesem Falconröhrchen $40 \mathrm{ml}$ phosphatgepufferte Salzlösung (PBS (1x)) zugetan und das Röhrchen für 10 Minuten bei 1300 rpm und $4{ }^{\circ} \mathrm{C}$ mit Bremse zentrifugiert. Der im Anschluss entstandene Überstand wurde abgeschüttet, und die im Falconröhrchen verbliebenen Zellen wurden aufgeschüttelt. Erneut wurden $40 \mathrm{ml}$ PBS (1x) hinzugegeben, um den bereits zuvor beschriebenen Waschvorgang noch zweimal zu wiederholen. Nach insgesamt drei Waschvorgängen wurde nach erneutem Aufschütteln des Zellpellets wieder $10 \mathrm{ml}$ 
PBS (1x) hinzugegeben. Eine Probe von $20 \mu \mathrm{l}$ dieser Zellsuspension wurde daraufhin zusammen mit $20 \mu \mathrm{l}$ Tryptanblau in einem 1,5-ml-Reaktionsgefäß (Cup) gemischt. Eine geringe Menge dieser Mischung wurde dann auf eine NeubauerZählkammer zur Bestimmung der genauen Zellzahl aufgebracht. Im Anschluss wurden die Zellen so auf verschiedene Cups verteilt, dass diese entweder zwischen $2 \times 10^{6}$ und $4 \times 10^{6}$ Zellen oder aber zwischen $12 \times 10^{6}$ und $2 \times 10^{7}$ Zellen enthielten. Die Cups mit der größeren Anzahl an Zellen wurden im weiteren Verlauf für eine Haplo-type-specific chromatin immunoprecipitation (HaploChIP) genutzt, was nicht Bestandteil dieser Dissertationsarbeit ist und daher im weiteren Verlauf nicht näher beschrieben wird. Die Cups mit der geringeren Zellzahl wurden auf Eis gestellt und im Anschluss wurden noch 0,5 ml PBS (1x) aus dem im weiteren Verlauf genutzten Qiagen-Kit hinzugegeben. Danach wurden diese Cups dann für 5 bis 10 Minuten erneut bei $1200 \mathrm{rpm}$ und $4{ }^{\circ} \mathrm{C}$ zentrifugiert. Der dabei entstandene PBS Überstand wurde dann abpipettiert und $350 \mu$ l eines zuvor selbst hergestellten Lysepuffers aus RLT Plus Puffer und Mercaptoethanol im Verhältniss 100:1 hinzugegeben. Im Anschluss wurde das Lysat noch gevortext bevor es bei $20^{\circ} \mathrm{C}$ im Gefrierschrank eingelagert wurde.

\subsubsection{Isolierung der gDNA}

Die Isolierung der gDNA erfolgte gemäß dem AllPrep DNA/RNA Mini Kit entsprechend dem Protokoll "Simultaneous Purification of Genomic DNA and Total RNA from Animal Cells“. So wurde das Lysat der PBL-Isolierung auf eine DNA-Säule aufgetragen und für 30 Sekunden bei 10 ooo rpm zentrifugiert. Hierdurch wurde die DNA aus dem Lysat auf der Membran der Säule gebunden. Im Zentrifugat hingegen befand sich die RNA, welche ebenfalls weiter untersucht wurde. Da dies aber genau wie die HaploChIP Arbeiten nicht Bestandteil dieser Dissertationsarbeit ist, wird auch hierauf im weiteren Verlauf nicht weiter eingegangen. Die Säule inklusiver gebundener DNA wurde dann vor der Weiterverarbeitung zunächst zwei Waschvorgängen unterzogen. Für den ersten Waschvorgang wurde die Säule mit $500 \mu \mathrm{l}$ AW 1 Puffer für 15 Sekunden bei 10000 rpm zentrifugiert. Für den zweiten Waschvorgang wurde die Säule dann mit $500 \mu \mathrm{l}$ AW 2 Puffer für 2 Minuten bei 13200 rpm zentrifugiert. Im Anschluss wurde die Säule für eine Minute bei 13 ooo rpm ohne einen Zusatz zentrifugiert, um sie zu trocknen. Danach wurden die Säule in einen 1,5-ml-Cup gestellt und $50 \mu$ EB-Puffer hinzugegeben. Nach einer Inkubationszeit von einer Minute wurde 
die Säule inklusive des 1,5-ml-Cups für eine Minute bei 10 ooo rpm zentrifugiert. Auf diese Weise konnte die DNA aus der Säule eluiert und in den 1,5-ml-Cup überführt werden. Nachdem der Cup noch einmal gevortext wurde, konnte die DNA dann vor der Weiterverarbeitung bei $-20{ }^{\circ} \mathrm{C}$ wieder eingelagert werden.

\subsubsection{Bestimmung der DNA-Konzentration}

Um bei den weiteren Untersuchungen sicherzustellen, dass die Konzentration der DNA in allen Proben sehr ähnlich ist, wurden alle DNA Proben mit Hilfe eines Photometers auf ihre Konzentration überprüft. Alle im Folgenden beschriebenen Arbeitsschritte wurden unter Kühlung der DNA auf Eis durchgeführt. Zu $3 \mu$ der isolierten DNA wurden daher zunächst $97 \mu$ Ampuwa hinzugegeben, um im Anschluss die Absorption dieses Gemisches im Photometer bei $260 \mathrm{~nm}$ und $280 \mathrm{~nm} \mathrm{zu}$ bestimmen. Das Absorptionsmaximum der DNA liegt bei $260 \mathrm{~nm}$, während das Absorptionsmaximum von eventuell als Verunreinigung in den Proben vorhandenen Proteinen bei $280 \mathrm{~nm}$ anzusiedeln ist. Daher kann durch das Verhältnis der Absorption bei $260 \mathrm{~nm}$ zu der Absorption bei $280 \mathrm{~nm}$ eine Aussage über die Reinheitsqualität der Probe getroffen werden. Da die Normwerte für gereinigte DNA für diesen Quotienten zwischen 1,7 und 1,9 liegen, wurden nur Proben weiterverarbeitet, die innerhalb dieses Wertebereichs lagen. Da als Zielkonzentration ein Wert von 2 ng DNA/ml angesetzt worden war, wurden alle Proben nach Bestimmung der Konzentration durch die Absorption bei $260 \mathrm{~nm}$ mit DNase/RNase-freiem Wasser so verdünnt, dass die Zielkonzentration von 2 ng $\mathrm{DNA} / \mathrm{ml}$ erreicht wurde. Im Anschluss wurden diese Proben dann vor der Weiterverarbeitung erneut bei $-20{ }^{\circ} \mathrm{C}$ eingelagert.

\subsubsection{Genotypisierung durch allelische Diskriminierung}

Für die Genotypisierung des SNP rs2569190 durch allelische Diskriminierung wurde zunächst eine 96-Well-Platte so befüllt, dass immer zwei benachbarte Wells dieselbe DNA enthielten. Je Well wurde die Platte mit 0,25 $\mu$ 4 40x SNP Genotyping Assay by Design (CD14 C__16043997_10 rs2569190), $5 \mu \mathrm{l}$ 2x Taq Man Genotyping Master Mix und 2,75 $\mu$ l Ampuwa befüllt. Hierzu wurden dann noch $2 \mu \mathrm{l}$ der entsprechend zu untersuchenden DNA mit einer Konzentration von 2 ng DNA/ml hinzugegeben, sodass sich in jedem Well insgesamt $10 \mu \mathrm{l}$ befanden. Außerdem wurden jeder Platte zwei Wells als Negativkontrolle mit $2 \mu$ Ampuwa anstelle von DNA befüllt. Diese befüllte 96-Well-Platte wurde dann in das StepOne Plus Real-Time PCR System eingelegt und ein Thermoprofil mit einer Holding 
Stage von 10 Minuten bei $95{ }^{\circ} \mathrm{C}$ und eine Cycling Stage mit insgesamt 45 Zyklen mit jeweils 15 Sekunden bei $95{ }^{\circ} \mathrm{C}$ und einer Minute bei $60{ }^{\circ} \mathrm{C}$ eingestellt. In einem Post-PCR Read hat das System die dann erreichten Ergebnisse ausgewertet und in Form einer Tabelle zur Weiterverarbeitung ausgegeben.

\subsubsection{DNA-Extraktion und Genotypisierung im Verlauf}

Aus organisatorischen Gründen konnten im Verlauf der Studie nicht mehr alle Laborarbeiten, wie zuvor beschrieben, durchgeführt werden. So wurde die Vorgehensweise bei der Extraktion der DNA so verändert, dass sie mit Hilfe und nach Anleitung eines EZ1 DNA Blood Kits und eines BioRobot EZ1 erfolgte. Genauso wurde die Bestimmung der Genotypen zwar mit dem gleichen SNP Genotyping Assay by Design (CD14 C__16043997_10 rs2569190), aber in einem Labor der Klinischen Pharmakologie der UMG unter der Leitung von Herrn Prof. Dr. rer. nat. M. Tzvetkov (Institut für Klinische Pharmakologie, Universitätsmedizin Göttingen) durchgeführt.

\subsection{Forschungsgruppe}

Die Erhebung der in dieser Dissertation genannten Ergebnisse ist auf die Arbeit einer aus mehreren Studenten bestehenden Forschungsgruppe zurückzuführen. Die Mitglieder dieser Forschungsgruppe waren hierbei nicht alle gleichzeitig, sondern in einem festgelegten Dienstplan für die Erhebung der Daten, die Abnahme von Blutproben und die Weiterverarbeitung der Blutproben im Labor verantwortlich. Ich selbst war hierbei insbesondere im Zeitraum von April 2012 bis Oktober 2012 für diese Aufgaben zuständig. Während ich mich bei der Bestimmung der Genotypen auf die Untersuchung des CD14 SNP rs2569190 spezialisiert habe, untersuchten die anderen Studenten andere Fragestellungen, jedoch am selben Patientenkollektiv. Dies bedeutet, dass durch mich auch Datenerhebungen und Laborarbeiten durchgeführt worden sind, die deutlich von dieser Dissertationsarbeit abzugrenzen sind. Im Gegenzug sind durch die anderen Studenten aber während ihres Einsatzes neben Arbeiten für ihre eigene Dissertation auch Erhebungen für meine Dissertationsarbeit durchgeführt worden. 


\subsection{Statistik}

Die in dieser Dissertationsarbeit angewandten statistischen Methoden wurden von Herrn Prof. Dr. T. Beissbarth (Institut für Medizinische Statistik, Universitätsmedizin Göttingen) überprüft und mit diesem abgestimmt. Die erhobenen und erarbeiteten Daten wurden mit Hilfe des Programms Statistica (Version 10, StatSoft, Tulsa, Oklahoma, USA) statistisch ausgewertet. Die Allelhäufigkeit und die daraus resultierende Wahrscheinlichkeit für einen Genotypen des Patientenkollektivs dieser Arbeit wurde mit Hilfe des HardyWeinberg-Equilibriums (HWE) kontrolliert, indem ein Chi-Quadrat-Test auf einen signifikanten Unterschied $(\mathrm{p}<0,05)$ zwischen der erwarteten und der realen Verteilung durchgeführt wurde. Das HWE besagt, dass sich in einer idealen Population die Allelhäufigkeit und die daraus resultierende Wahrscheinlichkeit für einen Genotypen von Generation zu Generation nicht verändern, sondern konstant bleiben. Dies gilt allerdings nur für autosomale Genloci in einer idealen Population. Diese ideale Population besteht aus einer ausreichend großen Anzahl von Individuen und es muss Panmixie herrschen (jedes Individuum hat die gleiche Chance sich mit jedem anderen Individuum des anderen Geschlechts zu paaren). Außerdem finden in dieser idealen Population weder Selektion noch Genimport, Genexport oder gar Mutationen statt. Daher ist die ideale Population nur ein Konstrukt, das so in der Realität nicht vorkommt. Dennoch kann das HWE zur annäherungsweisen Berechnungen für die Allelhäufigkeit und die daraus resultierende Wahrscheinlichkeit der Genotypen herangezogen werden.

Dabei gilt folgende Berechnung: Wenn das Allel A mit einer Häufigkeit von $\mathrm{p}$ und entsprechend das Allel a mit einer Häufigkeit von q in der Population vorkommt, so gilt $\mathrm{p}+\mathrm{q}=1$. Hieraus ergibt sich die Wahrscheinlichkeit der Genotypen wie folgt: $\mathrm{p}^{2}+2 \mathrm{pq}+\mathrm{q}^{2}=(\mathrm{p}+\mathrm{q})^{2}=1$. Dabei ist $\mathrm{p}^{2}$ die Häufigkeit des homozygoten Genotyps mit Allel A, $\mathrm{p}^{2}$ die Häufigkeit des homozygoten Genotyps mit Allel a und 2pq die Häufigkeit des heterozygoten Genotyps. Sollte sich die reale Häufigkeit der Genotypen von der nach dieser Formel errechneten erwarteten Verteilung nicht signifikant (also $\mathrm{p}>\mathrm{0}$,05) unterscheiden, so kann die reale Häufigkeit als im Hardy-Weinberg-Gleichgewicht stehend bezeichnet werden (Buselmaier und Tariverdian 2007). Die Kontrolle des HWE ist eine Möglichkeit, Genotypisierungen auf Fehler hin zu untersuchen (Teo et al. 2007). Sollten Abweichungen vom HWE festgestellt werden, so deutet dies neben der Möglichkeit eines Fehlers bei der Genotypisierung außerdem auf das Vorkommen von 
Selektion, Genimport, Genexport, Mutationen, fehlender Panmixie oder aber auf eine kleine Population hin (Alvarez 2008).

In dieser Dissertation wurden alle kategorialen Variablen, sofern möglich und geeignet, in Kontingenztafeln zusammengetragen und je nachdem, welche Ergebnisse untersucht werden sollten, entweder mit Hilfe des exakten Tests nach Fisher oder aber mit Hilfe des Chi-Quadrat-Testes auf Signifikanz (p < o,05) hin untersucht. Kontinuierliche Variablen wurden anhand des Mann-Whitney-Tests auf Signifikanz ( $\mathrm{p}<\mathrm{o,05})$ hin überprüft. Zur Durchführung von Ereigniszeitanalysen, bei denen die Zeit bis zum Eintreten eines bestimmten Ereignisses auf einen signifikanten Unterschied ( $\mathrm{p}<\mathrm{o,05}$ ) hin untersucht wird, wurde der Cox's F-Test benutzt. Um den Einfluss von möglichen Störfaktoren (Alter, Geschlecht, BMI und Art der Infektion: durch gramnegative Bakterien, grampositiv Bakterien und Pilze) und Kovariablen, die zu Beginn der Studie einen Unterschied mit einem Signifikanzwert von $\mathrm{p}<0,2$ aufzeigten (z.B. Vorerkrankungen), auszuschließen, wurde eine Cox-Regression durchgeführt. 


\section{Ergebnisse}

\subsection{Anthropomorphische Daten}

Insgesamt konnten im Zeitraum zwischen April 2012 und Juni 2014417 Kaukasier, die aufgrund einer Erkrankung oder eines Unfalls stationär auf die Intensivstationen 0117, 0118 oder 1014 der UMG aufgenommen worden waren, als Probanden in diese Studie eingeschlossen werden. Von diesen Patienten waren 138 weiblich (33\%) und 279 männlich (67\%). Das mittlere Alter der Patienten betrug $63 \mathrm{Jahre}$ und der durchschnittliche body mass index (BMI) betrug $28 \mathrm{~kg} / \mathrm{m}^{2}$.

\begin{tabular}{lcccc}
\hline Patienteneigenschaft & $\begin{array}{c}\text { Alle } \\
(\mathrm{n}=417)\end{array}$ & $\begin{array}{c}\text { CT/CC } \\
(\mathrm{n}=342)\end{array}$ & $\begin{array}{c}\text { TT } \\
(\mathrm{n}=75)\end{array}$ & p-Wert \\
\hline \hline Alter [Jahre] & $63 \pm 15$ & $63 \pm 15$ & $64 \pm 15$ & 0,4123 \\
Geschlecht männlich [\%] & 67 & 67 & 68 & 0,8241 \\
BMI [kg/m²] & $28 \pm 7$ & $28 \pm 7$ & $28 \pm 8$ & 0,9366 \\
\hline
\end{tabular}

Tabelle 3.1: Alter, Geschlecht und BMI des Patientenkollektivs

Die Werte entsprechen dem Mittelwert \pm einer Standardabweichung. Es sind keine signifikanten Unterschiede zu erkennen. 


\subsection{Genotypisierung anhand des SNP rs2569190}

Nach der Genotypisierung an der Stelle des SNP rs2569190 aller Patienten durch allelische Diskriminierung trugen 117 den homozygoten Genotyp CC, 225 trugen den heterozygoten Genotyp CT und 75 den homozygoten Genotyp TT.

\begin{tabular}{lcccc}
\hline Genotypisierung [n] & CC & CT & TT & p-Wert \\
\hline \hline SNP rs2569190 & 117 & 225 & 75 & 0,1833 \\
\hline
\end{tabular}

Tabelle 3.2: Verteilung der Genotypen des SNP rs256919o

Nach Kontrolle der erwarteten Verteilung der Genotypen mit der tatsächlich festgestellten Verteilung ergab sich ein nicht signifikanter Unterschied $(\mathrm{p}=0,1833)$. Daher entspricht diese Verteilung dem Hardy-Weinberg-Gleichgewicht. Die MAF in dieser Verteilung betrug 0,45. Bei der statistischen Auswertung wurden die Genotypen CC und CT in einer Gruppe zusammengefasst, da aufgrund der Ergebnisse anderer Studien ein Unterschied im Hinblick auf das T-Allel und daher insbesondere für homozygote TT-Genotypen zu erwarten war. 


\subsection{Klinische und intensivmedizinische Aufnahmedaten}

\begin{tabular}{|c|c|c|c|c|}
\hline & $\begin{array}{c}\text { Alle } \\
(\mathrm{n}=417)\end{array}$ & $\begin{array}{c}\text { CT/CC } \\
(n=342)\end{array}$ & $\begin{array}{c}\text { TT } \\
(n=75)\end{array}$ & p-Wert \\
\hline \multicolumn{5}{|l|}{ Vorerkrankungen [\%] } \\
\hline Hypertonie & 58 & 59 & 53 & 0,3877 \\
\hline Myokardinfarkt & 7 & 6 & 11 & 0,1987 \\
\hline COPD & 17 & 16 & 23 & 0,1324 \\
\hline Chronische Nierenerkrankung & 12 & 11 & 12 & 0,8834 \\
\hline NIDDM & 10 & 10 & 8 & 0,5562 \\
\hline IDDM & 12 & 11 & 16 & 0,2712 \\
\hline Chronische Lebererkrankung & 7 & 7 & 7 & 0,9138 \\
\hline Tumorerkrankung & 19 & 18 & 23 & 0,3312 \\
\hline Schlaganfall & 6 & 6 & 7 & 0,7867 \\
\hline \multicolumn{5}{|l|}{ Operative Vorgeschichte [\%] } \\
\hline Elektive Operation & 30 & 28 & 36 & \\
\hline Notfall-Operation & 51 & 52 & 48 & 0,3618 \\
\hline Keine Operation & 19 & 20 & 16 & \\
\hline \multicolumn{5}{|l|}{ Infektfokus [\%] } \\
\hline Lunge & 54 & 55 & 48 & \\
\hline Abdomen & 27 & 26 & 29 & \\
\hline Knochen oder Weichteile & 5 & 5 & 5 & \\
\hline Chirurgische Wunde & 2 & 1 & 4 & 0,4953 \\
\hline Urogenital & 2 & 2 & 4 & \\
\hline Primäre Bakteriämie & 7 & 7 & 4 & \\
\hline Andere & 4 & 4 & 5 & \\
\hline \multicolumn{5}{|l|}{ 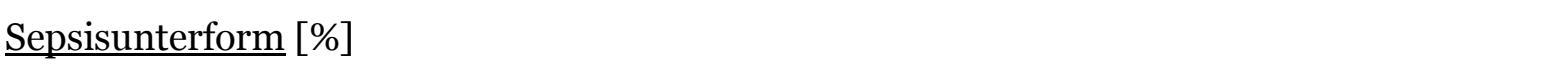 } \\
\hline Sepsis / schwere Sepsis & 39 & 39 & 43 & 0,5169 \\
\hline Septischer Schock & 61 & 61 & 57 & 0,5169 \\
\hline \multicolumn{5}{|l|}{ Morbiditäts-Scores [Punkte] } \\
\hline APACHE II & $21.5 \pm 7.3$ & $21.6 \pm 7 \cdot 3$ & $21.0 \pm 7 \cdot 3$ & 0.6236 \\
\hline SOFA & $9.2 \pm 4.0$ & $9.3 \pm 4.0$ & $8.7 \pm 4.2$ & 0,3340 \\
\hline \multicolumn{5}{|l|}{ Organunterstützung [\%] } \\
\hline Künstliche Beatmung & 84 & 84 & 84 & 0.9860 \\
\hline Gabe von Vasopressoren & 61 & 61 & 57 & 0.5134 \\
\hline Nierenersatzverfahren & 10 & 9 & 11 & 0.7271 \\
\hline
\end{tabular}

Tabelle 3.3: Klinische und intensivmedizinische Aufnahmedaten

Die Werte sind in Prozent oder in Mittelwerten \pm einer Standardabweichung angegeben. 
Die Verteilung der häufigsten Vorerkrankung wurde auf signifikante Unterschiede hin untersucht. Dabei wurden die Vorerkrankungen Hypertonie, Myokardinfarkt, chronisch obstruktive Lungenerkrankungen (chronic obstructive pulmonary disease; COPD), Nierenerkrankungen, nicht insulinpflichtiger Diabetes mellitus (non insulin-dependent diabetes mellitus; NIDDM), insulinpflichtiger Diabetes mellitus (insulin-dependent diabetes mellitus; IDDM), chronische Lebererkrankungen, Tumorerkrankungen und Schlaganfall berücksichtigt. Zwar war für keine der Vorerkrankungen ein signifikanter Unterschied zu erkennen, allerdings fielen Unterschiede für die Verteilung von Myokardinfarkt und COPD auf. Beide Vorerkrankungen traten häufiger in der Gruppe der homozygoten TTTräger auf. Bezüglich der operativen Vorgeschichte wurde unterschieden, ob die Patienten kurz vor Beginn der Sepsis im Rahmen einer elektiven Operation, im Rahmen einer Notfall-Operation oder aber gar nicht operiert worden waren. Hier waren keine signifikanten Unterschiede festzustellen. Genauso wurde kontrolliert, ob es bezüglich des SNP rs256919o eine unterschiedliche Häufigkeit des primären Infektfokus bei Beginn der Sepsis gab. Auch hier ließ sich kein signifikanter Unterschied feststellen. Allerdings betrug der Unterschied zwischen TThomozygoten und C-Allel-Trägern für den Infektfokus Lunge 7\%. Da sich die Sepsis in verschiedene Unterformen unterteilen lässt, wurde auch die Verteilung der verschiedenen Unterformen auf die Genotypgruppen analysiert. Hierbei wurden die Sepsis und die schwere Sepsis dem septischen Schock gegenübergestellt. Als Unterscheidungsmerkmal diente hierbei der Einsatz von Vasopressoren bei einer gleichzeitigen nicht anders als durch eine Sepsis zu erklärenden Hypotonie. Es ließ sich allerdings kein signifikanter Unterschied in Bezug auf den SNP rs256190 feststellen. Da sowohl der APACHE II Score als auch der SOFA Score Hilfsmittel zur Abschätzung der zu erwartenden Mortalität sind, wurden diese Scores für jeden Patienten gebildet und auf Unterschiede in ihrer Höhe bezüglich der Verteilung auf die SNP rs2569190-Genotypen untersucht. Zwar waren hier etwas erniedrigte Scores für TT-homozygote zu erkennen, allerdings erreichten diese keine Signifikanz. Da bei Sepsis-Patienten häufig der Einsatz von organunterstützenden Therapiemaßnahmen infolge von Organfehlfunktion oder aber sogar Organausfall notwendig ist, wurde auch die Verteilung dieser Therapiemaßnahmen ausgewertet. Als künstliche Beatmung galt hierbei jeglicher Einsatz von atemunterstützender Therapie (auch CPAP). Als Maßnahmen zur Unterstützung des Herzkreislaufsystems wurde die Gabe von 
Noradrenalin oder Dobutamin gewertet. Zu den Nierenersatzverfahren zählten alle gängigen und durchführbaren Dialyseverfahren wie z.B. Hämodialyse oder Hämofiltration. Es ließ sich aber kein signifikanter Unterschied bezüglich der notwendigen Therapiemaßnahmen in Abhängigkeit von der Genotypenverteilung des SNP rs2569190 erkennen. 


\subsection{Klinische und intensivmedizinische Verlaufsdaten}

\begin{tabular}{|c|c|c|c|c|}
\hline & $\begin{array}{c}\text { Alle } \\
(\mathrm{n}=417)\end{array}$ & $\begin{array}{c}\text { CT/CC } \\
(n=342)\end{array}$ & $\begin{array}{c}\mathrm{TT} \\
(\mathrm{n}=75)\end{array}$ & p-Wert \\
\hline \multicolumn{5}{|l|}{ SOFA Scores [Punkte] } \\
\hline SOFA-Gesamt & $6.8 \pm 3.6$ & $7.0 \pm 3 \cdot 7$ & $6.0 \pm 3.1$ & 0.0918 \\
\hline SOFA-Lunge & $1.9 \pm 0.8$ & $1.9 \pm 0.8$ & $1.8 \pm 0.8$ & 0,2215 \\
\hline SOFA-Herz-/Kreislaufsystem & $1.5 \pm 1.0$ & $1.5 \pm 1.0$ & $1.3 \pm 0.8$ & 0,2468 \\
\hline SOFA-ZNS & $1.9 \pm 1.1$ & $1.9 \pm 1.1$ & $1.6 \pm 1.0$ & $\mathbf{0 , 0 3 1 1}$ \\
\hline SOFA-Niere & $0.8 \pm 1.2$ & $0.9 \pm 1.2$ & $0.7 \pm 1.2$ & 0,5202 \\
\hline SOFA-Blutsystem & $0.3 \pm 0.6$ & $0.4 \pm 0.6$ & $0.3 \pm 0.5$ & 0,5071 \\
\hline SOFA-Leber & $0.4 \pm 0.7$ & $0.4 \pm 0.7$ & $0.3 \pm 0.6$ & 0,5180 \\
\hline \multicolumn{5}{|l|}{ Laborwerte im Serum } \\
\hline Leukozyten $[1000 / \mu \mathrm{l}]$ & $14 \pm 5$ & $14 \pm 5$ & $14 \pm 5$ & 0,9162 \\
\hline $\begin{array}{l}\mathrm{CRP}[\mathrm{mg} / \mathrm{l}] \\
\text { (n) }\end{array}$ & $\begin{array}{c}151 \pm 84 \\
(208)\end{array}$ & $\begin{array}{c}148 \pm 85 \\
(169)\end{array}$ & $\begin{array}{c}165 \pm 81 \\
(39)\end{array}$ & 0,2097 \\
\hline $\begin{array}{l}\text { Procalcitonin [ng/dl] } \\
\text { (n) }\end{array}$ & $\begin{array}{c}4.5 \pm 10.7 \\
(361)\end{array}$ & $\begin{array}{c}4.1 \pm 10.3 \\
(293)\end{array}$ & $\begin{array}{c}6.0 \pm 12.6 \\
(68)\end{array}$ & 0,0654 \\
\hline Kreatinin $[\mathrm{mg} / \mathrm{dl}]$ & $1.3 \pm 1.0$ & $1.3 \pm 1.1$ & $1.2 \pm 0.8$ & 0,8254 \\
\hline Kreatinin-Clearance [ml/min] & $103 \pm 68$ & $102 \pm 65$ & $108 \pm 81$ & 0,8614 \\
\hline Bilirubin [mg/dl] & $1.3 \pm 2.2$ & $1.3 \pm 2.3$ & $0.9 \pm 0.9$ & 0,1844 \\
\hline AST [IU/l] & $209 \pm 725$ & $238 \pm 804$ & $90 \pm 117$ & 0,1961 \\
\hline ALT [IU/l] & $106 \pm 224$ & $113 \pm 243$ & $73 \pm 87$ & 0,2341 \\
\hline Laktat (mmol/l) & $1.7 \pm 1.1$ & $1.7 \pm 1.2$ & $1.6 \pm 0.6$ & 0,2092 \\
\hline \multicolumn{5}{|l|}{ Liegedauer } \\
\hline auf der Intensivstation [d] & $17 \pm 15$ & $17 \pm 15$ & $18 \pm 17$ & 0,6259 \\
\hline \multicolumn{5}{|l|}{ Organunterstützung [d] } \\
\hline Tage ohne Vasopressoren & $11 \pm 7$ & $10 \pm 7$ & $11 \pm 7$ & 0,1734 \\
\hline Tage ohne Beatmung & $5 \pm 5$ & $5 \pm 5$ & $6 \pm 6$ & 0,1547 \\
\hline Tage ohne Dialyse & $14 \pm 8$ & $14 \pm 8$ & $14 \pm 8$ & 0,7254 \\
\hline \multicolumn{5}{|l|}{ Mortalität [\%] } \\
\hline Tod nach 30 Tagen & 21 & 23 & 13 & $\mathbf{0 , 0 4 9 0}$ \\
\hline Tod nach 90 Tagen & 31 & 32 & 27 & 0,2297 \\
\hline
\end{tabular}

Tabelle 3.4: Klinische und intensivmedizinische Verlaufsdaten

Die Werte sind in Prozent oder in Mittelwerten \pm einer Standardabweichung angegeben. 
Um herauszufinden, ob der SNP rs2569190 einen Einfluss auf den Krankheitsverlauf hat, wurden verschiedene Verlaufsparameter erhoben und auf signifikante Unterschiede hin untersucht. Da der SOFA Score als Faktor für die Schwere einer Erkrankung angesehen werden kann, wurde aus den VerlaufSOFA Scores aller Patienten unter Berücksichtigung der entsprechenden Genotypen der Mittelwert gebildet. Neben der Auswertung des Gesamt-SOFA Scores wurde auch eine Analyse der verschiedenen Organsysteme durchgeführt und die verschiedenen SOFA Subscores für die Organsysteme Lunge, Herz/Kreislaufsystem, ZNS, Niere, Blutsystem und Leber nochmals einzeln auf signifikante Unterschiede bezüglich der Genotypen des SNP rs2569190 untersucht. Hierbei zeigte sich ein signifikanter Unterschied von 0,3 Punkten für den SOFA-ZNS Score (p=o,o311). T-Allel-Träger hatten einen um o,3 Punkte niedrigeren SOFA-ZNS Score als Träger des C-Allels. Für alle anderen Subscores ließ sich allerdings kein signifikanter Unterschied nachweisen. Um herauszufinden, ob es einen möglichen Unterschied in Abhängigkeit vom SNP rs2569190 in der Schwere der Infektion gab, wurden außerdem verschiedene Laborwerte im Serum genauer betrachtet. Da die Werte für die Anzahl der Leukozyten und die Konzentration von CRP und Procalcitonin oft mit der Schwere einer Infektion korrelieren, wurden diese Werte zur Beurteilung der Schwere der Sepsis statistisch ausgewertet und unter dem Aspekt der Genotypenverteilung des SNP rs2569190 analysiert. Hierbei zeigte sich für die Anzahl der Leukozyten kein signifikanter Unterschied. Für die Konzentration des CRP hingegen konnte ein Unterschied von $17 \mathrm{mg} / \mathrm{l}$ festgestellt werden. Träger des T-Allels hatten eine um $17 \mathrm{mg} / \mathrm{l}$ höhere CRP-Konzentration als Träger des C-Allels. Dieser Unterschied erreichte allerdings keine Signifikanz. Auch für Procalcitonin konnte ein Unterschied von 1,9 ng/dl festgestellt werden, der sich jedoch im Grenzbereich zur Signifikanz aufhielt. Träger des T-Allels hatten hier genauso einen um 1,9 ng/dl höheren Wert als Träger des C-Allels. Zur genaueren Beurteilung der Nierenfunktion wurden sowohl die Kreatininkonzentration im Serum als auch die daraus resultierende Kreatininclearance berechnet. Hier konnte kein signifikanter Unterschied festgestellt werden. Auch die Leberwerte Bilirubin, AST und ALT wurden ausgewertet und den entsprechenden Genotypen zugeordnet. Für Bilirubin betrug der Unterschied zwischen den Genotypen nur o,4 mg/dl, während man für die AST einen Unterschied von $148 \mathrm{IU} / \mathrm{l}$ und für die ALT einen Unterschied von 40 IU/l erkennen konnte. In allen Fällen hatten Träger des C- 
Allels im Vergleich zu Trägern des T-Allels den höheren Wert. Allerdings erreichte keiner der Werte Signifikanz. Da Laktat als ein Marker für Kreislaufschock und Gewebshypoxie dient, wurde die Konzentration von Laktat in Relation zur Verteilung der Genotypen des SNP rs256919o ebenfalls betrachtet. Aber auch hier ließ sich kein signifikanter Unterschied feststellen.

Zur Beurteilung der Krankheitsschwere und der Immunkompetenz der Patienten wurde die Liegedauer der Patienten in Abhängigkeit von den Genotypen betrachtet. Je länger ein Patient auf der Intensivstation verbringt, desto schlechter ist sein Gesundheitszustand oder aber seine Immunkompetenz zu bewerten. Zwar lagen Patienten mit dem homozygoten TT-Genotyp durchschnittlich einen Tag länger auf der Intensivstation, jedoch erreichte dieser Unterschied nicht annähernd Signifikanz.

Als ein weiterer Parameter zu Untersuchung des Gesundheitszustandes der Patienten wurden die auf der Intensivstation verbrachten Tage ohne Organunterstützung betrachtet. Je mehr Tage ein Patient ohne Organunterstützung auf der Intensivstation verbracht hat, desto besser ist sein Gesundheitszustand bzw. seine Immunkompetenz zu bewerten. Als Organunterstützung zählten hierbei jede Art von künstlicher Beatmung (auch CPAP), die Gabe von Vasopressoren (Noradrenalin oder Dobutamin) und der Einsatz jeder Art von Nierenersatzverfahren (z. B. Hämodialyse oder Hämofiltration). Während für die Dialyse als Organunterstützung kein Unterschied festzustellen war, konnte man sowohl für die Beatmung als auch für den Einsatz von Vasopressoren einen Unterschied von einem Tag mehr ohne Organunterstützung für TT-homozygote feststellen. Allerdings erreichte keiner der beiden Werte Signifikanz. Auch die Mortalität der an einer Sepsis erkrankten Patienten wurde in Abhängigkeit von den Genotypen des SNP rs256919o analysiert. So wurde die Anzahl der Verstorbenen sowohl nach 30 als auch nach 90 Tagen ausgewertet. Es ließ sich ein signifikanter Unterschied $(p=0,0490)$ für die Mortalität nach 30 Tagen erkennen. Der Anteil der Verstorbenen unter den Trägern des T-Allels betrug $13 \%$, während der Anteil der Verstorbenen unter den Trägern des C-Allels $23 \%$ betrug. Nach 90 Tagen war hingegen kein signifikanter Unterschied bezüglich der Mortalität mehr festzustellen.

Da für die Mortalität 30 Tage nach Beginn der Sepsis ein signifikanter Unterschied ( $p=0,0490)$ mit Hinblick auf die verschieden Genotypen des SNP rs2569190 festgestellt werden konnte, wurde zusätzlich eine Überlebenszeitanalyse anhand 
der Kaplan-Meier-Methode durchgeführt. Auch hierbei konnte ein signifikanter Unterschied ( $\mathrm{p}=0,0261)$ zwischen den Trägern des SNP rs2569190 Genotyps CT/CC und Trägern des homozygoten Genotyps TT gezeigt werden. Während $77 \%$ der C-Allel-Träger die ersten 30 Tage nach Beginn der Sepsis überlebten, konnte für die homozygoten T-Allel-Träger nach 30 Tagen eine Überlebensrate von $87 \%$ festgehalten werden. Eine weitere Analyse der Mortalität nach 90 Tagen zeigte hingegen keinen signifikanten Unterschied zwischen den verschieden Genotypen mehr ( $\mathrm{p}=0$,2297). Während 90 Tage nach Beginn der Sepsis noch 68 \% der CAllel-Träger überlebt hatten, lag der Anteil der Überlebenden 90 Tage nach Beginn der Sepsis bei homozygoten Trägern des T-Allels bei $73 \%$.

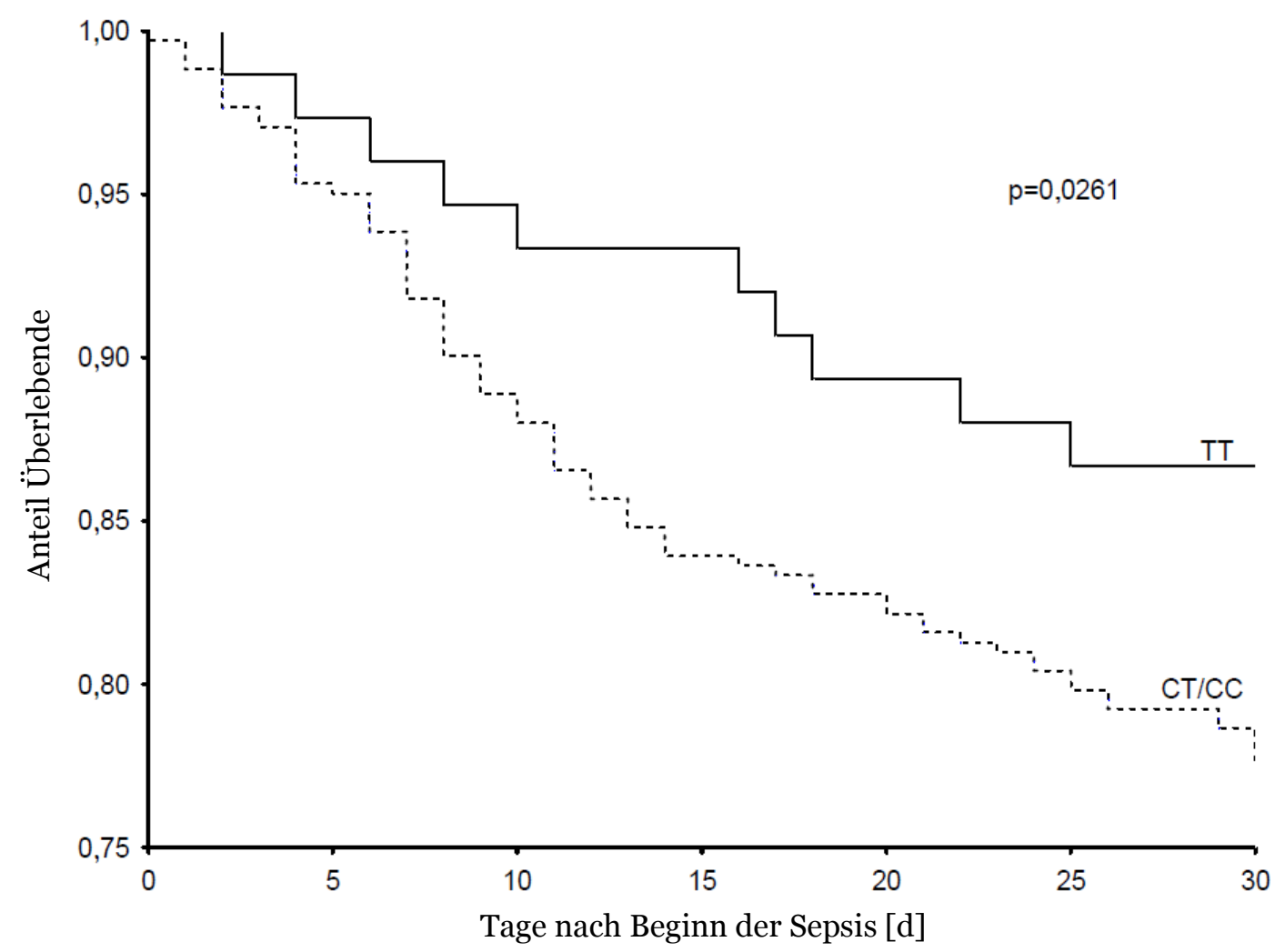

Abbildung 3.1: Kaplan-Meier Überlebenszeitanalyse nach 30 Tagen

Die Abbildung zeigt eine Kaplan-Meier Überlebenszeitanalyse 30 Tage nach Beginn der Sepsis für die beiden SNP rs256919o Genotypgruppen TT und CT/CC. Auf der x-Achse sind die Tage nach Beginn der Sepsis aufgetragen, während auf der y-Achse der prozentuale Anteil der Überlebenden abgebildet ist. Man kann erkennen, dass bei diesem untersuchten Patientenkollektiv der prozentuale Anteil der Überlebenden unter den Trägern des CT/CC-Genotyps niedriger ist als der prozentuale Anteil der Überlebenden aus der Gruppe der TT-Genotypen (p=o,o261, Cox's F-Test). 


\subsubsection{Mikrobiologisch nachgewiesene Krankheitserreger}

Die Verteilung der Krankheitserreger innerhalb des Patientenkollektivs, bedingt durch die verschiedenen SNP rs2569190-Genotypen, wurde genauer ausgewertet. Hierbei wurde die prozentuale Verteilung von grampositiven Bakterien, gramnegativen Bakterien, Pilzen und Viren analysiert. Es konnte allerdings kein signifikanter Unterschied bezüglich der Verteilung der Krankheitserreger zwischen den Genotypen festgestellt werden. Es bleibt jedoch anzumerken, dass innerhalb der Gruppe der CT/CC-Genotypen der Anteil an mit gramnegativen Bakterien infizierten Patienten im Vergleich zu den homozygoten T-Allel Trägern um $9 \%$ erhöht war $(\mathrm{p}=0,1393)$.

\begin{tabular}{lccc}
\hline Krankheitserreger[\%] & CT/CC (n=342) & TT (n=75) & p-Wert \\
\hline \hline Gramnegative Bakterien & $68 \%$ & $59 \%$ & 0,1393 \\
Grampositive Bakterien & $81 \%$ & $76 \%$ & 0,3450 \\
Pilze & $56 \%$ & $53 \%$ & 0,7979 \\
Viren & $11 \%$ & $7 \%$ & 0,3000 \\
\hline
\end{tabular}

Tabelle 3.5: Verteilung der Krankheitserreger

Die Tabelle zeigt die prozentuale Verteilung der Krankheitserreger beding durch die Genotypen des SNP rs256919o. Es konnte bei der Verteilung der Krankheitserreger kein signifikanter Unterschied festgestellt werden. 


\subsection{Analyse von Störfaktoren und Kovariablen}

Um den Einfluss von Stöfaktoren (Alter, Geschlecht, BMI, und Infektfokus) und Kovariablen, die zu Beginn der Sepsis einen p-Wert $<0,2$ hatten (Vorerkrankungen wie Myokardinfarkt und COPD), zu untersuchen, wurde eine multivariate Cox-Regression zur Analyse der Mortalität durchgeführt. Zusätzlich wurde auch der Einfluss des C-Allels des SNP rs256919o in die Untersuchung mit einbezogen. Während ein signifikanter Einfluss des Alters mit einer Hazard Ratio von 1,03 eher nicht von großer Bedeutung war, erreichte der Einfluss des männlichen Geschlechts mit einer Hazard Ratio von 1,63 fast Signifikanz. Auch die Bedeutung einer gramnegativen Infektion erreichte mit einer Hazard Ratio von o,68 einen p-Wert von o,0919. Hervorzuheben ist aber der signifikante Einfluss des CD 14 SNP rs2569190-C-Allels mit einer Hazard Ratio von 2,11 ( $\mathrm{p}=0,0282)$.

\begin{tabular}{lccc}
\hline Variable & Hazard Ratio & $95 \% \mathrm{KI}$ & $\mathrm{p}$-Wert \\
\hline Alter & 1,03 & $1,01-1,05$ & $<0,0001$ \\
Geschlecht (männlich) & 1,63 & $0,99-2,67$ & 0,0515 \\
BMI & 1,02 & $0,98-1,05$ & 0,2283 \\
Myokardinfarkt als Vorerkrankung & 0,94 & $0,43-2,08$ & 0,8959 \\
COPD als Vorerkrankung & 1,17 & $0,68-1,98$ & 0,5596 \\
Gramnegative Infektion & 0,68 & $0,43-1,06$ & 0,0919 \\
Grampositve Infektion & 0,74 & $0,44-1,24$ & 0,2612 \\
Infektion mit Pilzen & 0,74 & $0,48-1,15$ & 0,1920 \\
CD14 SNP rs2569190 C-Allel & 2,11 & $1,08-4,12$ & $\mathbf{0 , 0 2 8 2}$ \\
\hline
\end{tabular}

\section{Tabelle 3.6: Multivariate Cox-Regression zur Analyse von Störfaktoren und} Kovariablen

Die Tabelle beinhaltet die Ergebnisse einer multivariaten Cox-Regression zur Analyse von ausgewählten Störfaktoren und Kovariablen bezüglich der Mortalität.

\subsection{Publikation}

Die zuvor beschriebenen Ergebnisse konnten bereits am 28. Mai 2015 als Artikel unter dem Namen „The CD14 rs2569190 TT Genotype Is Associated with an Improved 30-Day Survival in Patients with Sepsis: A Prospective Observational Cohort Study" in der internationalen Online-Fachzeitschrift der Public Library of Science (PLOS) PLOS ONE veröffentlicht werden (Mansur et al. 2015). 


\section{Diskussion}

Das Ziel dieser Dissertationsarbeit war es herauszufinden, ob der CD 14 SNP rs2569190 mit dem Krankheitsverlauf an Sepsis erkrankter Patienten assoziiert ist. Deshalb wurden nach entsprechender Einwilligung Patienten in diese Studie eingeschlossen, die stationär auf einer von insgesamt drei chirurgischen Intensivstationen der UMG behandelt wurden und neben den Diagnosekriterien der Sepsis auch alle anderen Einschlusskriterien erfüllten. Im Anschluss erfolgte die Untersuchung des Genotyps an der Stelle des SNP rs2569190. Durch tägliche Visiten konnte der genaue Krankheitsverlauf jedes Patienten erfasst werden. Danach wurde dann untersucht, ob es einen Zusammenhang zwischen dem SNP rs2569190 und der Mortalität an Sepsis erkrankter Patienten auf der Intensivstation gibt. Hierbei konnte gezeigt werden, dass homozygote TTGenotypen 30 Tage nach Beginn der Sepsis eine signifikant niedrigere Mortalität im Vergleich zu Trägern des C-Allels aufzeigen. Während 30 Tage nach Beginn der Sepsis $23 \%$ der C-Allel-Träger verstorben waren, betrug der Anteil der Verstorbenen unter den TT-homozygoten nur $13 \%$. Soweit uns bekannt ist, zeigt dieses Ergebnis zum ersten Mal den positiven klinischen Einfluss des CD14 rs2569190-TT-Genotyps auf die Mortalität nach 30 Tagen innerhalb eines Patientenkollektivs, das ausschließlich aus Patienten kaukasischer Herkunft, die an einer Sepsis erkrankt sind, besteht. Diese Feststellung steht außerdem im Einklang zu den Ergebnissen von Studien, deren Studienteilnehmer aus einem brasilianischen Patientenkollektiv bestanden und bei denen ebenfalls ein positiver klinischer Einfluss auf die Mortalität für den CD14 rs256919o-TT-Genotyp bei schwer erkrankten Patienten festgestellt werden konnte. Eine TT-Homozygotie war insbesondere dann mit einer ehrhöhten Überlebenswahrscheinlichkeit schwer erkrankter Patienten auf Intensivstationen assoziiert, wenn diese an einer Sepsis erkrankt waren (D'Avila et al. 2006; Fallavena et al. 2009; Fallavena et al. 2013). Auch die Ergebnisse aus Untersuchgen an Patienten, die eine Brandverletzung erlitten hatten, lassen sich mit unseren Ergebnissen vereinbaren. Bei diesen Untersuchungen konnte nämlich gezeigt werden, dass Patienten, die Träger des CAllels waren, ein erhöhtes Risiko hatten, an einer Sepsis zu erkranken beziehungsweise zu versterben (Barber et al. 2006; Barber et al. 2007). Als besondere Stärke unserer Studie ist deshalb auch die Tatsache zu bewerten, dass abgesehen von anderen Störfaktoren (Alter, Geschlecht, BMI, und Infektfokus) 
und Kovariablen (z.B. Vorerkrankungen wie Myokardinfarkt oder COPD) zu Beginn der Sepsis für unser Patientenkollektiv das C-Allel als prognostischer Faktor mit einem signifikanten Einfluss (HR 2,11, p=0,0282) auf das Kurzzeitüberleben nachgewiesen werden konnte. Als mögliche Erklärung für den positiven klinischen Einfluss des TT-Genotyps auf die Mortalität 30 Tage nach Beginn der Sepsis könnten die Ergebnisse anderer Untersuchungen dienen, die zeigen konnten, dass homozygote TT-Genotypen eine signifikant stärkere proinflammatorische Immunantwort im Vergleich zu C-Allel-Trägern haben. So konnte gezeigt werden, dass Träger des C-Allels weniger TNF- $\alpha$ produzieren, während die proinflammatorische Immunantwort von Trägern des T-Allels stärker ausfällt (Gu et al. 2008; Lin et al. 2007). In einer Fall-Kontroll-Studie, welche den Einfluss des SNP rs2569190 zwischen Patienten mit einer akut dekompensierten Leberzirrhose bei gleichzeitiger Entwicklung von Fieber und einer gesunden Kontrollgruppe untersuchte, hatten T-Allel Träger zwar ein erhöhtes Risiko für die Entwicklung einer Sepsis, allerdings konnte auch hier gezeigt werden, dass diese T-Allel Träger eine erhöhte proinflammatorische Immunantwort haben (WC Fan et al. 2016). Obwohl bei unserer Untersuchung von CRP und Procalcitonin keine Signifikanz erreicht wurde, lassen die Ergebnisse dennoch einen Trend zu höheren Werten bei TT-homozygoten im Vergleich zu C-Allel-Trägern erkennen. Auch dies unterstützt die Idee der stärkeren Immunantwort bei TT-homozygoten und könnte in Zusammenhang mit dem erniedrigten Mortalitätsrisiko nach 30 Tagen gebracht werden. Diese Annahme wird außerdem durch den Verdacht einiger Forscher unterstützt, dass eine vorgegebene Immunsuppression, die mit einer verminderten proinflammatorischen Abwehrreaktion und daher mit einer erhöhten antiinflammatorischen Immunantwort einhergeht, das Hauptproblem an Sepsis erkrankter Patienten darstellt (Hotchkiss et al. 2013).

Zwar untersuchten wir in unserer Studie nicht die Suszeptibilität für die Entstehung einer Sepsis, aber der Vollständigkeit halber sei an dieser Stelle erwähnt, dass auch hier ein Zusammenhang vermutet wird. So konnte in einer Fall-Kontroll-Studie gezeigt werden, dass ein CC-homozygoter Polymorphismus in Zusammenhang mit einem erhöhten Erkrankungsrisiko für eine Pneumonie mit Streptococcus pneumoniae bei Kindern gebracht werden kann (Yuan et al. 2008). Auch in einer anderen Fall-Kontroll-Studie konnte das erhöhte Risiko für CChomozygote Neugeborene, an einer Sepsis zu erkranken, gezeigt werden (Esposito et al. 2014). Andere Studien aber konnten keinen oder zumindest keinen 
signifikanten Zusammenhang zwischen dem SNP rs2569190 und dem Auftreten einer Infektion oder einer Sepsis herstellen. So konnte in einer retrospektiven Fall-Kontroll-Studie kein Zusammenhang zwischen dem SNP rs2569190 und dem Auftreten einer Sepsis bei Neugeborenen hergestellt werden (Abu-Maziad et al. 2010). Genauso konnte kein signifikanter Unterschied bezüglich des SNP rs2569190 und der Wahrscheinlichkeit für die Entwicklung einer postpartalen Infektion mit Streptokokken der Gruppe A gezeigt werden (Davis et al. 2010). Eine weitere Fall-Kontroll-Studie, deren Studienteilnehmer chinesischer Abstammung waren, konnte ebenfalls keinen Zusammenhang zwischen der Wahrscheinlichkeit für die Entwicklung einer Sepsis und den unterschiedlichen Genotypen an der Stelle des SNP rs2569190 herausfinden (Wang et al. 2014). Auch für die Wahrscheinlichkeit des Auftretens einer Sepsis bei posttraumatischen Intensivpatienten ließ sich kein Zusammenhang mit dem SNP rs2569190 herstellen (Shalhub et al. 2009).

Genauso gibt es auch Untersuchungen, die entgegen unseren Ergebnissen keine Assoziation zwischen dem SNP rs2569190 und der Überlebenswahrscheinlichkeit einer Sepsis feststellen konnten. Beispielsweise wurden in einer Studie 319 dänische Patienten untersucht, die nachweislich an einer Sepsis durch eine gramnegative Bakteriämie erkrankt waren. Ein signifikanter Zusammenhang zwischen dem SNP rs2569190 und der Schwere einer Sepsis oder der Mortalität konnte aber nicht nachgewiesen werden (Jessen et al. 2007). Eine Fall-KontollStudie hingegen, die ausschließlich Patienten mit septischem Schock untersuchte, kam sogar zu dem Ergebnis, dass der TT-Genotyp mit einer erhöhten Mortalität einhergeht (Gibot et al. 2002). Eine im Jahr 2013 veröffentliche Meta-Analyse beschäftigte sich aufgrund der sich teilweise widersprechenden Ergebnisse daher nochmals ausführlich mit der Frage, ob der SNP rs2569190 mit einer erhöhten Morbidität für eine Sepsis einhergeht oder aber eventuell mit einer erhöhten Mortalität nach der Diagnosestellung einer Sepsis assoziiert ist. Insgesamt wurden 16 Studien zum Thema SNP rs2569190 und Morbidität und vier Studien zum Thema SNP rs256919o und Mortalität ausgewertet. Als Ergebnis dieser MetaAnalyse fand man heraus, dass bisher insgesamt kein signifikanter Zusammenhang zwischen dem Polymorphismus und der Morbidität oder Mortalität einer Sepsis festgestellt werden konnte. Allerdings konnten leichte Assoziationen bei asiatischen Probanden und bei Patienten mit septischem Schock nachgewiesen werden. Da die Ergebnisse der Meta-Analyse sich allerdings in 
vielen Bereichen im Grenzbereich zur Signifikanz bewegten, kam man zu der Schlussfolgerung, dass weitere Studien mit einer größeren Zahl von untersuchten Patienten mit einem einheitlicheren Patientenkollektiv notwendig sind, um bessere Aussagen bezüglich des Zusammenhangs zwischen dem Polymorphismus und der Morbidität und Mortalität der Sepsis treffen zu können (Zhang et al. 2013). Eine mögliche Erklärung für den Widerspruch der Ergebnisse könnte die Tatsache sein, dass die meisten anderen durchgeführten Studien ein Patientenkollektiv untersuchten, das zur Feststellung eines signifikanten Einflusses des TT-Genotyps auf die Mortalität von an Sepsis erkrankten Patienten eine zu kleine Anzahl an untersuchten Patienten aufwies.

Die Tatsache, dass bei unseren Untersuchungen zwar eine Assoziation zwischen dem CD14 rs256919o TT-Genotypen und der Mortalität 30 Tage nach Beginn der Sepsis nachgewiesen werden konnte, allerdings 90 Tage nach Beginn der Sepsis keine Signifikanz mehr nachzuweisen war, könnte bedeuten, dass der TT-Genotyp nur mit der Kurzzeitmortalität assoziiert ist, aber in keinen oder aber nur in einen geringen Zusammenhang mit der Langzeitmortalität zu bringen ist. Hingegen konnte aber eine andere Untersuchung, welche den SNP rs11568821 des programmed cell death 1 (PD1)-Gens bei Probanden, die dem Patientenkollektiv dieser Dissertationsarbeit entstammen, analysierte, einen signifikanten Zusammenhang zwischen dem PD1 SNP rs11568821 GG-Genotyp und der Mortalität 90 Tage nach Beginn der Sepsis nachweisen (Mansur et al. 2014). Es konnte bereits zuvor gezeigt werden, dass dieser PD1 SNP die transkriptionelle Aktivität beeinflusst und eine wichtige Rolle bei der Immunsuppression bei an einer Sepsis erkrankten Patienten spielt (Kristjansdottir et al. 2010; Prokunina et al. 2002). Dies soll verdeutlichen, dass natürlich nicht ein SNP allein die Mortalität bei Sepsis-Patienten beeinflussen kann, sondern dass die Gesamtheit der individuellen genetischen Voraussetzungen des Patienten den Krankheitsverlauf variiert.

Auch sollte im Rahmen dieser Arbeit die Frage näher erörtert werden, ob der SNP rs256919o in Zusammenhang mit der Schwere einer Sepsis gebracht werden kann. Bei der Beurteilung des Gesundheitszustandes der Patienten fiel zunächst auf, dass bei der Erhebung der Vorerkrankungen das Risiko der homozygoten TT-Träger um 7 \% erhöht war, an einer COPD zu leiden ( $\mathrm{p}=0,1324)$ und um 5 \% erhöht war, in der Vorgeschichte bereits einen Herzinfarkt erlitten zu haben $(p=0,1987)$. Zwar erreichten diese Unterschiede keine Signifikanz, aber dennoch lässt sich 
insbesondere die höhere Wahrscheinlichkeit für Herzinfarkte mit den Ergebnissen anderer Studien vereinbaren, die zeigen konnten, dass der Anteil des T-Allels unter Patienten, die einen Herzinfarkt erlitten hatten, signifikant erhöht war (Hubacek et al. 1999). Allerdings ist auch hier zu erwähnen, dass die Studienergebnisse nicht immer eindeutig sind. So konnte nämlich eine andere Studie keinen Zusammenhang zwischen dem Auftreten eines Herzinfarktes oder einer KHK und dem SNP rs2569190 nachweisen (Haberbosch et al. 2009). Das von uns festgestellte häufigere Auftreten der COPD bei T-Allel Trägern kann auch in Zusammenhang mit den Ergebnissen von anderen Untersuchungen gebracht werden. Zwar wurde bisher kein direkter Zusammenhang zwischen COPD und dem SNP rs2569190 nachgewiesen, aber das häufigere Auftreten anderer Lungenerkrankungen. So konnte beispielsweise gezeigt werden, dass auch bei Patienten, die an atopischem Asthma leiden, der Anteil der T-Allel Träger erhöht ist (Zhang et al. 2015). Als mögliche Erklärung für das häufigere Auftreten dieser Erkrankungen könnte die bei T-Allel Trägern verstärkte Immun- und damit auch Entzündungsrektion dienen. Durch diese Entzündungen könnte es nämlich einerseits zum erhöhten Auftreten von Arteriosklerose und andererseits zum Umbau des Lungengewebes kommen (Pu et al. 2013). Auch bei der Verteilung der Krankheitserreger konnten wir keinen signifikanten Unterschied feststellen. Dennoch passen auch hier unsere Ergebnisse zu den Erkenntnissen einer anderen Arbeit, die zeigen konnte, dass der Anteil des CT-Genotyps unter Patienten, die an einer grampositiven Sepsis litten, erhöht war (Surbatovic et al. 2010). Dies bedeutet, dass ein CT-heterozygoter Polymorphismus mit einer erhöhten Wahrscheinlichkeit für eine grampositive Sepsis vergesellschaftet ist. Allerdings konnten wir lediglich einen Unterschied von $5 \%$ feststellen, was eventuell dadurch zu erklären ist, dass wir die CC-Genotypen und die CT-Genotypen in einer Gruppe zusammengefasst haben. Interessanterweise war bei unseren Probanden auch die Wahrscheinlichkeit für Träger des C-Allels im Vergleich zu TT-Homozygoten, an einer gramnegativen Sepsis zu erkranken, um 9 \% erhöht $(\mathrm{p}=0,1393)$.

Betrachtet man die Unterformen der Sepsis als eine Art Schweregradeinteilung, bei der der septische Schock die schwerste Form der Sepsis darstellt, so muss man sagen, dass wir hier keinen signifikanten Unterschied der Schwere der Sepsis feststellen konnten. Die Verteilung der Genotypen des SNP rs2569190 zeigte keinen Anhalt für eine signifikante Differenz. Zu diesem Schluss kam auch eine Studie, die die Verteilung der Genotypen auf die Unterformen der Sepsis als Maß 
für die Schwere der Erkrankung beobachtete (Jessen et al. 2007). Hierzu passt, dass auch die Schwere der Sepsis bei Aufnahme auf die Intensivstation keinen Unterschied zeigte, wenn man die initiale Höhe des APACHE II und SOFA Scores als Referenz betrachtet. Sieht man die prozentuale Verteilung der bei Aufnahme auf die Intensivstation notwendigen Organunterstützungen (Beatmung, Einsatz von Vasopressoren oder Nierenersatzverfahren), die Zahl der Tage ohne Organunterstützung, die Höhe des Laktats und die Liegedauer auf der Intensivstation ebenfalls als ein Maß für die Schwere der Sepsis an, so ließen sich auch hier keine signifikanten Zusammenhänge bei der Verteilung auf die Genotypen des SNP rs2569190 zeigen. Dies passt daher ebenfalls zu der zuvor beschriebenen These, dass die Schwere der Sepsis nicht mit dem SNP rs2569190 assoziiert ist.

Eine weitere Frage dieser Arbeit war es herauszufinden, ob es auf den SNP rs2569190 zurückzuführende Unterschiede im Hinblick auf die Organfunktion während einer Sepsis gibt. Um dies herauszufinden, wurden neben dem Gesamt-SOFA Score auch die organspezifischen Subscores gebildet. Während für die Organsysteme Lunge, Herz-/Kreislaufsystem, Niere, Blutsystem und Leber keine relevanten Unterschiede bezüglich des SNP rs256919o festgestellt werden konnten, konnte für das ZNS ein signifikanter Punkteunterschied von $+0,3$ Punkten für C-Allel-Träger errechnet werden. Dies deutet auf eine erhöhte Beeinträchtigung der Neurologie oder aber des Bewusstseins bei diesen Patienten hin. Eine mögliche Erklärung dafür könnte darin begründet sein, dass C-AllelTräger weniger sCD14 produzieren. Während früherer Untersuchungen zum SNP rs256919o hatte man nämlich bereits zeigen können, dass der TT-Genotyp mit einer erhöhten Serumkonzentration von sCD14 und einer erniedrigten Konzentration von IgE einhergeht (Baldini et al. 1999). Hierdurch haben Träger des C-Allels im Vergleich zu TT-homozygoten eine niedrigere LPS-Neutralisierung. Dieser erhöhte LPS-Spiegel wiederum könnte für die erhöhte Wahrscheinlichkeit neurologischer Probleme verantwortlich sein. So deuten nämlich die Ergebnisse von Studien an Tiermodellen, die zeigen konnten, dass die periphere Injektion von LPS Veränderungen der neuropsychologischen Leistung und kognitive Fehlfunktion zur Folge haben, auf einen Einfluss des LPS auf das ZNS hin (Fan et al. 2005; Hsieh et al. 2002). Andererseits untersuchte eine Metaanalyse den Einfluss proinflammatorischer Genvarianten auf die Wahrscheinlichkeit der Entwicklung eines ischämischen Schlaganfalles. Insgesamt wurden 99 Studien in 
die Untersuchung aufgenommen. Bei der Auswertung der Ergebnisse kam man zu der Schlussfolgerung, dass ein signifikanter Zusammenhang zwischen der Wahrscheinlichkeit der Entwicklung eines ischämischen Schlaganfalles und den unterschiedlichen Genotypen an der Stelle des SNP rs2569190 bisher nicht eindeutig hergestellt werden konnte (Misra et al. 2016). Unseren Ergebnissen bezüglich der Assoziation des SNP rs2569190 mit dem Punktewert des SOFA-ZNS Scores sollte aber nicht zu viel Bedeutung beigemessen werden, denn der SOFAZNS Score kann beispielsweise auch durch die Gabe von sedativ wirkendenden Medikamenten beeinflusst werden. Genau diese sedativ wirkenden Medikamente kommen nämlich regelmäßig bei Sepsis-Patienten als Therapie zum Einsatz und könnten daher einen potentiellen Störfaktor für die Höhe des SOFA-ZNS Scores darstellen.

Eine mögliche Schwäche unserer Untersuchung könnte auch darin begründet sein, dass wir ausschließlich den klinischen Einfluss des CD14 SNP rs2569190 beobachtet haben. Daher kann nicht ausgeschlossen werden, dass andere bedeutende SNPs, die in der Nähe des CD14 SNP rs256919o lokalisiert sind und bedingt durch das Kopplungsungleichgewicht ebenfalls vererbt werden, für die festgestellte Assoziation der Genotypen mit der 30-Tage-Mortalität verantwortlich sind. Eine weitere Fehlerquelle könnte das elektronische Patientendatenaufzeichnungssystem darstellen. Dieses System zeichnet nämlich verschiedene klinische Parameter, wie z.B. Blutdruck, Herzfrequenz oder Atemfrequenz automatisch auf. Zwar wurden die Daten vor ihrer Erfassung immer auf Plausibilität überprüft, aber dennoch können an dieser Stelle Messfehler nicht mit absoluter Sicherheit ausgeschlossen werden.

Der Vollständigkeit halber sei an dieser Stelle erwähnt, dass neben den Forschungen auf dem Gebiet der Sepsis natürlich auch noch andere sehr relevante Ergebnisse in Zusammenhang mit dem SNP rs2569190 gebracht werden können. So wird für T-Allel-Träger ein erhöhtes Risiko, an Tuberkulose und Sarkoidose zu erkranken, vermutet (Areeshi et al. 2013; Fridlender et al. 2010). In einer anderen Studie war der Anteil der TT-homozygoten Träger unter den Probanden mit allergischer Rhinitis signifikant häufiger nachzuweisen (Han et al. 2010). Eine weitere Studie, die sich mit dem Thema nach der Häufigkeit des Auftretens von allergischer Sensibilisierung, gemessen anhand der IgE-Konzentration im Serum, der Häufigkeit von Hautausschlag und von Husten bei Kindern beschäftigte, berücksichtigte neben dem Genotyp an Stelle des SNP rs2569190 auch die 
Endotoxinkonzentration, der die Kinder ausgesetzt waren. Man kam zu dem Ergebnis, dass Kinder mit dem CC-Genotyp, die einer erhöhten Endotoxinkonzentration ausgesetzt waren, ein geringeres Risiko für eine allergische Sensibilisierung oder für Hautausschlag hatten. Allerdings bestand bei genau diesen Kindern dafür eine erhöhtes Risiko, einen nicht atopischen Husten zu entwickeln (Simpson et al. 2006). Der TT-Genotyp scheint auch mit einem erhöhten Risiko für Reisediarrhoe einherzugehen. So konnte in einer Studie gezeigt werden, dass US-amerikanische und kanadische Menschen häufiger an einer Reisediarrhoe erkranken, wenn sie den TT-Genotyp besitzen (Mohamed et al. 2011). In einer spanischen Studie sollte kontrolliert werden, ob es eventuell einen Zusammenhang zwischen verschiedenen proinflammatorischen Genpolymorphismen u.a. auch SNP rs2569190 und dem Auftreten von kolorektalen Karzinomen gibt. In einer Fall-Kontroll-Studie wurde eine große Zahl von Probanden aus Barcelona auf diesen Zusammenhang hin untersucht. Es konnte jedoch kein signifikanter Einfluss zwischen den Genpolymorphismen und der Morbidität für ein kolorektales Karzinom festgestellt werden (Landi et al. 2006). Gleiches gilt für das Auftreten von Magenkarzinomen. Auch hier konnte kein signifikanter Unterschied bezüglich der verschiedenen Genotypen an Stelle des SNP rs256919o und der Häufigkeit des Auftretens von Magenkarzinom festgestellt werden (Hold et al. 2009). Bei einer weiteren Studie des SNP rs256919o konnte bei einer großen Gruppe chinesischer Kinder herausgefunden werden, dass wenn diese an juveniler idiopathischer Arthritis leiden, der Anteil der T-Allel-Frequenz signifikant erhöht ist (Zeng et al. 2009). Aber auch bei Patienten mit Leberzirrhose konnte eine Assoziation mit dem SNP rs256919o gefunden werden. So trat der Genotyp TT bei Probanden mit nicht-alkoholischer Steatohepatitis (NASH) signifikant häufiger als bei Probanden ohne NASH auf (Brun et al. 2006). Eine andere Studie wiederum untersuchte, ob es bei Patienten im Zustand nach einer Nierentransplantation und dem Auftreten einer akuten Abstoßungsreaktion unter anderem ein Unterschied des Genotyps bedingt durch den SNP rs2569190 gibt. Hierbei konnte jedoch für den SNP rs2569190 kein signifikanter Unterschied gefunden werden (Hwang et al. 2009). Genauso konnte kein Zusammenhang zwischen den verschiedenen Genotypen des SNP rs2569190 und dem Auftreten von thromboembolischen Ereignissen festgestellt werden (Zee et al. 2009).

Als Schlussfolgerung der Ergebnisse unserer Studie kann daher festgehalten werden, dass durch diese Untersuchungen, soweit uns bekannt ist, zum ersten Mal 
nachgewiesen werden konnte, dass der TT-Genotyp des SNP rs2569190 mit einem positiven Einfluss auf das Kurzzeitüberleben von Sepsis-Patienten kaukasischer Herkunft vergesellschaftet ist. Ein Einfluss des SNP rs2569190 auf die Schwere der Sepsis konnte nicht nachgewiesen werden. Bei der Beurteilung der verschiedenen Organsysteme mit Hilfe des SOFA Scores konnte hingegen ein signifikant erhöhter SOFA-ZNS Score gefunden werden, der bei großzügiger Verwendung von sedierenden Medikamenten allerdings kritisch zu bewerten ist. Daher sollten zukünftige Studien, die das Kurzzeitüberleben von Sepsis-Patienten untersuchen, auch den Einfluss des CD14 SNP rs256919o berücksichtigen. Eine Untersuchung des CD14 SNP rs256919o an einem Patientenkollektiv, das aus einer anderen ethnischen Gruppe besteht, erscheint uns ebenfalls sinnvoll. 


\section{Zusammenfassung}

Der Rezeptor CD14 spielt bei der Erkennung pathogener Keime durch das angeborene Immunsystem eine Schlüsselrolle. Er aktiviert nach der Identifizierung von infektiösen Erregern eine Reaktions-Kaskade, die in der Ausschüttung von proinflammatorischen Zytokinen mündet. Deshalb erschien uns die Untersuchung dieses Rezeptors auf mögliche genetische Polymorphismen, die Einfluss auf die Immunantwort nehmen, als sinnvoll. Durch die Ergebnisse anderer Studien gab es eine starke Evidenz dafür, dass der CD14 SNPrs2569190 die Funktion des angeborenen Immunsystems beeinflussen könnte. Während das C-Allel anscheinend das Risiko, an einer Infektion zu erkranken, erhöht, wird das T-Allel immer wieder in Zusammenhang mit einer erhöhten Überlebenswahrscheinlichkeit schwer erkrankter Patienten auf Intensivstationen gebracht. Da vorausgegangene Untersuchungen auf einen Einfluss des SNP rs2569190 auf das klinische Bild der Sepsis hindeuteten und die Sepsis eine schwere Komplikation einer Infektion darstellt, wurde der CD14 SNPrs2569190 an einem Patientenkollektiv untersucht, das ausschließlich aus Patienten bestand, die an einer Sepsis erkrankt waren.

Das Ziel dieser Studie war es herauszufinden, ob der CD14 SNPrs2569190 mit dem Mortalitätsrisiko, der Schwere einer Sepsis oder einer Veränderung der Organfunktion an einer Sepsis erkrankter Patienten assoziiert sein könnte. Hierfür wurden im Zeitraum von April 2012 bis Juni 2014 insgesamt 417 Patienten untersucht, die auf einer von insgesamt drei Intensivstationen der UMG stationär aufgenommen worden waren, die ACCP/SCCM-Konsensus-Konferenz-Kriterien zur Diagnose einer Sepsis erfüllten und bereit waren, an unserer Studie teilzunehmen. Neben der täglichen Erfassung klinischer Parameter über einen Zeitraum von insgesamt 30 Tagen wurde jedem Patienten Blut zur DNAExtraktion und Genotypisierung entnommen.

Die Genotypverteilung unseres Patientenkollektivs entsprach dem erwarteten Hardy-Weinberg-Gleichgewicht mit einer MAF von 0,45. Wir konnten dabei herausfinden, dass ein signifikanter Unterschied zwischen den verschiedenen Genotypen bezüglich des Mortalitätsrisikos besteht. Während homozygote TTGenotypen nach 30 Tagen ein Mortalitätsrisiko von 13 zeigten, betrug der Anteil der Verstorbenen unter den Trägern des C-Allels $23 \%(\mathrm{p}=0,0490)$. Auch eine multivariate Cox-Regression lieferte eine HR von 2,11 bezüglich des Einflusses des 
CD14 SNPrs2569190 auf das Kurzzeitüberleben der Patienten ( $\mathrm{p}=0,0282)$. Dieser signifikante Unterschied war allerdings 90 Tage nach Beginn der Sepsis nicht mehr festzustellen. Dies könnte bedeuten, dass der CD14 SNPrs2569190 zwar mit dem Kurzzeitüberleben assoziiert ist, aber für die langfristige Überlebenswahrscheinlichkeit einer Sepsis nicht relevant ist. Eine mögliche Erklärung hierfür könnte die bei T-Allel-Trägern erhöhte Ausschüttung von proinflammatorischen Zytokinen sein, welche eine stärkere Immunantwort hervorrufen, die vor allem in der ersten Phase der Sepsis von großer Bedeutung ist. Außerdem konnte gezeigt werden, dass der CD14 SNPrs2569190 in dieser Studie keinen Einfluss auf die Schwere der Sepsis hat, da sich die Verteilung der Genotypen auf die Unterformen Sepsis, schwere Sepsis und septischer Schock nicht signifikant unterschied. Auch konnte kein signifikanter Zusammenhang zwischen den initial ermittelten Punktewerten des APACHE II und des SOFA Scores, der Höhe der Entzündungswerte, der Liegedauer auf der Intensivstation oder der Anzahl von Tagen, an denen keine Organunterstützung notwendig war, festgestellt werden. Weiterhin konnte bei der Untersuchung der Organfunktionen im Verlauf anhand der SOFA Subscores gezeigt werden, dass es einen signifikanten Unterschied bei der Funktion des ZNS, bedingt durch den CD14 SNP rs256919o, gibt. Hier hatten die TT-homozygoten einen um 0,3 Punkte niedrigeren ZNS-SOFA Score ( $\mathrm{p}=0,0311)$, während sich die Punkte der anderen organspezifischen SOFA Scores nicht signifikant unterschieden. Als Erklärung hierfür könnten eine durch den SNP verursachte erniedrigte Konzentration von sCD14 und eine damit einhergehende erhöhte Konzentration von LPS dienen, welche möglicherweise einen negativen Einfluss auf kognitive Funktionen haben kann. Dieses Ergebnis muss allerdings mit Vorsicht betrachtet werden, da es zum Beispiel durch die Gabe von sedierenden Medikamenten im Rahmen der Therapie der Sepsis stark beeinflusst worden sein könnte.

So kann man zusammenfassend festhalten, dass dies die erste Untersuchung ist, die eine positive Assoziation des TT-Genotyps des SNP rs2569190 mit dem Kurzzeitüberleben (30 Tage) von Patienten kaukasischer Herkunft, die an einer Sepsis erkrankt sind, zeigen konnte. 


\section{Anhang}

CRF

Patientennummer:

$\square$ Datenbank

durch:

\section{Clinical Report Form}

\section{Bedeutung genetischer}

\section{Polymorphismen der angeborenen Immunabwehr bei Sepsis und}

\section{Organversagen}

Zentrum Anästhesiologie, Rettungs- und Intensivmedizin (ZARI)

Robert-Koch-Str. 40, 37099 Göttingen

Projektleiter: $\quad$ PD Dr. med. José Hinz

Dr. med. Ashham Mansur

Tel.: +49-551-39 22995 (Sekretariat)

Studienärzte: $\quad$ PD Dr. med. José Hinz, Tel +49-551-39 22995,

Pieper919-4082

Dr. med. Ashham Mansur, Tel +49-551-39 22995,

Pieper919-4049 


\section{Richtlinien}

\section{Einschlusskriterien}

I. Nachweis der Infektion

$\square$ Mikrobiologischer Nachweis oder klinische Kriterien

II. Systemisches inflammatorisches Response-Syndrom (mind. 2 Kriterien)

$\square$ Fieber $\left(\geq 38^{\circ} \mathrm{C}\right)$ oder Hypothermie $\left(\leq 36^{\circ} \mathrm{C}\right)$

$\square$ Tachykardie (Herzfrequenz $\geq 90 / \mathrm{min}$ )

Tachypnoe (Atemfrequenz $\geq 20 / \mathrm{min}$ )

oder Hyperventilation ( $\mathrm{PaCO} 2 \leq 33 \mathrm{mmHg}$ )

Leukozytose $\left(\geq 12000 / \mathrm{mm}^{3}\right)$

$\square$ oder Leukopenie $\left(\leq 4000 / \mathrm{mm}^{3}\right)$

oder $\geq 10 \%$ unreife Neutrophile im Differentialblutbild

\section{Auschlusskriterien}

Alter unter 18 Jahre $\quad \square$ Nein

Bekannte Schwangerschaft $\quad \square$ Nein

Behandlung mit Immunsuppressiva bzw. Chemotherapie $\quad \square$ Nein

Bekannter Myokardinfarkt $\quad \square$ Nein

oder Verdacht auf Myokardinfarkt innerhalb der letzten 6 Wochen

Herzinsuffizienz mit NYHA-Klassifikation IV $\quad \square$ Nein

HIV-Infektion $\quad \square$ Nein

Bei nichterwartetem Überleben der nächsten 28 Tage $\quad \square$ Nein aufgrund einer vorbestehenden unheilbaren Erkrankung inklusive:

a. Unheilbarem Krebs

b. Lungenerkrankung im Endstadium

c. Sauerstoffbedarf in der Häuslichkeit

d. Nierenerkrankung im Endstadium

Eine fehlende Bereitschaft des Patienten

Nein

oder des gesetzlichen Vertreters zur Teilnahme an der Studie 
Patientennummer:

Einwilligungserklärung

Einwilligung durch

$\square$ Patient

$\square$ Gesetzlichen Betreuer

$\square$ Wiedereinwilligungsfähigen Patienten

Einwilligung erfolgte am

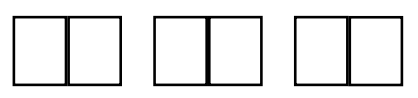

\section{Blutentnahme}

$30 \mathrm{ml}$ Patientenblut Abnahmeort: $\square$ Arterie $\square$ Vene

Tag der Blutentnahme

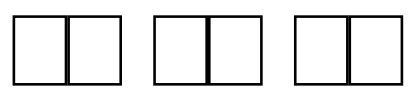

\section{Genetische Abstammung}
$\square$ Weiß/Kaukasisch
Andere

\section{Krankenhausaufnahme}

Datum der Krankenhausaufnahme:
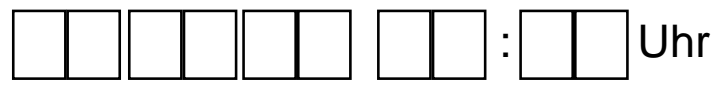

$\square$ intern $\square$ extern

Grund der Krankenhausaufnahme:

Datum der Aufnahme auf ICU:
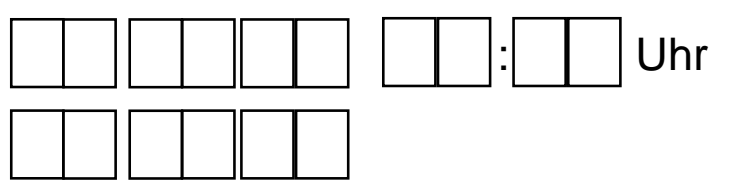

Datum Beginn Sepsis:

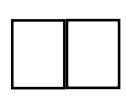

Körpergewicht $(\mathrm{kg})$

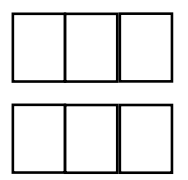

Körpergröße (cm)

\section{Operativer Status}

Postoperativ nach Notfall-OP

Ja $\square$

Nein $\square$

Postoperativ nach elektiver OP

Ja $\square$

Nein 
Patientennummer:

\section{Vorerkrankungen}

\section{Kardiovaskulär}

Angina Pectoris

Arrhythmie

Vitium

Myokardinfarkt

Angeborener Herzfehler

PAVK

Arterielle Hypertonie

Andere

Atmung

COPD

Asthma Bronchiale

Cystische Fibrose

Heimbeatmung

Andere

\section{Niere}

$\square \quad$ Chronisches Nierenversagen

Andere (

.)

\section{Diabetes mellitus}

Diabetes (insulinabhängig)

Diabetes (nicht insulinabhängig)

Diabetes mit Organschäden

\section{Immunsystem}

Tumor

Lymphom

Leukämie

Metastasen

Rheumatoide Arthritis

SLE

Andere

Neurologie

Apoplex

\section{Andere}

Andere (

Andere (....

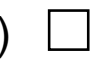

Andere

.)

Andere

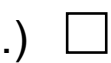

Lebererkrankung

Gastrointestinale Blutung

Andere 
Patientennummer:

\section{Vormedikation}

Lipidsenker

Tagesdosis:

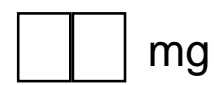

$\square$ Atorvastatin (Sortis)

$\square$ Simvastatin (Gerosim; Zocor)

$\square$ Pravastatin (Mevalotin; Pravasin)

$\square$ Fluvastatin (Cranoc; Lescol; Locol)

$\square$ Lovastatin (Mevinacor)

$\square$ Rosuvastatin (Crestor)

\section{Weitere:}

$\square$ Beta-Blocker (-ol)

$\square$ ACE Hemmer (-pril)

$\square$ Coronartherapeutika (Molsidomin; Nitrate)

$\square$ Antidiabetika (Metformin; Glibenclamid; Glimepirid; ...)

$\square$ Diruetika (Furosemid; Spironolacton; HCT; ...)

$\square$ Bronchodilatatoren (Salbutamol; Ipratropiumbromid; Theophyllin; ...)

$\square$ Antihypertensiva andere

Antiarrhythmika (Na-Kanal-, K-Kanal- oder Ca-Kanal-Blocker)

$\square$ Antikoagulantien (Cumarine, Heparin, ...)

\section{Hausarzt}

Name:

Vorname:

Geschlecht: $\square$ weiblich $\square$ männlich

Straße: Hausnummer:

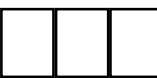

PLZ:

Ort:

Telefonnummer:
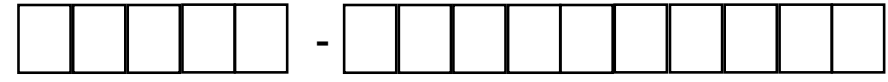
durch:

Tag 1 ICU - Beginn Sepsis

Datum:
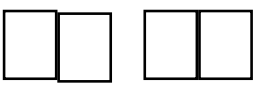
\begin{tabular}{l}
$\square=$ Beginn Sepsis \\
\hline
\end{tabular}

SOFA

Von

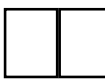



APACHE II

Niedrigste

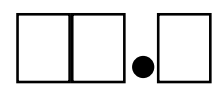

Leukozytenzahl $\left(10^{3} / \mathrm{mm}^{3}\right)$

Höchste



Niedrigste $\square \cdot \square$

Hämatokrit (\%)

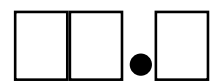

Thrombozytenzahl $\left(10^{3} / \mathrm{mm}^{3}\right)$

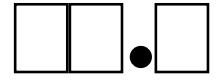

Herz-Kreislaufsystem

Herzfrequenz $\left(\min ^{-1}\right)$

Mittlerer Blutdruck (mmHg)

Höchste

Höchster

Systolischer Blutdruck (mmHg)Höchster

Dobutamin $(\mu \mathrm{g} / \mathrm{kg} / \mathrm{min})$ Höchste Dosis

Adrenalin $(\mu \mathrm{g} / \mathrm{min})$ Höchste Dosis

Noradrenalin ( $\mu \mathrm{g} / \mathrm{min}) \quad$ Höchste Dosis

\section{Atmung / Säure-Basen Haushalt}

Atemfrequenz $\left(\mathrm{min}^{-1}\right)$

Höchste

$\mathrm{PaO} 2(\mathrm{mmHG})$

Entsprechender PaCO2 (mmHg)

Entsprechende $\mathrm{FiO} 2$

Beatmung*

Arterieller $\mathrm{pH}$

Höchster

Base Excess

Höchster
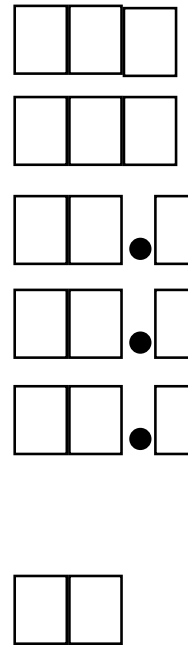

Niedrigster

Niedrigster



Niedrigste
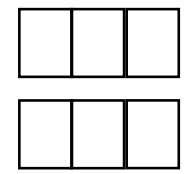

Niedrigste

Niedrigste
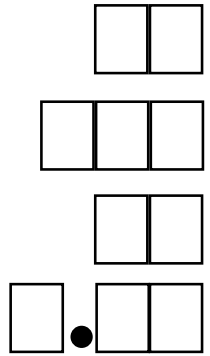

Nein

Niedrigster

Niedrigster
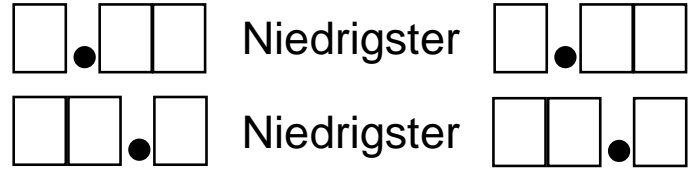

Höchster

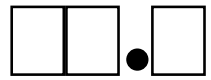

* Beatmung beinhaltet auch alle unterstützenden Beatmungsvarianten, wie CPAP, NAVA, etc. 
Patientennummer:

\section{Tag 1 ICU - Beginn Sepsis}

\section{Leber}

Bilirubin ( $\mathrm{mg} / \mathrm{dl})$

AST / ALT (IU/I)

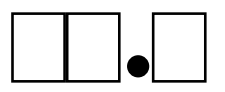

Quick (\%) / aPTT (sec)
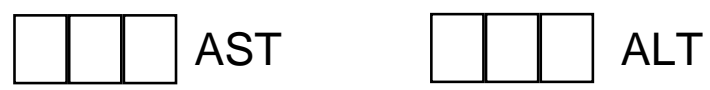

Systemische Antikoagulation

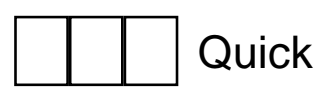

$\mathrm{Ja}$

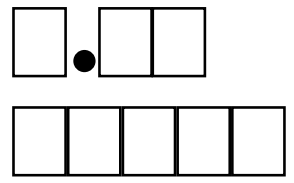

Ja $\square$ in

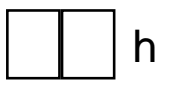

Nein $\square$

${ }^{*}$ CVVHF, Hämodialyse, Peritonealdialyse

\section{Elektrolyte}

Natrium $(\mathrm{mmol} / \mathrm{l})$

Höchster

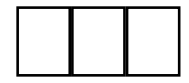

Niedrigster

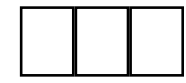

Kalium (mmol/l)

Höchster

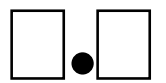

Niedrigster

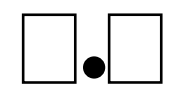

ZNS Glasgow Coma Scale

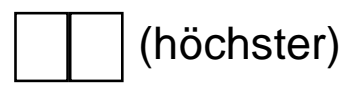

\section{Entzündungswerte}

$\mathrm{CRP}(\mathrm{mg} / \mathrm{l})$

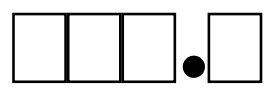

Procalcitonin $(\mu \mathrm{g} / \mathrm{l})$

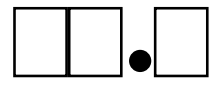

Röntgen Thorax Datum:
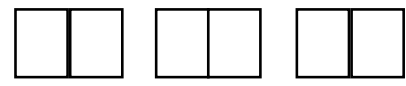

(Tag 1)

Lungeninfiltrate

Ja

Nein $\square$

- Lobär

- Lokal

- Diffus bilateral

Ja

Nein 
Patientennummer:

\section{Tag _ ICU ab Beginn Sepsis durch:}

Datum:

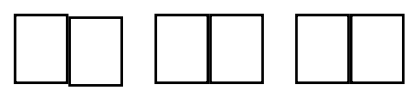

Von 00:00 Uhr bis 23:59 Uhr

Temperatur $\left({ }^{\circ} \mathrm{C}\right)$

Höchste

Niedrigste

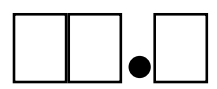

Leukozytenzahl $\left(10^{3} / \mathrm{mm}^{3}\right)$

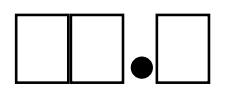

Hämatokrit (\%)

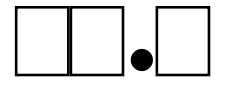

Thrombozytenzahl $\left(10^{3} / \mathrm{mm}^{3}\right)$

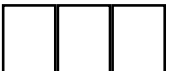

\section{Herz-Kreislaufsystem}

Herzfrequenz $\left(\min ^{-1}\right)$

Mittlerer Blutdruck (mmHg)

Höchste

Höchster

Systolischer Blutdruck (mmHg)Höchster

Dobutamin $(\mu \mathrm{g} / \mathrm{kg} / \mathrm{min})$ Höchste Dosis

Adrenalin $(\mu \mathrm{g} / \mathrm{min})$ Höchste Dosis

Noradrenalin ( $\mu \mathrm{g} / \mathrm{min}) \quad$ Höchste Dosis

\section{Atmung / Säure-Basen Haushalt}

Atemfrequenz $\left(\mathrm{min}^{-1}\right)$

Höchste

$\mathrm{PaO} 2(\mathrm{mmHG})$

Entsprechender PaCO2 (mmHg)

Entsprechende $\mathrm{FiO} 2$

Beatmung*

Arterieller $\mathrm{pH}$

Höchster

Base Excess

Höchster
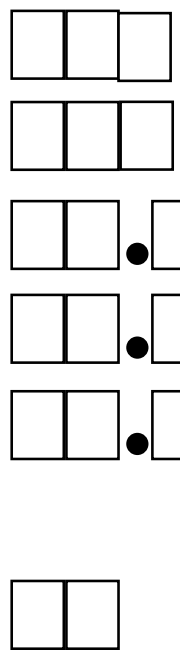

Niedrigster

Niedrigster
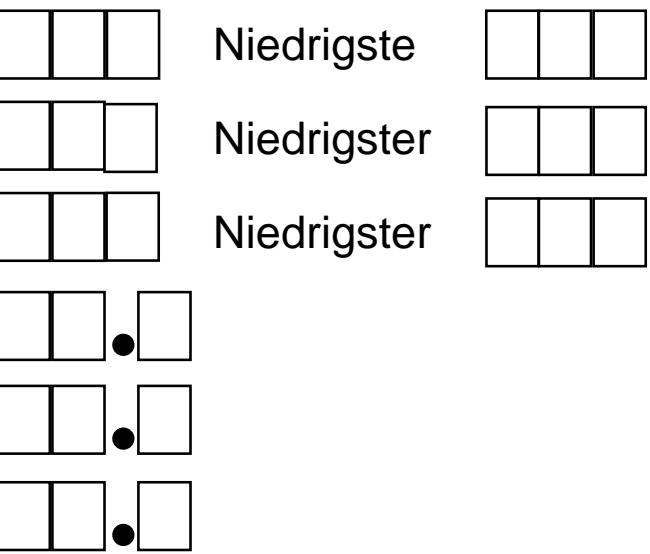

Niedrigste

Niedrigste

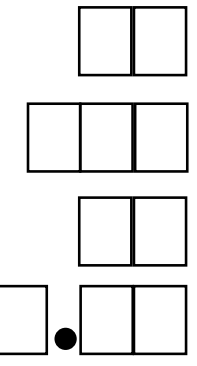

Nein

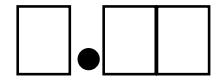

Niedrigster



Niedrigster
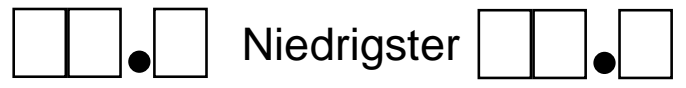

Laktat (mmol/l)

Höchster

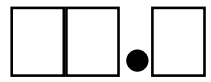

* Beatmung beinhaltet auch alle unterstützenden Beatmungsvarianten, wie CPAP, NAVA, etc. 
Patientennummer:

\section{Tag _ ICU ab Beginn Sepsis}

\section{Leber}

Bilirubin (mg/dl)

AST / ALT (IU/I)

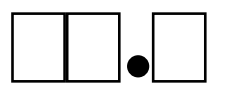

Quick (\%) / aPTT (sec)
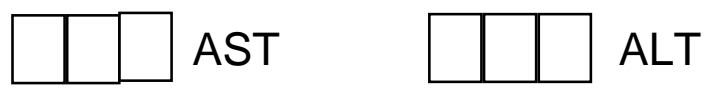

Systemische Antikoagulation

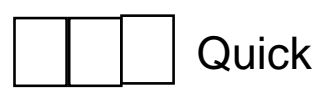

$\mathrm{Ja}$

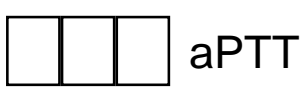

Nein $\square$

Niere

Kreatinin $(\mathrm{mg} / \mathrm{dl})$

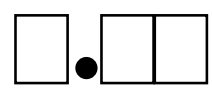

Urinausscheidung (ml)

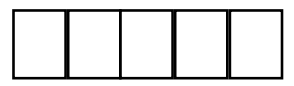

in



Dialyse*

Ja $\square$

Nein $\square$

${ }^{*}$ CVVHF, Hämodialyse, Peritonealdialyse

\section{Elektrolyte}

Natrium $(\mathrm{mmol} / \mathrm{l})$

Höchster

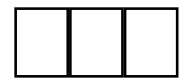

Niedrigster

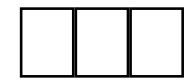

Kalium (mmol/l)

Höchster

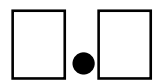

Niedrigster

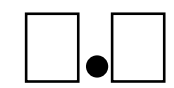

ZNS Glasgow Coma Scale

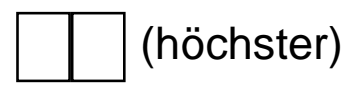

\section{Entzündungswerte}

CRP (mg/l)

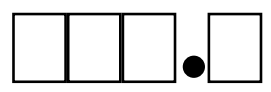

Procalcitonin $(\mu \mathrm{g} / \mathrm{l})$

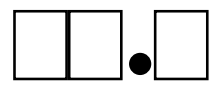

Röntgen Thorax Datum:
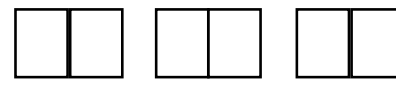

(Tag 2)

Lungeninfiltrate

Ja

Nein $\square$

- Lobär

- Lokal

- Diffus bilateral

$\mathrm{Ja}$

Nein 
Patientennummer:

\section{Mikrobiologie}

\section{Erreger}

Andere

Streptococcus pneumoniae

Haemophilus influenzae

Mycoplasma pneumoniae

Legionella spp.

Chlamydia pneumoniae

Staphylococcus aureus

Pseudomonas aeruginosa

Candida

Staphylococcus epidermidis

Escherichia coli
Nachweis über

Bronchialsekret Blutkultur Serologie 
Patientennummer:

\section{Antibiotikatherapie}




Patientennummer:

Weitere Antibiotikatherapie
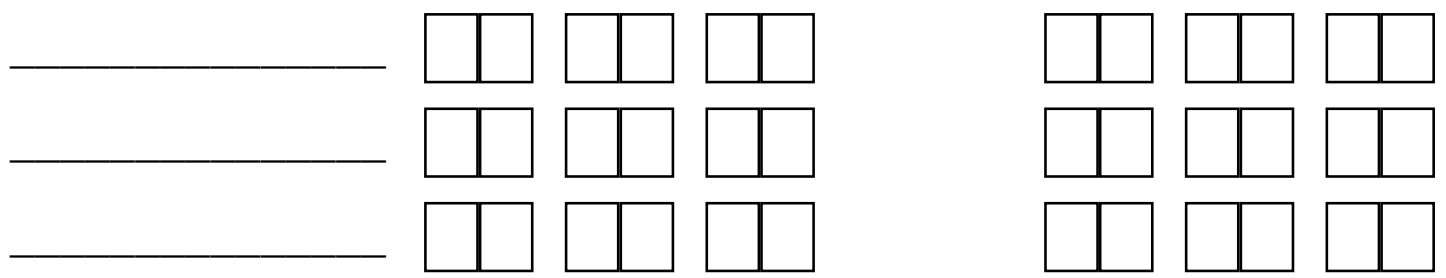

\section{ICU Entlassung}

ICU Entlassung

$\square$ lebend

$\square$ verstorben

Datum der ICU Entlassung:


Falls lebend, Entlassung nach:

$\square$ intern $\square$ extern

$\square$ ICU $\square$ IMC $\square$ Normalstation $\square$ Pflege/Reha

Datum der KH Entlassung:
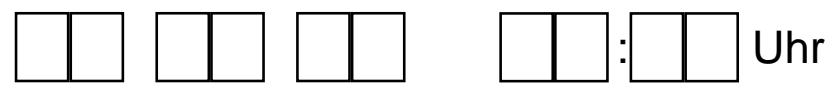

30-Tage-Überleben $\square$ kontrolliert

Falls verstorben, Todesursache:

$\square$ Herzkreislaufversagen durch Sepsis bedingt

$\square$ Herzkreislaufversagen anderer Ursache

$\square$ Multiorganversagen durch Sepsis bedingt

$\square$ Persistierende oder rezidivierende Sepsis

$\square$ Therapieversagen

$\square$ andere Ursache: 


\section{Literaturverzeichnis}

Abu-Maziad A, Schaa K, Bell EF, Dagle JM, Cooper M, Marazita ML, Murray JC (2010): Role of polymorphic variants as genetic modulators of infection in neonatal sepsis. Pediatr Res $\underline{68}, 323-$ 329

Aggarwal BB (2003): Signalling pathways of the TNF superfamily: a double-edged sword. Nat Rev Immunol $\underline{3}, 745-756$

Akira S, Takeda K (2004): Toll-like receptor signalling. Nat Rev Immunol 4 , 499-511

Akira S, Uematsu S, Takeuchi O (2006): Pathogen recognition and innate immunity. Cell $\underline{124}$, 783801

Alexander C, Rietschel ET (2001): Bacterial lipopolysaccharides and innate immunity. J Endotoxin Res $\underline{7}, 167-202$

Alexopoulou L, Holt AC, Medzhitov R, Flavell RA (2001): Recognition of double-stranded RNA and activation of NF-kappaB by Toll-like receptor 3 . Nature $\underline{413}, 732-738$

Alvarez G (2008): Deviations from Hardy-Weinberg proportions for multiple alleles under viability selection. Genet Res (Camb) 90, 209-216

Angus DC, van der Poll T (2013): Severe sepsis and septic shock. N Engl J Med $\underline{369}, 840-851$

Angus DC, Linde-Zwirble WT, Lidicker J, Clermont G, Carcillo J, Pinsky MR (2001): Epidemiology of severe sepsis in the United States: analysis of incidence, outcome, and associated costs of care. Crit Care Med 29, 1303-1310

Antal-Szalmas P, Strijp JA, Weersink AJ, Verhoef J, Van Kessel KP (1997): Quantitation of surface CD14 on human monocytes and neutrophils. J Leukoc Biol $\underline{61}, 721-728$

Areeshi MY, Mandal RK, Panda AK, Bisht SC, Haque S (2013): CD14 -159 C>T gene polymorphism with increased risk of tuberculosis: evidence from a meta-analysis. PloS one $\underline{8}$, e64747

Armant MA, Fenton MJ (2002): Toll-like receptors: a family of pattern-recognition receptors in mammals. Genome Biol $\underline{3}$, Reviews 3011

Baldini M, Lohman IC, Halonen M, Erickson RP, Holt PG, Martinez FD (1999): A Polymorphism* in the 5 ' flanking region of the CD14 gene is associated with circulating soluble CD14 levels and with total serum immunoglobulin E. Am J Respir Cell Mol Biol 20, 976-983

Barash Y, Calarco JA, Gao W, Pan Q, Wang X, Shai O, Blencowe BJ, Frey BJ (2010): Deciphering the splicing code. Nature $\underline{465}, 53-59$

Barber RC, Chang LY, Arnoldo BD, Purdue GF, Hunt JL, Horton JW, Aragaki CC (2006): Innate immunity SNPs are associated with risk for severe sepsis after burn injury. Clin Med Res $\underline{4}, 250-$ 255

Barber RC, Aragaki CC, Chang LY, Purdue GF, Hunt JL, Arnoldo BD, Horton JW (2007): CD14-159 C allele is associated with increased risk of mortality after burn injury. Shock $\underline{27}, 232-237$ 
Bazil V, Baudys M, Hilgert I, Stefanova I, Low MG, Zbrozek J, Horejsi V (1989): Structural relationship between the soluble and membrane-bound forms of human monocyte surface glycoprotein CD14. Mol Immunol 26, 657-662

Bell JK, Mullen GE, Leifer CA, Mazzoni A, Davies DR, Segal DM (2003): Leucine-rich repeats and pathogen recognition in Toll-like receptors. Trends Immunol 24, 528-533

Bouza C, Lopez-Cuadrado T, Saz-Parkinson Z, Amate-Blanco JM (2014): Epidemiology and recent trends of severe sepsis in Spain: a nationwide population-based analysis (2006-2011). BMC Infect Dis $\underline{14}, 3863$

Bræne I, Reiz B, Erdmann J (2013): Tippfehler im Genom: erbliche Ursachen von Herzerkrankungen. BIOspektrum $\underline{19}, 642-644$

Brun P, Castagliuolo I, Floreani AR, Buda A, Blasone L, Palu G, Martines D (2006): Increased risk of NASH in patients carrying the $\mathrm{C}(-159) \mathrm{T}$ polymorphism in the $\mathrm{CD} 14$ gene promoter region. Gut $\underline{55}$, 1212

Bufler P, Stiegler G, Schuchmann M, Hess S, Kruger C, Stelter F, Eckerskorn C, Schutt C, Engelmann $H$ (1995): Soluble lipopolysaccharide receptor (CD14) is released via two different mechanisms from human monocytes and CD14 transfectants. Eur J Immunol 25, 604-610

Bulut Y, Faure E, Thomas L, Karahashi H, Michelsen KS, Equils O, Morrison SG, Morrison RP, Arditi $M$ (2002): Chlamydial heat shock protein 60 activates macrophages and endothelial cells through Toll-like receptor 4 and MD2 in a MyD88-dependent pathway. J Immunol 168, 1435-1440

Burgmann H, Winkler S, Locker GJ, Presterl E, Laczika K, Staudinger T, Knapp S, Thalhammer F, Wenisch C, Zedwitz-Liebenstein K, et al. (1996): Increased serum concentration of soluble CD14 is a prognostic marker in gram-positive sepsis. Clin Immunol Immunopathol $\underline{80}$, 307-310

Buselmaier W, Tariverdian G: Humangenetik. Mit 162 Tabellen. 4., neu bearb. Aufl. Auflage; Springer Medizin, Heidelberg 2007

Caroff M, Karibian D (2003): Structure of bacterial lipopolysaccharides. Carbohydr Res $\underline{338}$, 24312447

Caroff M, Karibian D, Cavaillon JM, Haeffner-Cavaillon N (2002): Structural and functional analyses of bacterial lipopolysaccharides. Microbes Infect $\underline{4}, 915-926$

Chiavone PA, Sens YA (2003): Evaluation of APACHE II system among intensive care patients at a teaching hospital. Sao Paulo Med J 121, 53-57

Choi HC, Lee KY (2004): CD14 glycoprotein expressed in vascular smooth muscle cells. J Pharmacol Sci $\underline{95}, 65-70$

D'Avila LC, Albarus MH, Franco CR, Aguiar BB, Oliveira JR, Dias FS, Alho CS (2006): Effect of CD14 $260 C>T$ polymorphism on the mortality of critically ill patients. Immunol Cell Biol 84, 342-348

Davis SM, Clark EA, Nelson LT, Silver RM (2010): The association of innate immune response gene polymorphisms and puerperal group A streptococcal sepsis. Am J Obstet Gynecol 202, 308.e301308 
Decker T, Muller M, Stockinger S (2005): The yin and yang of type I interferon activity in bacterial infection. Nat Rev Immunol $\underline{5}, 675-687$

Deonarain R, Chan DC, Platanias LC, Fish EN (2002): Interferon-alpha/beta-receptor interactions: a complex story unfolding. Curr Pharm Des $\underline{8}$, 2131-2137

Diebold SS, Kaisho T, Hemmi H, Akira S, Reis e Sousa C (2004): Innate antiviral responses by means of TLR7-mediated recognition of single-stranded RNA. Science 303, 1529-1531

Dinarello CA (1996): Biologic basis for interleukin-1 in disease. Blood 87, 2095-2147

Eckert JK, Kim YJ, Kim JI, Gurtler K, Oh DY, Sur S, Lundvall L, Hamann L, van der Ploeg A, Pickeers P, et al. (2013): The crystal structure of lipopolysaccharide binding protein reveals the location of a frequent mutation that impairs innate immunity. Immunity $\underline{39}$, 647-660

Engel C, Brunkhorst FM, Bone HG, Brunkhorst R, Gerlach H, Grond S, Gruendling M, Huhle G, Jaschinski U, John S, et al. (2007): Epidemiology of sepsis in Germany: results from a national prospective multicenter study. Intensive Care Med $\underline{33}$, 606-618

Esper AM, Moss M, Lewis CA, Nisbet R, Mannino DM, Martin GS (2006): The role of infection and comorbidity: Factors that influence disparities in sepsis. Crit Care Med 34, 2576-2582

Esposito S, Zampiero A, Pugni L, Tabano S, Pelucchi C, Ghirardi B, Terranova L, Miozzo M, Mosca F, Principi N (2014): Genetic polymorphisms and sepsis in premature neonates. PloS one $\underline{9}$, e101248

Fallavena PR, Borges TJ, Paskulin DD, Paludo FJ, Goetze TB, de Oliveira JR, Nobrega OT, Dias FS, Alho CS (2009): The influences of CD14 -260C>T polymorphism on survival in ICU critically ill patients. Immunol Invest $\underline{38}, 797-811$

Fallavena PR, de Jesus Borges T, Paskulin DD, Thurow HS, de Oliveira Paludo FJ, Dos Santos Froes C, Graebin P, Dias FS, de Toledo Nobrega O, Alho CS (2013): The synergy of -260T T CD14 and 308GG TNF-alpha genotypes in survival of critically ill patients. Scand J Immunol $\underline{77}$, 62-68

Fan LW, Pang Y, Lin S, Tien LT, Ma T, Rhodes PG, Cai Z (2005): Minocycline reduces lipopolysaccharide-induced neurological dysfunction and brain injury in the neonatal rat. J Neurosci Res $\underline{82}$, 71-82

Faustino NA, Cooper TA (2003): Pre-mRNA splicing and human disease. Genes Dev 17, 419-437

Ferreira FL, Bota DP, Bross A, Melot C, Vincent JL (2001): Serial evaluation of the SOFA score to predict outcome in critically ill patients. Jama $\underline{286}, 1754-1758$

Ferrero E, Hsieh CL, Francke U, Goyert SM (1990): CD14 is a member of the family of leucine-rich proteins and is encoded by a gene syntenic with multiple receptor genes. J Immunol $\underline{145}$, 331-336

Fleischmann C, Thomas-Rueddel DO, Hartmann M, Hartog CS, Welte T, Heublein S, Dennler U, Reinhart K (2016): Fallzahlen und Sterblichkeitsraten von Sepsis-Patienten im Krankenhaus. Dtsch Arztebl Int 113, 159-166

Fridlender ZG, Schwartz A, Kohan M, Amir G, Glazer M, Berkman N (2010): Association between CD14 gene polymorphisms and disease phenotype in sarcoidosis. Respir Med 104, 1336-1343 
Friedman G, Silva E, Vincent JL (1998): Has the mortality of septic shock changed with time. Crit Care Med 26, 2078-2086

Fujihara M, Muroi M, Tanamoto K, Suzuki T, Azuma H, Ikeda H (2003): Molecular mechanisms of macrophage activation and deactivation by lipopolysaccharide: roles of the receptor complex. Pharmacol Ther $\underline{100}, 171-194$

Funda DP, Tuckova L, Farre MA, Iwase T, Moro I, Tlaskalova-Hogenova H (2001): CD14 is expressed and released as soluble CD14 by human intestinal epithelial cells in vitro: lipopolysaccharide activation of epithelial cells revisited. Infect Immun $\underline{69}, 3772-3781$

Gibot S, Cariou A, Drouet L, Rossignol M, Ripoll L (2002): Association between a genomic polymorphism within the CD14 locus and septic shock susceptibility and mortality rate. Crit Care Med 30, 969-973

Gioannini TL, Teghanemt A, Zhang D, Levis EN, Weiss JP (2005): Monomeric endotoxin:protein complexes are essential for TLR4-dependent cell activation. J Endotoxin Res 11, 117-123

Godowski PJ (2005): A smooth operator for LPS responses. Nat Immunol $\underline{6}$, 544-546

Gong JP, Dai LL, Liu CA, Wu CX, Shi YJ, Li SW, Li XH (2002): Expression of CD14 protein and its gene in liver sinusoidal endothelial cells during endotoxemia. World J Gastroenterol $\underline{8}$, 551-554

Gonzaga-Jauregui C, Lupski JR, Gibbs RA (2012): Human genome sequencing in health and disease. Annu Rev Med 63, 35-61

Griffin JD, Ritz J, Nadler LM, Schlossman SF (1981): Expression of myeloid differentiation antigens on normal and malignant myeloid cells. J Clin Invest $\underline{68}, 932-941$

Gu W, Dong H, Jiang DP, Zhou J, Du DY, Gao JM, Yao YZ, Zhang LY, Wen AQ, Liu Q, et al. (2008): Functional significance of $\mathrm{CD} 14$ promoter polymorphisms and their clinical relevance in a Chinese Han population. Crit Care Med $\underline{36}$, 2274-2280

Guillot L, Balloy V, McCormack FX, Golenbock DT, Chignard M, Si-Tahar M (2002): Cutting edge: the immunostimulatory activity of the lung surfactant protein-A involves Toll-like receptor $4 . \mathrm{J}$ Immunol $\underline{168}$, 5989-5992

Haberbosch W, Unkelbach K, Schuster D, Gardemann A, Tillmanns H, Holschermann H (2009): CD14 promoter polymorphism (- 159C-->t) is not associated with myocardial infarction or coronary artery disease in patients with assumed high genetic risk. Thorac Cardiovasc Surg $\underline{57}$, 386-390

Hailman E, Lichenstein HS, Wurfel MM, Miller DS, Johnson DA, Kelley M, Busse LA, Zukowski MM, Wright SD (1994): Lipopolysaccharide (LPS)-binding protein accelerates the binding of LPS to CD14. J Exp Med 179, 269-277

Hall MJ, Williams SN, DeFrances CJ, Golosinskiy A (2011): Inpatient care for septicemia or sepsis: a challenge for patients and hospitals. NCHS Data Brief, 1-8

Han D, She W, Zhang L (2010): Association of the CD14 gene polymorphism C-159T with allergic rhinitis. Am J Rhinol Allergy 24, e1-3 
Harrison DA, Welch CA, Eddleston JM (2006): The epidemiology of severe sepsis in England, Wales and Northern Ireland, 1996 to 2004: secondary analysis of a high quality clinical database, the ICNARC Case Mix Programme Database. Crit Care 10, R42

Hashimoto C, Hudson KL, Anderson KV (1988): The Toll gene of Drosophila, required for dorsalventral embryonic polarity, appears to encode a transmembrane protein. Cell $\underline{52}$, 269-279

Hayashi F, Smith KD, Ozinsky A, Hawn TR, Yi EC, Goodlett DR, Eng JK, Akira S, Underhill DM, Aderem A (2001): The innate immune response to bacterial flagellin is mediated by Toll-like receptor 5 . Nature $\underline{410}, 1099-1103$

Haziot A, Chen S, Ferrero E, Low MG, Silber R, Goyert SM (1988): The monocyte differentiation antigen, $\mathrm{CD} 14$, is anchored to the cell membrane by a phosphatidylinositol linkage. J Immunol $\underline{141}, 547-552$

Hehlgans T, Pfeffer K (2005): The intriguing biology of the tumour necrosis factor/tumour necrosis factor receptor superfamily: players, rules and the games. Immunology $\underline{115}, 1-20$

Heil F, Hemmi H, Hochrein H, Ampenberger F, Kirschning C, Akira S, Lipford G, Wagner H, Bauer S (2004): Species-specific recognition of single-stranded RNA via toll-like receptor 7 and 8 . Science $\underline{303}, 1526-1529$

Hemmi H, Takeuchi O, Kawai T, Kaisho T, Sato S, Sanjo H, Matsumoto M, Hoshino K, Wagner H, Takeda K, et al. (2000): A Toll-like receptor recognizes bacterial DNA. Nature $\underline{408}$, 740-745

Hold GL, Rabkin CS, Gammon MD, Berry SH, Smith MG, Lissowska J, Risch HA, Chow WH, Mowat NA, Vaughan TL, et al. (2009): CD14-159C/T and TLR9-1237T/C polymorphisms are not associated with gastric cancer risk in Caucasian populations. Eur J Cancer Prev $\underline{18}, 117-119$

Hornung V, Guenthner-Biller M, Bourquin C, Ablasser A, Schlee M, Uematsu S, Noronha A, Manoharan M, Akira S, de Fougerolles A, et al. (2005): Sequence-specific potent induction of IFNalpha by short interfering RNA in plasmacytoid dendritic cells through TLR7. Nat Med 11, 263-270

Horovitz JH, Carrico CJ, Shires GT (1974): Pulmonary response to major injury. Arch Surg 108, 349355

Hotchkiss RS, Monneret G, Payen D (2013): Sepsis-induced immunosuppression: from cellular dysfunctions to immunotherapy. Nat Rev Immunol $\underline{13}, 862-874$

Hsieh PF, Chia LG, Ni DR, Cheng LJ, Ho YP, Tzeng SF, Chang MH, Hong JS (2002): Behavior, neurochemistry and histology after intranigral lipopolysaccharide injection. Neuroreport $\underline{13}, 277-$ 280

Hubacek JA, Rothe G, Pit'ha J, Skodova Z, Stanek V, Poledne R, Schmitz G (1999): C(-260)-->T polymorphism in the promoter of the CD14 monocyte receptor gene as a risk factor for myocardial infarction. Circulation 99 , 3218-3220

Hural JA, Kwan M, Henkel G, Hock MB, Brown MA (2000): An intron transcriptional enhancer element regulates IL-4 gene locus accessibility in mast cells. J Immunol $\underline{165}$, 3239-3249

Hwang YH, Ro H, Choi I, Kim H, Oh KH, Hwang Jl, Park MH, Kim S, Yang J, Ahn C (2009): Impact of polymorphisms of TLR4/CD14 and TLR3 on acute rejection in kidney transplantation. Transplantation $\underline{88}, 699-705$ 
Imler JL, Hoffmann JA (2001): Toll receptors in innate immunity. Trends Cell Biol 11, 304-311

International-Human-Genome-Sequencing-Consortium (2004): Finishing the euchromatic sequence of the human genome. Nature $\underline{431}, 931-945$

Jersmann HP (2005): Time to abandon dogma: CD14 is expressed by non-myeloid lineage cells. Immunol Cell Biol 83, 462-467

Jessen KM, Lindboe SB, Petersen AL, Eugen-Olsen J, Benfield T (2007): Common TNF-alpha, IL-1 beta, PAI-1, UPA, CD14 and TLR4 polymorphisms are not associated with disease severity or outcome from Gram negative sepsis. BMC Infect Dis $\underline{7}, 108$

Juffermans NP, Verbon A, van Deventer SJ, Buurman WA, van Deutekom H, Speelman P, van der Poll T (1998): Serum concentrations of lipopolysaccharide activity-modulating proteins during tuberculosis. J Infect Dis $\underline{178}, 1839-1842$

Kagan JC, Medzhitov R (2006): Phosphoinositide-mediated adaptor recruitment controls Toll-like receptor signaling. Cell $\underline{125}$, 943-955

Kagan JC, Su T, Horng T, Chow A, Akira S, Medzhitov R (2008): TRAM couples endocytosis of Tolllike receptor 4 to the induction of interferon-beta. Nat Immunol $\underline{9}, 361-368$

Karin M, Ben-Neriah Y (2000): Phosphorylation meets ubiquitination: the control of NF-[kappa]B activity. Annu Rev Immunol 18, 621-663

Klein RD, Su GL, Aminlari A, Alarcon WH, Wang SC (1998): Pulmonary LPS-binding protein (LBP) upregulation following LPS-mediated injury. J Surg Res $\underline{78}$, 42-47

Klug WS, Cummings MR, Spencer CA: Genetik. 8. aktualisierte Aufl. Auflage; Pearson Studium, München [u.a.] 2007

Knaus WA (2002): APACHE 1978-2001: the development of a quality assurance system based on prognosis: milestones and personal reflections. Arch Surg 137, 37-41

Knaus WA, Draper EA, Wagner DP, Zimmerman JE (1985): APACHE II: a severity of disease classification system. Crit Care Med $\underline{13}, 818-829$

Kristjansdottir H, Steinsson K, Gunnarsson I, Grondal G, Erlendsson K, Alarcon-Riquelme ME (2010): Lower expression levels of the programmed death 1 receptor on CD4+CD25+ T cells and correlation with the PD-1.3A genotype in patients with systemic lupus erythematosus. Arthritis Rheum $\underline{62}, 1702-1711$

Kruger C, Schutt C, Obertacke U, Joka T, Muller FE, Knoller J, Koller M, Konig W, Schonfeld W (1991): Serum CD14 levels in polytraumatized and severely burned patients. Clin Exp Immunol 85, 297-301

Kurt-Jones EA, Popova L, Kwinn L, Haynes LM, Jones LP, Tripp RA, Walsh EE, Freeman MW, Golenbock DT, Anderson L, et al. (2000): Pattern recognition receptors TLR4 and CD14 mediate response to respiratory syncytial virus. Nat Immunol $\underline{1}$, 398-401 
Labeta MO, Durieux JJ, Fernandez N, Herrmann R, Ferrara P (1993): Release from a human monocyte-like cell line of two different soluble forms of the lipopolysaccharide receptor, CD14. Eur J Immunol 23, 2144-2151

Lamping N, Hoess A, Yu B, Park TC, Kirschning CJ, Pfeil D, Reuter D, Wright SD, Herrmann F, Schumann RR (1996): Effects of site-directed mutagenesis of basic residues (Arg 94, Lys 95, Lys 99) of lipopolysaccharide (LPS)-binding protein on binding and transfer of LPS and subsequent immune cell activation. J Immunol 157, 4648-4656

Landi S, Gemignani F, Bottari F, Gioia-Patricola L, Guino E, Cambray M, Biondo S, Capella G, Boldrini L, Canzian F, et al. (2006): Polymorphisms within inflammatory genes and colorectal cancer. J Negat Results Biomed $\underline{5}, 15$

Landmann R, Reber AM, Sansano S, Zimmerli W (1996): Function of soluble CD14 in serum from patients with septic shock. J Infect Dis $\underline{173}, 661-668$

Lemaitre B, Nicolas E, Michaut L, Reichhart JM, Hoffmann JA (1996): The dorsoventral regulatory gene cassette spatzle/Toll/cactus controls the potent antifungal response in Drosophila adults. Cell $\underline{86}, 973-983$

LeVan TD, Bloom JW, Bailey TJ, Karp CL, Halonen M, Martinez FD, Vercelli D (2001): A common single nucleotide polymorphism in the CD14 promoter decreases the affinity of Sp protein binding and enhances transcriptional activity. J Immunol 167, 5838-5844

Levy MM, Fink MP, Marshall JC, Abraham E, Angus D, Cook D, Cohen J, Opal SM, Vincent JL, Ramsay G (2003): 2001 SCCM/ESICM/ACCP/ATS/SIS International Sepsis Definitions Conference. Crit Care Med 31, 1250-1256

Levy MM, Dellinger RP, Townsend SR, Linde-Zwirble WT, Marshall JC, Bion J, Schorr C, Artigas A, Ramsay G, Beale R, et al. (2010): The Surviving Sepsis Campaign: results of an international guideline-based performance improvement program targeting severe sepsis. Crit Care Med $\underline{38}$, 367-374

Lin B, Noring R, Steere AC, Klempner MS, Hu LT (2000): Soluble CD14 levels in the serum, synovial fluid, and cerebrospinal fluid of patients with various stages of Lyme disease. J Infect Dis $\underline{181}$, $1185-1188$

Lin J, Yao YM, Yu Y, Chai JK, Huang ZH, Dong N, Sheng ZY (2007): Effects of CD14-159 C/T polymorphism on CD14 expression and the balance between proinflammatory and antiinflammatory cytokines in whole blood culture. Shock $\underline{28}, 148-153$

Malm J, Nordahl EA, Bjartell A, Sorensen OE, Frohm B, Dentener MA, Egesten A (2005): Lipopolysaccharide-binding protein is produced in the epididymis and associated with spermatozoa and prostasomes. J Reprod Immunol $\underline{66}$, 33-43

Mannel DN, Echtenacher B (2000): TNF in the inflammatory response. Chem Immunol 74, 141-161

Mansur A, Hinz J, Hillebrecht B, Bergmann I, Popov AF, Ghadimi M, Bauer M, Beissbarth T, Mihm S (2014): Ninety-day survival rate of patients with sepsis relates to programmed cell death 1 genetic polymorphism rs11568821. J Investig Med 62, 638-643 
Mansur A, Liese B, Steinau M, Ghadimi M, Bergmann I, Tzvetkov M, Popov AF, Beissbarth T, Bauer M, Hinz J (2015): The CD14 rs2569190 TT Genotype Is Associated with an Improved 30-Day Survival in Patients with Sepsis: A Prospective Observational Cohort Study. PloS one 10, e0127761

Mathison JC, Tobias PS, Wolfson E, Ulevitch RJ (1992): Plasma lipopolysaccharide (LPS)-binding protein. A key component in macrophage recognition of gram-negative LPS. J Immunol $\underline{149}$, 200206

Matsumoto M, Funami K, Tanabe M, Oshiumi H, Shingai M, Seto Y, Yamamoto A, Seya T (2003): Subcellular localization of Toll-like receptor 3 in human dendritic cells. J Immunol 171, 3154-3162

Mayr FB, Yende S, Linde-Zwirble WT, Peck-Palmer OM, Barnato AE, Weissfeld LA, Angus DC (2010): Infection rate and acute organ dysfunction risk as explanations for racial differences in severe sepsis. Jama $\underline{303}, 2495-2503$

Mayr FB, Yende S, Angus DC (2014): Epidemiology of severe sepsis. Virulence $\underline{5}$, 4-11

Medzhitov R, Janeway C, Jr. (2000): Innate immune recognition: mechanisms and pathways. Immunol Rev 173, 89-97

Mertens J, Bregadze R, Mansur A, Askar E, Bickeboller H, Ramadori G, Mihm S (2009): Functional impact of endotoxin receptor CD14 polymorphisms on transcriptional activity. J Mol Med (Berl) 87, 815-824

Misra S, Kumar P, Kumar A, Sagar R, Chakravarty K, Prasad K (2016): Genetic association between inflammatory genes (IL-1alpha, CD14, LGALS2, PSMA6) and risk of ischemic stroke: A metaanalysis. Meta Gene $\underline{8}, 21-29$

Mohamed JA, DuPont HL, Flores J, Palur H, Nair P, Jiang ZD, Guo D, Belkind-Gerson J, Okhuysen PC (2011): Single nucleotide polymorphisms in the promoter of the gene encoding the lipopolysaccharide receptor CD14 are associated with bacterial diarrhea in US and Canadian travelers to Mexico. Clin Infect Dis 52, 1332-1341

Moreno R, Vincent IL, Matos R, Mendonca A, Cantraine F, Thijs L, Takala J, Sprung C, Antonelli M, Bruining $\mathrm{H}$, et al. (1999): The use of maximum SOFA score to quantify organ dysfunction/failure in intensive care. Results of a prospective, multicentre study. Working Group on Sepsis related Problems of the ESICM. Intensive Care Med 25, 686-696

Nikaido H (2003): Molecular basis of bacterial outer membrane permeability revisited. Microbiol Mol Biol Rev $\underline{67}$, 593-656

O'Neill LA, Bowie AG (2007): The family of five: TIR-domain-containing adaptors in Toll-like receptor signalling. Nat Rev Immunol $\underline{7}$, 353-364

Okamura Y, Watari M, Jerud ES, Young DW, Ishizaka ST, Rose J, Chow JC, Strauss JF, 3rd (2001): The extra domain A of fibronectin activates Toll-like receptor 4. J Biol Chem 276, 10229-10233

Oosting $\mathrm{M}$, Cheng SC, Bolscher JM, Vestering-Stenger R, Plantinga TS, Verschueren IC, Arts $\mathrm{P}$, Garritsen A, van Eenennaam H, Sturm P, et al. (2014): Human TLR10 is an anti-inflammatory pattern-recognition receptor. Proc Natl Acad Sci U S A $\underline{111}$, E4478-4484 
Oshiumi H, Sasai M, Shida K, Fujita T, Matsumoto M, Seya T (2003): TIR-containing adapter molecule (TICAM)-2, a bridging adapter recruiting to toll-like receptor 4 TICAM-1 that induces interferon-beta. J Biol Chem 278, 49751-49762

Philips (2018): IntelliSpace Critical Care and Anesthesia. Internetquelle: https://www.philips.de/healthcare/product/HCNOCTN332/intellispace-critical-care-andanesthesia\#galleryTab=PI (24.02.2018)

Poltorak A, He X, Smirnova I, Liu MY, Van Huffel C, Du X, Birdwell D, Alejos E, Silva M, Galanos C, et al. (1998): Defective LPS signaling in $\mathrm{C} 3 \mathrm{H} / \mathrm{HeJ}$ and C57BL/10ScCr mice: mutations in Tlr4 gene. Science $\underline{282}, 2085-2088$

Prokunina L, Castillejo-Lopez C, Oberg F, Gunnarsson I, Berg L, Magnusson V, Brookes AJ, Tentler D, Kristjansdottir H, Grondal G, et al. (2002): A regulatory polymorphism in PDCD1 is associated with susceptibility to systemic lupus erythematosus in humans. Nat Genet $\underline{32}, 666-669$

Pu H, Yin J, Wu Y, Zhang D, Wang Y, Zhou R, Jiang L, Liu Y (2013): The association between CD14 gene C-260T polymorphism and coronary heart disease risk: a meta-analysis. Mol Biol Rep $\underline{40}$, 4001-4008

Pugin J, Heumann ID, Tomasz A, Kravchenko VV, Akamatsu Y, Nishijima M, Glauser MP, Tobias PS, Ulevitch RJ (1994): CD14 is a pattern recognition receptor. Immunity $\underline{1}$, 509-516

Rahman MM, McFadden G (2006): Modulation of tumor necrosis factor by microbial pathogens. PLoS Pathog $\underline{2}$, e4

Reinhart K, Brunkhorst FM, Bone HG, Bardutzky J, Dempfle CE, Forst H, Gastmeier P, Gerlach H, Grundling M, John S, et al. (2010): Diagnose, Therapie und Nachsorge der Sepsis 1. Revision der S$2 \mathrm{k}$ Leitlinien der Deutschen Sepsis-Gesellschaft e.V. (DSG) und der Deutschen Interdisziplinären Vereinigung für Intensiv- und Notfallmedizin (DIVI). Anaesthesist $\underline{59}$, 347-370

Rock FL, Hardiman G, Timans JC, Kastelein RA, Bazan JF (1998): A family of human receptors structurally related to Drosophila Toll. Proc Natl Acad Sci U S A $\underline{95}, 588-593$

Rowe DC, McGettrick AF, Latz E, Monks BG, Gay NJ, Yamamoto M, Akira S, O'Neill LA, Fitzgerald KA, Golenbock DT (2006): The myristoylation of TRIF-related adaptor molecule is essential for Tolllike receptor 4 signal transduction. Proc Natl Acad Sci U S A 103, 6299-6304

Samarajiwa SA, Forster S, Auchettl K, Hertzog PJ (2009): INTERFEROME: the database of interferon regulated genes. Nucleic Acids Res $\underline{37}$, D852-857

Schroder NW, Heine H, Alexander C, Manukyan M, Eckert J, Hamann L, Gobel UB, Schumann RR (2004): Lipopolysaccharide binding protein binds to triacylated and diacylated lipopeptides and mediates innate immune responses. J Immunol 173, 2683-2691

Schromm AB, Lien E, Henneke P, Chow JC, Yoshimura A, Heine H, Latz E, Monks BG, Schwartz DA, Miyake K, et al. (2001): Molecular genetic analysis of an endotoxin nonresponder mutant cell line: a point mutation in a conserved region of MD-2 abolishes endotoxin-induced signaling. J Exp Med $\underline{194}, 79-88$

Schumann RR (2011): Old and new findings on lipopolysaccharide-binding protein: a soluble pattern-recognition molecule. Biochem Soc Trans $\underline{39}$, 989-993 
Schumann RR, Leong SR, Flaggs GW, Gray PW, Wright SD, Mathison JC, Tobias PS, Ulevitch RJ (1990): Structure and function of lipopolysaccharide binding protein. Science 249, 1429-1431

Seki E, Brenner DA (2008): Toll-like receptors and adaptor molecules in liver disease: update. Hepatology $\underline{48}, 322-335$

Setoguchi M, Nasu N, Yoshida S, Higuchi Y, Akizuki S, Yamamoto S (1989): Mouse and human CD14 (myeloid cell-specific leucine-rich glycoprotein) primary structure deduced from cDNA clones. Biochim Biophys Acta 1008, 213-222

Shalhub S, Junker CE, Imahara SD, Mindrinos MN, Dissanaike S, O'Keefe GE (2009): Variation in the TLR4 gene influences the risk of organ failure and shock posttrauma: a cohort study. J Trauma 66, 115-122; discussion 122-113

Sherry ST, Ward MH, Kholodov M, Baker J, Phan L, Smigielski EM, Sirotkin K (2001): dbSNP: the NCBI database of genetic variation. Nucleic Acids Res $\underline{29}$, 308-311

Shimazu R, Akashi S, Ogata H, Nagai Y, Fukudome K, Miyake K, Kimoto M (1999): MD-2, a molecule that confers lipopolysaccharide responsiveness on Toll-like receptor 4. J Exp Med 189, 1777-1782

Simpson A, John SL, Jury F, Niven R, Woodcock A, Ollier WE, Custovic A (2006): Endotoxin exposure, CD14, and allergic disease: an interaction between genes and the environment. Am J Respir Crit Care Med 174, 386-392

Singer M, Deutschman CS, Seymour CW, Shankar-Hari M, Annane D, Bauer M, Bellomo R, Bernard GR, Chiche JD, Coopersmith CM, et al. (2016): The Third International Consensus Definitions for Sepsis and Septic Shock (Sepsis-3). JAMA $\underline{315}$, 801-810

Smiley ST, King JA, Hancock WW (2001): Fibrinogen stimulates macrophage chemokine secretion through toll-like receptor 4. J Immunol $\underline{167}$, 2887-2894

Stark GR (2007): How cells respond to interferons revisited: from early history to current complexity. Cytokine Growth Factor Rev $\underline{18}$, 419-423

Sugawara S, Arakaki R, Rikiishi H, Takada H (1999): Lipoteichoic acid acts as an antagonist and an agonist of lipopolysaccharide on human gingival fibroblasts and monocytes in a CD14-dependent manner. Infect Immun 67, 1623-1632

Surbatovic M, Grujic K, Cikota B, Jevtic M, Filipovic N, Romic P, Strelic N, Magic Z (2010): Polymorphisms of genes encoding tumor necrosis factor-alpha, interleukin-10, cluster of differentiation-14 and interleukin-1ra in critically ill patients. J Crit Care $\underline{25}$, 542.e541-548

Szabo G, Dolganiuc A, Mandrekar P (2006): Pattern recognition receptors: a contemporary view on liver diseases. Hepatology 44, 287-298

Teo YY, Fry AE, Clark TG, Tai ES, Seielstad M (2007): On the usage of HWE for identifying genotyping errors. Ann Hum Genet 71, 701-703; author reply 704

Termeer C, Benedix F, Sleeman J, Fieber C, Voith U, Ahrens T, Miyake K, Freudenberg M, Galanos C, Simon JC (2002): Oligosaccharides of Hyaluronan activate dendritic cells via toll-like receptor 4. J Exp Med 195, 99-111 
Ulevitch RJ, Tobias PS (1995): Receptor-dependent mechanisms of cell stimulation by bacterial endotoxin. Annu Rev Immunol 13, 437-457

Venter JC, Adams MD, Myers EW, Li PW, Mural RJ, Sutton GG, Smith HO, Yandell M, Evans CA, Holt RA, et al. (2001): The sequence of the human genome. Science 291, 1304-1351

Vercelli D (2002): The functional genomics of CD14 and its role in IgE responses: an integrated view. J Allergy Clin Immunol $\underline{109}$, 14-21

Vidal K, Donnet-Hughes A (2008): CD14: a soluble pattern recognition receptor in milk. Adv Exp Med Biol 606, 195-216

Vincent JL, Moreno R, Takala J, Willatts S, De Mendonca A, Bruining H, Reinhart CK, Suter PM, Thijs LG (1996): The SOFA (Sepsis-related Organ Failure Assessment) score to describe organ dysfunction/failure. On behalf of the Working Group on Sepsis-Related Problems of the European Society of Intensive Care Medicine. Intensive Care Med 22, 707-710

Vincent JL, de Mendonca A, Cantraine F, Moreno R, Takala J, Suter PM, Sprung CL, Colardyn F, Blecher S (1998): Use of the SOFA score to assess the incidence of organ dysfunction/failure in intensive care units: results of a multicenter, prospective study. Working group on "sepsis-related problems" of the European Society of Intensive Care Medicine. Crit Care Med 26, 1793-1800

Vives-Pi M, Somoza N, Fernandez-Alvarez J, Vargas F, Caro P, Alba A, Gomis R, Labeta MO, PujolBorrell R (2003): Evidence of expression of endotoxin receptors CD14, toll-like receptors TLR4 and TLR2 and associated molecule MD-2 and of sensitivity to endotoxin (LPS) in islet beta cells. Clin Exp Immunol 133, 208-218

Vreugdenhil AC, Dentener MA, Snoek AM, Greve JW, Buurman WA (1999): Lipopolysaccharide binding protein and serum amyloid $A$ secretion by human intestinal epithelial cells during the acute phase response. J Immunol $\underline{163}$, 2792-2798

Wajant H, Pfizenmaier K, Scheurich P (2003): Tumor necrosis factor signaling. Cell Death Differ $\underline{10}$, 45-65

Wang DG, Fan JB, Siao CJ, Berno A, Young P, Sapolsky R, Ghandour G, Perkins N, Winchester E, Spencer J, et al. (1998): Large-scale identification, mapping, and genotyping of single-nucleotide polymorphisms in the human genome. Science $\underline{280}, 1077-1082$

Wang H, Wei Y, Zeng Y, Qin Y, Xiong B, Qin G, Li J, Hu D, Qiu X, Sooranna SR, et al. (2014): The association of polymorphisms of TLR4 and CD14 genes with susceptibility to sepsis in a Chinese population. BMC Med Genet $\underline{15}, 123$

Weissmann G (2010): Pattern recognition and gestalt psychology: the day Nusslein-Volhard shouted "Toll!". FASEB J 24 , 2137-2141

Werdan K, Schuster HP (2005): Internistische Notfallmedizin. Internist (Berl) 46, 955-956

Wilkinson SG (1996): Bacterial lipopolysaccharides--themes and variations. Prog Lipid Res $\underline{35}$, 283343

Wurfel MM, Kunitake ST, Lichenstein H, Kane JP, Wright SD (1994): Lipopolysaccharide (LPS)binding protein is carried on lipoproteins and acts as a cofactor in the neutralization of LPS. J Exp Med 180, 1025-1035 
Yamamoto M, Sato S, Mori K, Hoshino K, Takeuchi O, Takeda K, Akira S (2002): Cutting edge: a novel Toll/IL-1 receptor domain-containing adapter that preferentially activates the IFN-beta promoter in the Toll-like receptor signaling. J Immunol $\underline{169}$, 6668-6672

Yuan FF, Marks K, Wong M, Watson S, de Leon E, McIntyre PB, Sullivan JS (2008): Clinical relevance of TLR2, TLR4, CD14 and FcgammaRIIA gene polymorphisms in Streptococcus pneumoniae infection. Immunol Cell Biol $\underline{86}, 268-270$

Zee RY, Bubes V, Shrivastava S, Ridker PM, Glynn RJ (2009): Genetic risk factors in recurrent venous thromboembolism: A multilocus, population-based, prospective approach. Clin Chim Acta 402, 189-192

Zeng HS, Chen XY, Luo XP (2009): The association with the -159C/T polymorphism in the promoter region of the CD14 gene and juvenile idiopathic arthritis in a Chinese Han population. J Rheumatol 36, 2025-2028

Zhang AQ, Yue CL, Gu W, Du J, Wang HY, Jiang J (2013): Association between CD14 promoter $159 \mathrm{C} / \mathrm{T}$ polymorphism and the risk of sepsis and mortality: a systematic review and meta-analysis. PloS one $\underline{8}$, e71237

Zhang YN, Li YJ, Li H, Zhou H, Shao XJ (2015): Association of CD14 C159T polymorphism with atopic asthma susceptibility in children from Southeastern China: a case-control study. Genet Mol Res 14 , 4311-4317

Zweigner J, Gramm HJ, Singer OC, Wegscheider K, Schumann RR (2001): High concentrations of lipopolysaccharide-binding protein in serum of patients with severe sepsis or septic shock inhibit the lipopolysaccharide response in human monocytes. Blood $\underline{98}$, 3800-3808 